\title{
EVALUATION OF TRANSPORT RELATIVE TO THE TIDAL MIXING FRONT ON SOUTHERN GEORGES BANK
}

\author{
by
}

Jody M. Katrein

B.S., Maine Maritime Academy, 1999

Submitted in partial fulfillment of the requirements of the degree of

Master of Science

at the

MASSACHUSETTS INSTITUTE OF TECHNOLOGY
and the
WOODS HOLE OCEANOGRAPHIC INSTITUTION

September 2001

(C) 2001 Jody M. Katrein

MBL/WHOI

All rights reserved.

The author hereby grants to MIT and WHOI permission to reproduce paper and electronic copies of this thesis in whole or in part and distribute them publiclv. 


\title{
EVALUATION OF TRANSPORT RELATIVE TO THE TIDAL MIXING FRONT ON SOUTHERN GEORGES BANK
}

\author{
by \\ Jody M. Katrein \\ Submitted to the department of Ocean Engineering at the \\ Massachusetts Institute of Technology and to the department of \\ Applied Ocean Physics and Engineering at the Woods Hole Oceanographic \\ Institution on August 10, 2001 in partial fulfillment of the requirements for the \\ Degree of Master of Science in Ocean Engineering.
}

\begin{abstract}
As part of Phase III of the U.S. GLOBEC Georges Bank program, drogued drifters and dye tracer were released into the pycnocline on the southern flank of Georges Bank to measure advective and diffusive transport relative to the tidal mixing front in May 1999. Potential density measurements placed the tidal mixing front around the 50-55 $\mathrm{m}$ isobath on the southern flank. Drogued drifter movement relative to the front was on the order of the drifter's slip velocity and therefore did not support the existence of a mean, advective flow. No movement relative to the front of the dye patch center of mass also indicated a lack of advective flow. Diffusive transport did occur as the dye patch spread laterally both toward and away from the front much as would be predicted by the diffusion relationship of Okubo (1971), who summarized diffusion experiments in the surface ocean. The dye did not spread symmetrically, but was rather elongated along the isobaths. This can be attributed to vertical shear in the along-isobath current that was measured by the shipboard ADCP.
\end{abstract}

Thesis Supervisor: Dr. James R. Ledwell

Title: Senior Scientist, Woods Hole Oceanographic Institution 


\section{Acknowledgements}

I would like to extend my sincere appreciation to my thesis advisor, $\mathrm{Dr}$. Jim Ledwell. His knowledge, enthusiasm, and patience were invaluable throughout this project. His constant emphasis on learning not only guided me through the project contained herein, but encouraged me to seek a broad education while in the program.

My gratitude is extended to many people in the WHOI community for their contributions. Dr. Jim Churchill provided the drifter data and much valuable insight in this project. Cindy Sellers provided several of the mapping codes, as well as indispensable computer support. I would also like to thank Dr. John Trowbridge, Terry Donoghue, Arthur Newhall, and Dr. Miles Sundermeyer for their guidance.

The staffs of the BU/MIT NROTC Postgraduate Command, the MIT Course 13 Office, and the WHOI Education Office all deserve recognition for keeping my administrative boat afloat throughout my time in the program. I also gratefully acknowledge the U.S. Navy for providing me the time and resources to participate in the program.

I'd like also to thank the friends that have selflessly supported me throughout my graduate work, especially Kristy Turcotte, an enduring roommate and listener, Jason Fraser, who kept the dream alive, and Gray Eldridge, who not only provided critical proofreading, but was also my moral support and ticket to great times in Woods Hole and beyond. And to my loving family, I thank you.

The National Science Foundation (Grant \#OCE9806498) sponsored the data collection described within.

The United States Navy funded the author's participation in this thesis project. 


\section{Contents}

$\begin{array}{ll}\text { Abstract } & 3\end{array}$

$\begin{array}{lr}\text { Acknowledgements } & 5\end{array}$

1 Introduction 9

2 Designating and Finding the Front 19

2.1 Front Definition .................................................. 19

2.2 Calculating the Location from Cruise Data ......................... 19

2.3 Estimating the Extended Location ................................. 23

3 Evaluation of Transport Using Drifters 25

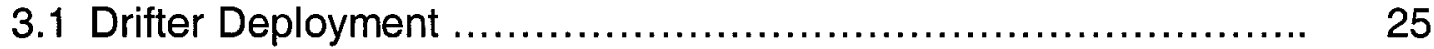

3.2 Fitting the Drifter Record ...................................... 28

3.3 Associated Errors ...................................................... 30

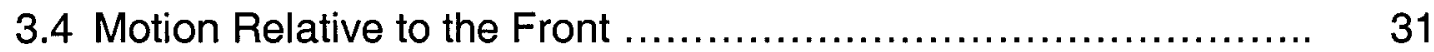

4 Evaluation of Transport Using a Dye Tracer 39

4.1 Data Construction ................................................. 39

4.2 Dye Patch Advection ............................................... 41

4.3 Dye Patch Diffusion ............................................ 46

4.3.1 Rotating the Axes ....................................... 47

4.3.2 Calculation of Diffusion Statistics ......................... 50

4.4 Advective Dispersion ............................................ 53

4.4.1 Dye Versus Depth ....................................... 53

4.4.2 Shear Dispersion ...................................... 55 
4.4.3 The Effect of Strain on Dispersion ........................ 58

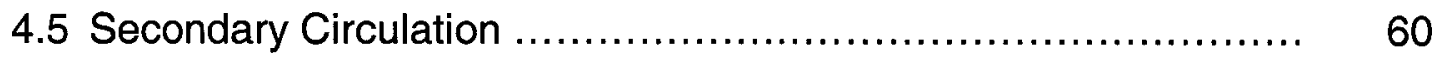

5 Summary and Discussion 63

Appendices

$\begin{array}{ll}\text { A Front-Finding Program } & 69\end{array}$

$\begin{array}{ll}\text { B More on Drifters } & 79\end{array}$

B.1 Drifter Data Files ................................................ $\quad 79$

B.2 Fitting the Drifter Record ....................................... $\quad 80$

B.2.1 The Fit Program ........................................... 80

B.2.2 Fit Results ................................................ 82

C More on Dye $\quad 91$

C.1 Dye Programs ................................................... 91

C.1.1 Dye Mapping ............................................. 91

C.2.2 Objective Analysis and Vertical Contouring .................... 94

C.2 Additional Figures ................................................ 99

C.2.1 Dye Section Choices ......................................... 99

C.2.2 Dye Contours .............................................. 102 


\section{Chapter 1}

\section{Introduction}

Georges Bank is a unique topographic feature on the southeast edge of the Gulf of Maine (see Figure 1). It is a shallow bank, with depths on the crest of fewer than $\mathbf{4 0}$ meters. It has a very steep northern flank and a more gently sloping southern flank (Butman and Beardsley, 1987). This area has historically been recognized as a productive fishing ground. Its stocks of cod, haddock, swordfish, lobster, and scallops, to name a few (Cohen and Grosslein, 1987), have seen fluctuations in abundance over time, and exactly what effect predation, environment, overfishing, and pollution have on these fluctuations is not fully understood (Fogarty et. al., 1987). The goal of the U.S. Global Ocean Ecosystem Dynamics (GLOBEC) Northwest Atlantic Georges Bank Program is to understand coupling between the physical and biological environments of the area (Weibe et al., 2001). The work contained herein is part of Phase III of the program and seeks to evaluate and better understand the transport mechanisms, both advective and diffusive, relative to the tidal mixing front on the southern flank of Georges Bank. It is hoped that this will provide information that is useful in the study of nutrient and phytoplankton transport.

The southern flank of Georges Bank is characterized as a compound frontal zone (Csanady and Magnell, 1987) having two front systems. One front with moderate density gradients separating the shelf-water and the slope-water (the shelf/slope front) persists year-round. This front intersects the bottom at the 80-100 $\mathrm{m}$ isobath, and its location migrates $10-20 \mathrm{~km}$ seasonally. In summer, the seasonal thermocline is established in the area and strong tidal mixing over the top of the bank causes another front, the tidal mixing front, to develop. This 


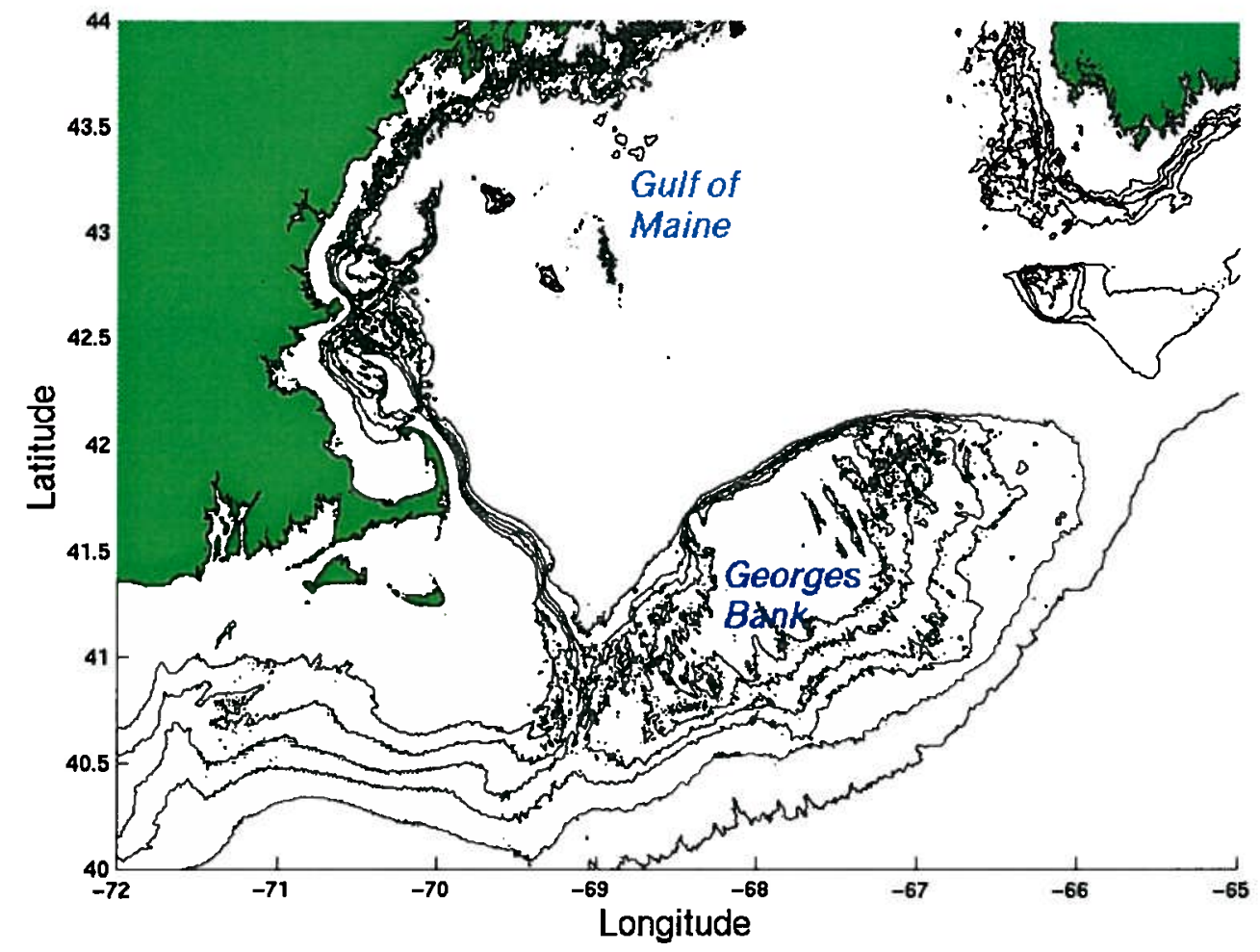

Figure 1. Map of Georges Bank. The 50, 60, 70, 80, 100, and 1000-m isobaths are shown.

front occurs at more shallow isobaths than the shelf/slope front (see Chapter 2) and separates vertically well-mixed water on the bank from the warmer stratified waters. The tidal mixing front on the southern flank only persists through summer (Butman and Beardsley, 1987; Csanady and Magnell, 1987).

These fronts can act as barriers to horizontal transport. Georges Bank, due to its topography, is more or less surrounded by fronts as tidal mixing causes the waters over its crest to be homogeneous year-round. On the flanks of the bank, tidal rectification, topography and stratification drive a clockwise, around- 
bank circulation, and exchange between the waters on the bank and the stratified water surrounding it depends on processes that can overcome the control of these factors (Csanady and Magnell, 1987). Such dynamics have caused many to wonder then just what controls the productivity of Georges Bank.

Nutrient availability is essential to sustain such a productive system. However it has been estimated that some $44 \mathrm{~g} \mathrm{~N} \mathrm{~m}^{-2}$ of particulate nitrogen leave the Georges Bank shelf annually (Walsh et. al., 1987), and these nutrients must somehow be replaced to maintain a mass balance. As the upper slope waters are rich in dissolved nitrate, about $130 \mathrm{~g} \mathrm{~N} \mathrm{~m}^{-2}$ compared to only $6 \mathrm{~g} \mathrm{~N} \mathrm{~m}^{-2}$ in the winter shelf waters, they seem a likely source for the needed input to the Georges Bank system. The nutrient-rich slope waters are likely either advected as part of the mean inflow and outflow or diffused onto the bank (Csanady and Magnell, 1987; Walsh et. al. 1987). As particles can be advected or diffused, the same transport mechanisms can also account for transport of plankton and larval organisms onto the bank.

Understanding the circulation of this area has been a difficult task. Its seasonal variability, strong tidal forces, unpredictable storms and Gulf core rings, and unique topography (Butman and Beardsley, 1987; Flagg, 1987; Noble and Butman, 1985; Lewis et. al., 2001) all contribute to a complicated physical regime with linear and non-linear interactions, and make modeling the system a daunting task. Early work on modeling the circulation of Georges Bank was done by John Loder (1980). Loder's work to describe the tidal rectification of currents evolved through manipulation of the momentum equations in two dimensions, allowing no along-isobath variation. Loder showed how $\mathrm{M}_{2}$ tidal forcing on a varying topography, similar to that of Georges Bank, could contribute to a tidally rectified, mean, clockwise, along-isobath circulation around the bank. He also offered a description of the cross-isobath circulation, and included velocity magnitude estimates. Loder predicted that for a homogeneous system, residual alongisobath currents would exist on the order of $10 \mathrm{~cm} \mathrm{~s}^{-1}$ on the northwest side of 
the bank and 1-2 $\mathrm{cm} \mathrm{s}^{-1}$ on the southern flank. Centered roughly on the $60 \mathrm{~m}$ isobath, a cross-isobath circulation pattern with two opposing horizontal circulation cells was predicted. The cells were such that cross-isobath convergence occurred near the bottom and divergence occurred at the surface (Loder, 1980; Loder and Wright, 1985).

Following the work of Loder, Chen and Beardsley and others did a number of numerical studies on the effect of tidal forcing around banks. Their studies (1995; 1998; Chen et. al., 1995) were based on the Blumberg and Mellor model, a 3-dimensional, Boussinesq, hydrostatic, non-linear, coastal ocean model. Use of a turbulent closure scheme represented vertical mixing and allowed for a free surface. Chen and Beardsley's approach differed significantly from that of Loder in that it incorporated not only the effect of varying bottom topography, but also allowed varying sea surface, stratification, internal tide generation, and tidal mixing. However, both approaches worked with 2-dimensional systems that had no along-isobath variation in the independent variables, and both described the temperature distributions as simple linear functions of depth. This approach progressed from modeling a symmetric bank (i.e. Chen and Beardsley, 1995), to an asymmetric bank (i.e. Chen et. al., 1995), to a bank with a structure based on bathymetric data from Georges Bank (i.e. Chen and Beardsley, 1998). Homogeneous systems were modeled as in Loder's work (1980), as well as systems with weak and strong stratification for each of the given bank conditions.

For the case of the symmetric bank (Chen and Bearsdley, 1995), running the model with a bank depth of $100 \mathrm{~m}$ in the homogeneous case yielded a topography-controlled, surface-intensified along-isobath jet such that flow was clockwise around the bank. In the case of weak stratification, the tidal currents caused turbulent mixing that formed a $60 \mathrm{~m}$-thick mixed layer over the bank and tidal mixing fronts near the shelf break. The tidal mixing and thermal diffusion also caused a bottom mixed layer to form over the sloping sides of the bank. This changes the structure of the velocity field, pulling the maximum value to a 
depth of $30 \mathrm{~m}$ above the top of the bank and increasing the maximum alongisobath velocity. In the case of strong stratification, the increased stratification impedes tidal mixing so that now the mixed layer over the bank is only $40 \mathrm{~m}$ thick. Otherwise, the structure is the same as in the weak stratification case except that the velocity is further intensified and the maximum value is now only $20 \mathrm{~m}$ above the bottom. It is also of interest to note that the horizontal scale of the along-isobath residual velocity increases as stratification increases. The cross-isobath velocities will be examined for the following case.

Reducing the depth of the bank to $50 \mathrm{~m}$ creates a situation that more closely resembles Georges Bank (in the extent of this model) and is similar to the parameters used in Loder's (1980) work. This case also investigates the dependence of tidal mixing and residual flow on bottom topography. With this adjustment to depth in the model, mass conservation yields increased barotropic tidal currents in all stratification cases, with maximum along-isobath and crossisobath tidal currents of $\approx 50 \mathrm{~cm} \mathrm{~s}^{-1}$ and $\approx 70 \mathrm{~cm} \mathrm{~s}^{-1}$, respectively, which is $15-20$ $\mathrm{cm} \mathrm{s}^{-1}$ greater than in the previously mentioned case. In both of the stratified cases, the increase in tidal current increased the turbulent mixing, therefore contributing enough energy to overcome the buoyancy force of the stratification such that all the water over bank was well mixed, creating very well defined fronts. Also, the maximum along-isobath velocities are now at the surface. Results from modeling the homogeneous case, which is comparable to Loder's work, show cross-isobath velocities on the order of $0.1 \mathrm{~cm} \mathrm{~s}^{-1}$, while Loder's value for a similar set of parameters was on the order of $1-10 \mathrm{~cm} \mathrm{~s}^{-1}$. Clearly these are different by 1-2 orders of magnitude. It should be noted that changes in the depth of the bank never changed the horizontal scale of the residual alongisobath flow. Also, steepening the sides of the bank did not change the thickness of the bottom boundary layer along the slope, but did strengthen the residual flow (Chen and Beardsley, 1995). 
Chen et. al. (1995) furthered this model by modeling the bank as an asymmetrical feature, much like Georges Bank (see Figure 1). The depth of the bank sloped from $40 \mathrm{~m}$ on the northern side to $120 \mathrm{~m}$ on the southern side. Running the model in the homogeneous case again showed that the alongisobath current is topography controlled. A jet of northeastward flow along the northern flank tops out at $16 \mathrm{~cm} \mathrm{~s}^{-1}$, while on the southern flank there is a weaker southwestward flow of $3 \mathrm{~cm} \mathrm{~s}^{-1}$. Again adding the weak stratification to the model causes the entire water column over the bank to be vertically well mixed and turbulent mixing fronts to form at the shelf break on both flanks. In this case, the southwestward velocity along the southern flank is strengthened not only by the topography, but also by the presence of the tidal mixing front. Adding strong stratification further restricted turbulent mixing in the upper water column and pulled the fronts onto the bank. The along-isobath velocity is also further intensified. The bottom boundary layer that was seen in the symmetric model is again seen here.

The homogeneous case yielded a cross-isobath circulation with a single horizontal circulation cell on either side of the flank with water moving up the sloping bottom (on-bank) and upwelling, then downwelling over the outer flank. Water on the top of the bank tended to flow southward off the bank at all depths, with the maximum velocity occurring on the northern side. Weak stratification yielded a double circulation cell centered on the front on either side of the bank. Adding the strong stratification produced a strong asymmetry across the bank. On the southern flank, there were multiple circulation cells, the strongest of which were near the shelf break where the bottom slope steepens and the mixing was relatively weak. As the water got shallower and vertical mixing increased, the mean cross-isobath and vertical residual flows got weaker. Their respective values of $5 \mathrm{~cm} \mathrm{~s}^{-1}$ and $0.1 \mathrm{~cm} \mathrm{~s}^{-1}$ at the shelf break decreased to $0.5 \mathrm{~cm} \mathrm{~s}^{-1}$ and $0.01 \mathrm{~cm} \mathrm{~s}^{-1}$, respectively, near the tide-induced mixing front. In contrast, there was only one strong circulation cell centered at the tidal front on the northern 
flank. Water over the top of the bank is vertically well-mixed, and the residual current resembles that of the homogeneous case as it flows southward off the bank at all depths (Chen et. al., 1995).

The Blumberg and Mellor model approach was again used by Chen and Beardsley (1998) on a finite-amplitude model of the bank's topography from data from a transect across the bank. Running this model for the case of strong stratification is comparable to the conditions on Georges Bank at the time of our GLOBEC study. The result was similar to the case of strong stratification on an asymmetric bank (i.e. Chen et. al., 1995), with water over the bank being vertically well-mixed, and accelerated mean along-isobath velocities occurring at the tidal mixing fronts. The mean cross-isobath flow on the northern flank is contained in double circulation cells with surface divergence and bottom convergence at the edge of the front and another area of convergence at the surface in the stratified region adjacent to the front. The secondary circulation on the southern flank involved multiple horizontal circulation cells, with residual cross-bank currents on the order of $0.01-0.5 \mathrm{~cm} \mathrm{~s}^{-1}$ and vertical velocities on the order of $0.5-3 \mathrm{~cm} \mathrm{~s}^{-1}$.

Modeling of the bank has also been expanded to include 3-dimensions, high-resolution bottom topography, and wind forcing (Chen et. al., 2001). This model was run with early-summer stratification conditions, and remarkably, this 3-d model reinforces the basic dynamics observed in the 2-d finite amplitude model (i.e. Chen and Beardsley, 1998). The tidal mixing fronts occurred over the 40-60 $\mathrm{m}$ isobaths and were again associated with enhanced, tidally rectified, along-isobath currents on both flanks. It also predicted upwelling from the bottom at the tidal mixing front on the southern flank, with the upwelled water diverging into the adjacent well-mixed and stratified waters. Several closed, horizontal circulation cells characterized the off-bank stratified region. It should also be noted that the model suggested the presence of a near-bottom, cross- 
isobath, on-bank current on the southern flank (Chen et. al., 2001). Such a current could be a source of nutrients to the Georges Bank system.

While these models suggest a great deal about the seasonal, tide-induced residual currents on Georges Bank and the possibility of any cross-front velocity and hence advective transport, they are still unable to account for many of the events that occur randomly in the area. One such event is the random presence of warm-core Gulf Stream rings. These anticyclonic eddies can entrain shelf waters and can enhance phytoplankton production within and at the edge of the ring (Ryan et. al., 2001). Warm-core rings can also play a significant role in cross-front exchange, as one ring is estimated to daily draw up to $3 \%$ of the total shelf water (within the $180 \mathrm{~m}$ isobath) off the bank (Csanady and Magnell, 1987), but where the water that replaces it comes from isn't well understood (Flagg, 1987). One ring that was observed in May 1997 was noted as bringing nutrientrich Scotian Shelf Water to the southern flank of Georges Bank and hence influencing the flank's hydrographic, nutrient, and biological distributions (Ryan et. al., 2001). While influential, these warm-core rings are not predictable. In waters off the southern flank of Georges Bank there is an average of 3 to 9 rings per year, and the length of time they persist is also variable (Csanady and Magnell, 1987). This makes predicting and modeling the influence of the warmcore rings on the circulation of Georges Bank very difficult.

Wind events can also affect cross-frontal exchange by relaxing the front and increasing vertical mixing (Csanady and Magnell, 1987). There is significant interannual/seasonal variability in the winds that has been integrated into models of the circulation (Chen et. al., 2001; Lewis et. al., 2001; Manning and Strout, 2001). However storm events such as hurricanes and nor'easters are more difficult to predict over the time scale of the models and contribute to the difficulty of understanding the cross-frontal mechanisms on Georges Bank.

Several of the Georges Bank models have predicted an on-bank flow along the bottom on the southern flank (i.e. Loder, 1980; Loder and Wright, 1985; 
Chen et. al., 1995; Chen et. al., 2001). Loder and Wright (1985) have attributed this predicted on-bank bottom flow of dense water to the relaxation of the isopycnals at the tidal front as they respond to internal friction. However, until recently no direct measurement of such an on-bank flow had been achieved. As part of another experiment in Phase III of the GLOBEC Georges Bank Program, the dye tracer Flourescein was injected into the bottom mixed layer on the openocean side of the tidal mixing front to assess Lagrangian water movement. This experiment yielded an observation of on-bank diapycnal flow through the tidal mixing front on the southern flank of $1.6 \mathrm{~cm} \mathrm{~s}^{-1}$ (Houghton, submitted).

The on-bank bottom flow may not be the only transport mechanism at work on southern Georges Bank. In the summer, water on top of Georges Bank is cooler and denser than the adjacent surface waters over the flanks. This means that the crest water is equal in density to a layer of water within the pycnocline (Csanady and Magnell, 1987), which is clearly demonstrated in Figure 2.1. Horizontal transport within a layer of fluid of equal density doesn't require diapycnal mixing. A column of fluid in that layer would have to acquire potential vorticity as it is moved on-bank and the layer's thickness increased, however if potential vorticity can be modified, then the pycnocline layer with the same density as the bank crest is a candidate for transport within the Georges Bank system.

The study contained herein considers the pycnocline as a source of water, nutrients, and phytoplankton to Georges Bank. Tracking of drifters drogued in the pycnocline and dye injected in the pycnocline will be evaluated to determine if advection and diffusion are responsible for motions relative to the tidal mixing front on the southern flank of Georges Bank. 


\section{Chapter 2}

\section{Designating and Finding the Front}

\subsection{Front Definition}

Fronts, or "linear convergences where water properties...are markedly different on either side of the convergence," (Open University, 1989) can be defined by biological, chemical, or physical properties. In this investigation, the tidal mixing front, where the tidal forces acting on spatially varying bathymetry have caused an area of well-mixed water to form next to stratified water, is the focus. As such, the definition of the front is based on the physical property of potential density. The front, or rather its on-bank edge, is hereafter defined as the first location in a transect where the water column has a potential density value at the surface that differs from the potential density value at the bottom by less than $0.05 \mathrm{~kg} \mathrm{~m}^{-3}$. On one side of this location the water column is vertically stratified, and on the other it is relatively homogeneous (Flagg, 1987).

\subsection{Calculating the Location from Cruise Data}

In situ hydrographic measurements were made from a sled during tow-yo runs on a cruise in late spring of 1999 (Ledwell et. al., 2000). Potential density was calculated for all points along the runs using the sea surface as the reference pressure surface. The density data then was interpolated onto a uniform grid of latitude, longitude, and depth so that the potential density values 
for a specified geographic coordinate could easily be compared (see Appendix A for full interpolation program). For each coordinate in the latitude and longitude grids, the surface and deep potential density values were then compared to see if they met the $0.05 \mathrm{~kg} \mathrm{~m}^{-3}$ tolerance level. It should be noted here that since the tow-yo method was used, the CTD sled never came right to the surface, nor did it touch the bottom (see Figure 2.1). Therefore, surface density values are actually the shallowest values, typically 1-3 $\mathrm{m}$ below the surface, after interpolation and deep values are the deepest values, which are typically about $10 \mathrm{~m}$ off the bottom. If the tolerance level was met, as shown in Figure 2.1, that column was tagged as a front location and its coordinates and time of sampling, as obtained through interpolation of the time data, were noted. Four such locations/times, as given in Table 2.1 and plotted in Figure 2.2, were found in the Georges Bank southern flank survey data that were acquired during the dye/drifter survey (Note: The front references used throughout the text, Fronts 1, 2, 3, and 4, were used for simplicity and correspond to Surveys $22,24,26$, and 28 , respectively, in the original labeling of the cruise data in Ledwell et. al. (2000)). 


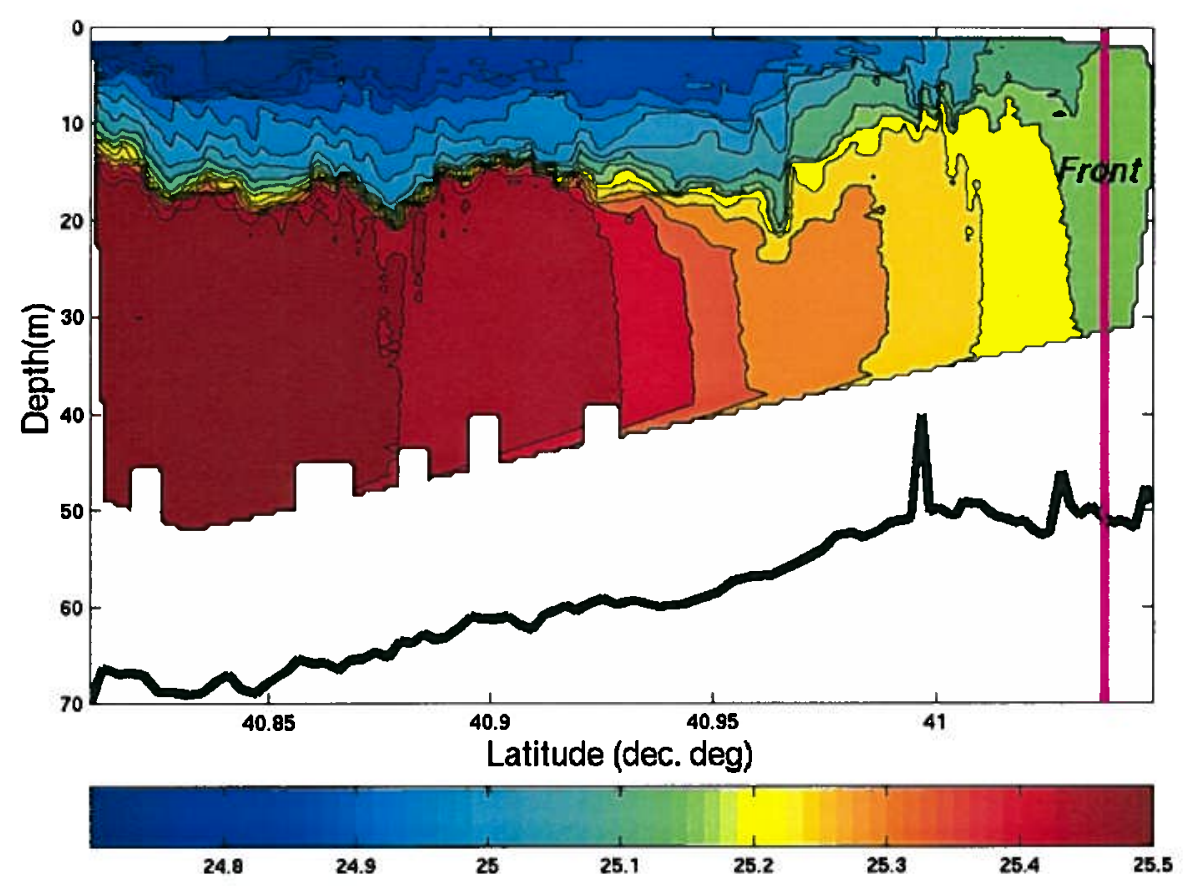

Figure 2.1. Finding a front location via potential density. Potential density $-1000 \mathrm{~kg} \mathrm{~m}^{-3}$ is given on a grid of depth vs. latitude. The black line represents the bottom. The magenta line to the right is a front location. This plot represents Front \#4. 


\begin{tabular}{|c|c|c|c|c|c|}
\hline $\begin{array}{c}\text { Front } \\
\text { Location }\end{array}$ & $\begin{array}{l}\text { GLOBEC } \\
\text { Survey \# }\end{array}$ & $\begin{array}{c}\text { Survey } \\
\text { Transect \# }\end{array}$ & $\begin{array}{c}\text { Time } \\
\text { (year-day) }\end{array}$ & $\begin{array}{l}\text { Latitude } \\
\qquad\left({ }^{\circ} \mathrm{N}\right)\end{array}$ & $\begin{array}{l}\text { Longitude } \\
\left.\qquad{ }^{\circ} \mathrm{W}\right)\end{array}$ \\
\hline 1 & 22 & 3 & 143.1352 & 41.0628 & -67.7108 \\
\hline 2 & 24 & 2 & 144.1046 & 41.0674 & -67.7562 \\
\hline 3 & 26 & 1 & 144.8531 & 40.9829 & -67.8640 \\
\hline 4 & 28 & 1 & 146.1547 & 41.0444 & -67.8466 \\
\hline
\end{tabular}

Table 2.1. Front location coordinates for southern Georges Bank, and the times they were found. GLOBEC survey and transect numbers are given as a reference to original cruise report (Ledwell et. al., 2000).

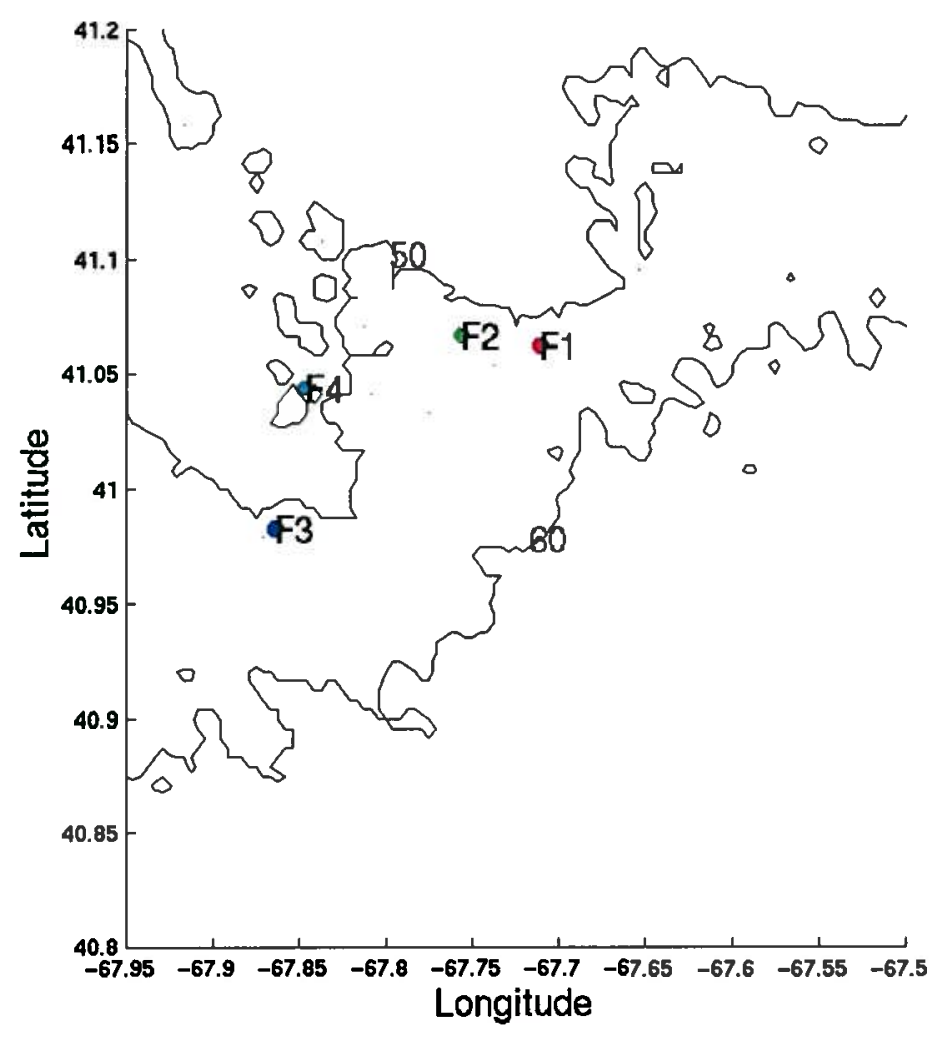

Figure 2.2. Front locations for the southern flank survey. 


\subsection{Estimating the Extended Location}

The two-dimensional view of the front obtained from hydrographic sections (Figure 2.1) is somewhat misleading in that this view doesn't consider the presence of occasional Gulf Stream eddies or current instabilities. As such, the locations reported should be considered "typical conditions" that can be greatly affected by random events (Csanady and Magnell, 1987). Based on the findings of earlier models (e.g. Loder, 1980; Chen and Beardsley, 1995; Chen et. al., 2001), the assumption was made that the front was aligned with the isobaths. Satellite SST images of the area support this assumption. Figure 2.3 (courtesy, J. Bisagni, UMass) shows the change in sea surface temperature associated with a front, which appears to be aligned with the bathymetry of the southern side of the bank. Though limited by the resolution of the satellite image, the progression from the blue area on the top of the bank to the greenish area is roughly where the tidal mixing front is expected to exist. Since the four front locations were found at different phases of the tide, and indicate only points where the front exists, one must imagine that the front extends through these points while following the bathymetry beneath the point. A reasonable estimate for the angle of orientation of the isobaths along the southern flank (see Figure 3.3 ) is $58^{\circ}$ from true north (Loder and Wright, 1985).

Also, the tidal excursion in the area is about $10 \mathrm{~km}$ (Chen and Beardsley, 1998). The tidal mixing front has been predicted near the $50-60 \mathrm{~m}$ isobath in numerical models with summer stratification conditions (Chen et. al., 1995; Chen and Beardsley, 1998; Chen et. al., 2001). These predictions, coupled with the 10 $\mathrm{km}$ tidal excursion, would agree with the front position from our data being around the $50-55 \mathrm{~m}$ isobath. 


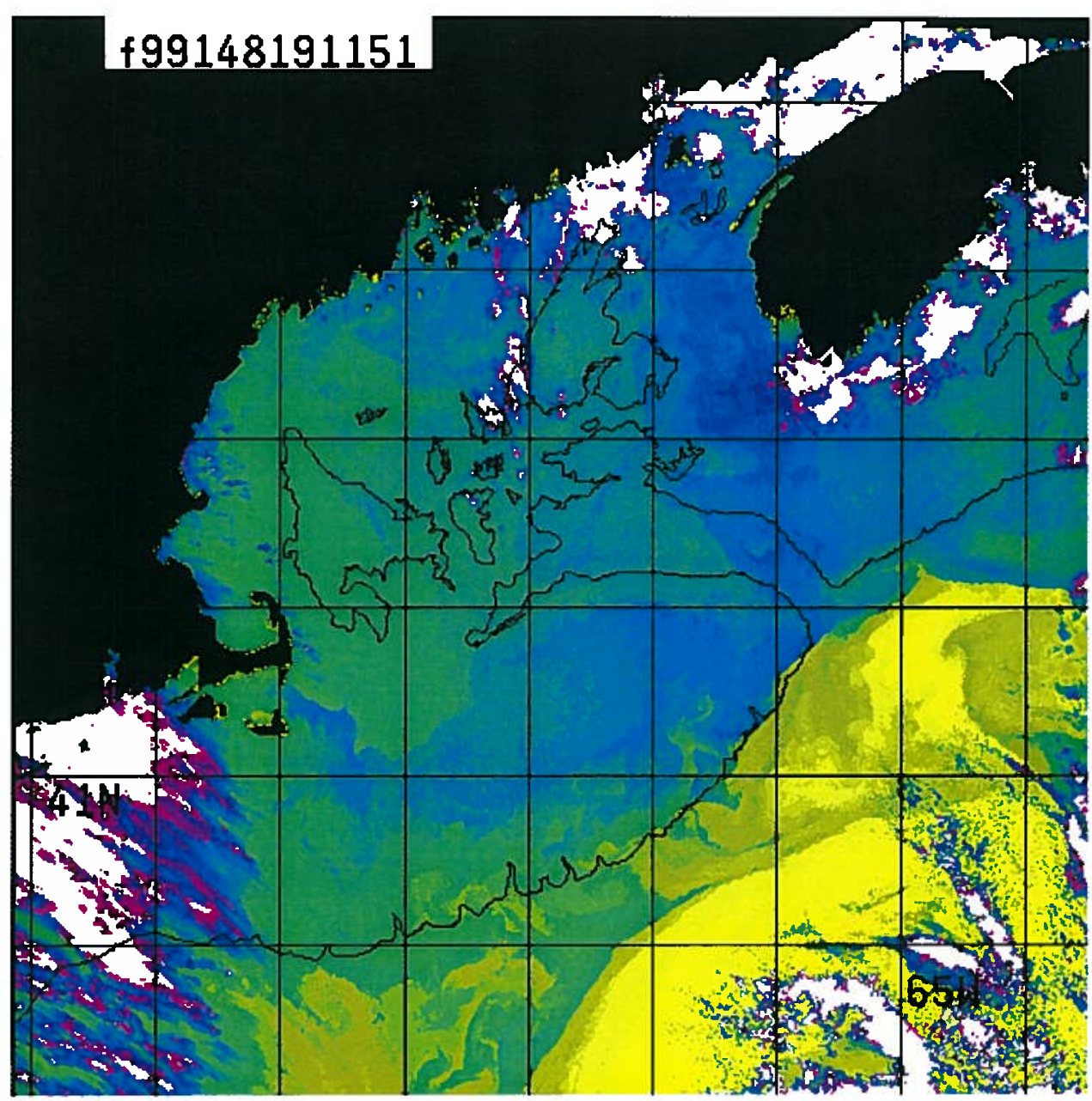

Figure 2.3. Sea surface temperature satellite picture of the Georges Bank area taken on year-day 148, with the 120-m isobath drawn. Note that the change in sea surface temperature around the bank approximately parallels this topography. This figure was downloaded directly from the web site (http://globec.cmast.umassd.edu:8080/jg/dsp2gif?/ data2/glob3/pub/1999/5/f99148191151.std.Z) (courtesy, J. Bisagni, UMass). 


\section{Chapter 3}

\section{Evaluation of Transport Using Drifters}

\subsection{Drifter Deployment}

To determine if a mean advective flow relative to the tidal mixing front exists, the behavior of drifters was observed. The drifters are classified by their current following properties and may therefore be characterized as either surface drifters, i.e. those that follow the surface current, or drogued drifters, those that follow subsurface currents. The drogues were $6 \mathrm{~m}$ long by $1.6 \mathrm{~m}$ in diameter and hence provided a minimum 40:1 drag ratio (For full drifter design and deployment details, see Ledwell et al., 2000). GPS was used for positioning, with positions being periodically sent to ARGOS satellites. Seven drifters were used in conjunction with the southern flank pycnocline dye experiment. Two were surface drifters, while the rest were drogued. Table 3.1 gives the details about where and when each drifter was deployed. Drifter \#10, a drogued drifter, though deployed was not used in this study as it stopped transmitting before it was able to give useful location information.

ARGOS position transmission was not perfect, resulting in several gaps of 3 hours or more in the position data (Ledwell et. al., 2000). Figure 3.1 shows an example of the resulting drifter coordinates and trajectories for drifter \#6, which was drogued to $39.4 \mathrm{~m}$. 


\begin{tabular}{|c|c|c|c|c|c|}
\hline $\begin{array}{l}\text { Drifter } \\
\text { ID }\end{array}$ & Style & $\begin{array}{l}\text { Start } \\
\text { Date }\end{array}$ & $\begin{array}{l}\text { Start } \\
\text { Time } \\
\text { GMT }\end{array}$ & $\begin{array}{l}\text { Start } \\
\text { Latitude/ } \\
\text { Longitude }\end{array}$ & Start Water Mass \\
\hline 6 & $\begin{array}{l}\text { Drogued to } \\
39.4 \mathrm{~m}\end{array}$ & $5 / 24 / 1999$ & $05: 13$ & $\begin{array}{l}40^{\circ} 51.67^{\prime} \\
67^{\circ} 38.66^{\prime}\end{array}$ & Beneath dye patch in stratified region \\
\hline 9 & Surface & $5 / 23 / 1999$ & 15:17 & $\begin{array}{l}41^{\circ} 00.40^{\prime} \\
67^{\circ} 40.50^{\prime}\end{array}$ & On stratified water side of front \\
\hline 10 & \begin{tabular}{|l} 
Drogued to \\
$19.4 \mathrm{~m}$
\end{tabular} & $5 / 23 / 1999$ & 18:38 & $\begin{array}{l}40^{\circ} 52.27^{\prime} \\
67^{\circ} 39.47^{\prime} \\
\end{array}$ & $\begin{array}{l}\text { Within dye patch in stratified region- } \\
\text { stopped transmission } 5 / 24 / 99\end{array}$ \\
\hline 11 & Surface & $5 / 23 / 1999$ & 18:19 & $\begin{array}{l}40^{\circ} 51.94^{\prime} \\
67^{\circ} 39.41^{\prime}\end{array}$ & Above dye patch in stratified region \\
\hline 22 & $\begin{array}{l}\text { Drogued to } \\
19.4 \mathrm{~m}\end{array}$ & $5 / 23 / 1999$ & $18: 19$ & $\begin{array}{l}40^{\circ} 51.94^{\prime} \\
67^{\circ} 39.41^{\prime}\end{array}$ & Within dye patch in stratified region \\
\hline 37 & \begin{tabular}{|l} 
Drogued to \\
$19.4 \mathrm{~m}$
\end{tabular} & $5 / 23 / 1999$ & 18:03 & $\begin{array}{l}40^{\circ} 51.73^{\prime} \\
67^{\circ} 39.33^{\prime}\end{array}$ & Within dye patch in stratified region \\
\hline 65 & $\begin{array}{l}\text { Drogued to } \\
19.4 \mathrm{~m}\end{array}$ & $5 / 24 / 1999$ & 05:50 & $\begin{array}{l}40^{\circ} 49.44^{\prime} \\
67^{\circ} 38.21^{\prime}\end{array}$ & $\sim 3 \mathrm{~km}$ south of dye \\
\hline
\end{tabular}

Table 3.1. Summary of drifter deployment details (Ledwell et. al., 2000). 

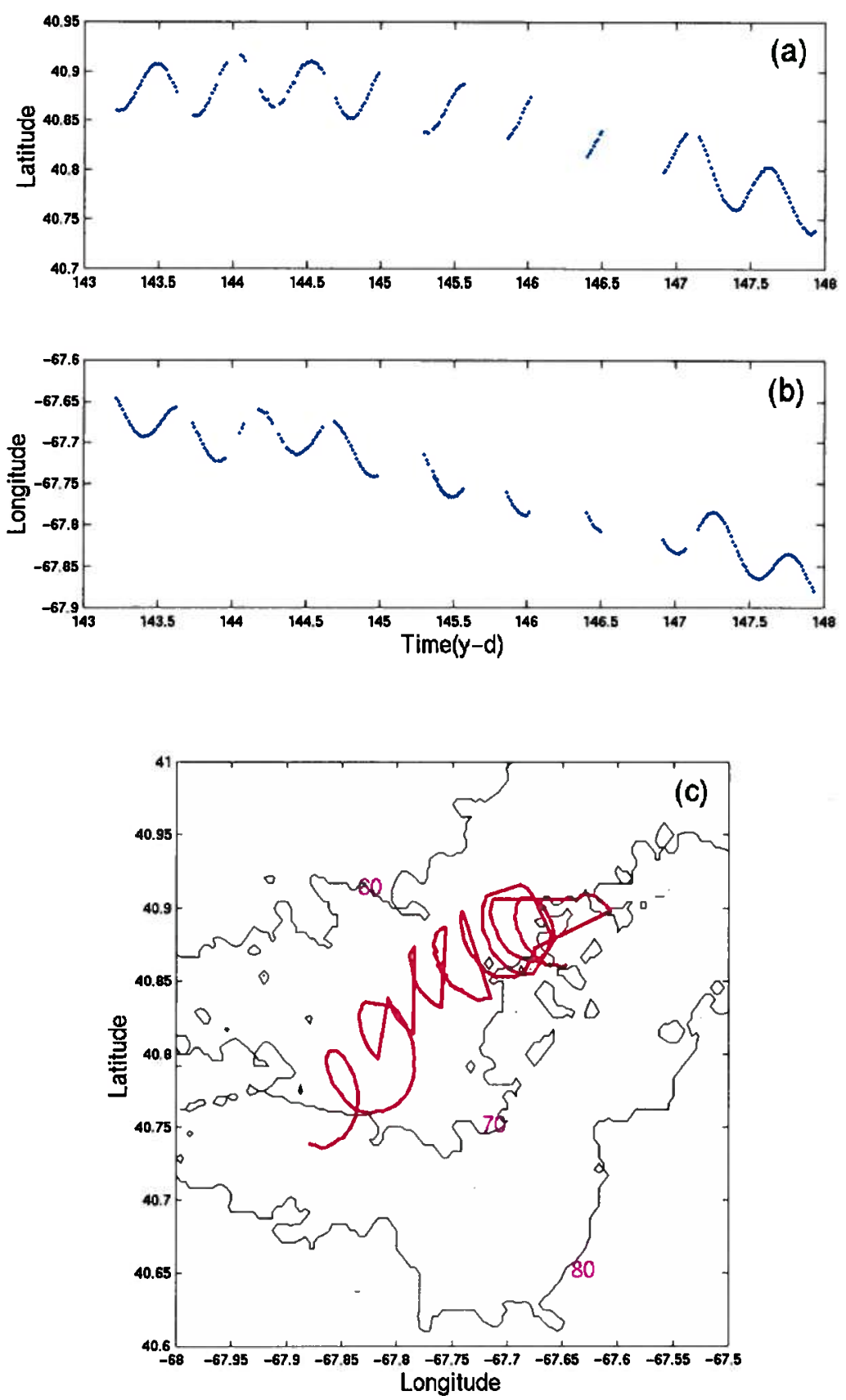

Figure 3.1. Raw drifter data showing gaps in location information. a) Latitude and b) longitude data from Drifter \#6, and $c$ ) the resulting incomplete drifter trajectory. 


\subsection{Fitting the Drifter Record}

To compare the drifter movements to the location of the front, a more complete set of trajectories than was available from the ARGOS transmissions was necessary. A fitting routine was applied to the location record of each drifter in the study with a goal of less than $150 \mathrm{~m}$ difference between the fitted locations and the observed locations for the times when the drifter records were available. The fitting routine (see Appendix $B$ ) is a least squares regression of a model of the form $y=X b$, where $y$ represents a matrix of observed latitude or longitude components and $X$ is a vector model of tidal and non-tidal forcing, which is expressed as harmonic functions with a higher order time dependence, given by:

$$
\begin{aligned}
& X=\left[\begin{array}{lllll}
\sin \left(M_{2} t\right) & \cos \left(M_{2} t\right) & \sin \left(S_{2} t\right) & \cos \left(S_{2} t\right) & \ldots
\end{array}\right. \\
& \begin{array}{lllll}
\sin \left(N_{2} t\right) & \cos \left(N_{2} t\right) & \sin \left(O_{1} t\right) & \cos \left(O_{1} t\right) & \ldots
\end{array} \\
& \left.\sin \left(K_{1} t\right) \quad \cos \left(K_{1} t\right) \quad t \quad \begin{array}{llll}
t^{2} & t^{3} & t^{4} & t^{5}
\end{array}\right]
\end{aligned}
$$

where $M_{2}, S_{2}, N_{2}, O_{1}$, and $K_{1}$ are tidal frequencies and $t$ is time. The five tidal frequencies that were modeled are given in Table 3.2 (Moody et. al., 1984). The model output, $b$, is a matrix containing the coefficients to the tidal and non-tidal function components. The coefficients are then applied to a complete time record to produce the fitted coordinates. Figure 3.2 shows an example of the resulting fitted drifter coordinates and trajectories for drifter \#6.

\begin{tabular}{|c|c|}
\hline Tidal Component & Frequency (rad/sec) \\
\hline M2 & $0.140519 \mathrm{e}-3$ \\
\hline $\mathrm{S} 2$ & $0.145440 \mathrm{e}-3$ \\
\hline $\mathrm{N} 2$ & $0.137880 \mathrm{e}-3$ \\
\hline $\mathrm{O} 1$ & $0.675977 \mathrm{e}-4$ \\
\hline $\mathrm{K} 1$ & $0.729212 \mathrm{e}-4$ \\
\hline
\end{tabular}

Table 3.2. Georges Bank tidal frequencies used in model. 

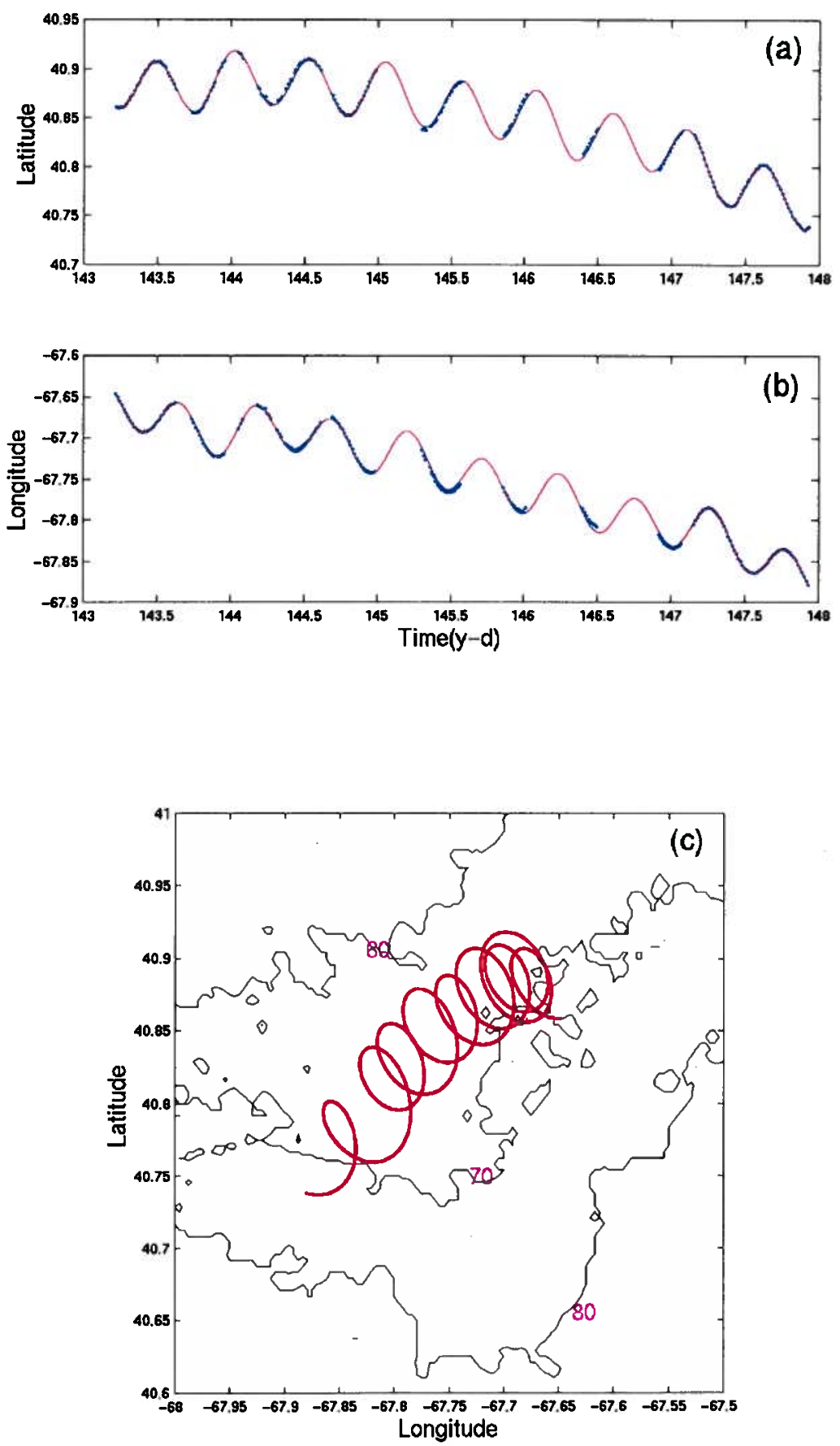

Figure 3.2. Fitted drifter data. a) Latitude and b) longitude data from Drifter \#6, with the original data plotted as blue dots and the fitted data shown as a red line. c) The resulting complete drifter trajectory. 
Note in Figure 3.2 (a) and (b) how closely the fit matches the original data for this very sparse location record. Similar figures for the six drifters used in the study are given in Appendix B.

\subsection{Associated Errors}

The RMS error for each drifter's latitude and longitude fit was calculated and the results are given in Table 3.3. Overall, the fitted data match the raw data very well, and for most cases are within $100 \mathrm{~m}$ of the desired fit. This was considered an acceptable error, as it was on the order of the GPS error in the original data. The accuracy of the GPS system is limited, and can create errors in the drifter position of $30-200 \mathrm{~m}$.

\begin{tabular}{|l|c|c|c|c|c|c|}
\hline Drifter & $\mathbf{6}$ & $\mathbf{9}$ & $\mathbf{1 1}$ & $\mathbf{2 2}$ & $\mathbf{3 7}$ & $\mathbf{6 5}$ \\
\hline Latitude RMS $(\mathrm{km})$ & 0.19 & 0.27 & 0.21 & 0.24 & 0.20 & 0.21 \\
\hline Longitude RMS (km) & 0.20 & 0.19 & 0.20 & 0.40 & 0.29 & 0.40 \\
\hline
\end{tabular}

Table 3.3. RMS error for latitude and longitude fits.

The effect of wind on the drifters was also considered to make sure that this effect wasn't masking the current signal from the drogued drifters. Following the formulation from Geyer (1988), the horizontal forces on a float and drogue can be estimated if the assumption is made that virtually all shear lies close to the surface. Letting the subscripts $f$ and $d$ refer to the float and drogue, respectively, and defining $C$ as the corresponding drag coefficient, $A$ as the horizontally projected area, $U_{s}$ as the surface velocity, and $U$ as the slip velocity, the relationship between the horizontal forces on the float and the horizontal forces on the drogue can be given as: 


$$
C_{f} A_{f} U_{s}^{2}=C_{d} A_{d} U^{2}
$$

We then define the drag ratio, $r$ (Geyer, 1989):

$$
r=\frac{C_{f} A_{f}}{C_{d} A_{d}}
$$

where the assumption $r<<1$ is valid for most drifter configurations. Combining (3.2) and (3.3), we get the relationship:

$$
\frac{U}{U_{s}} \cong r^{1 / 2}
$$

In our case, the drag ratio of the drogue was 40:1, or $r=\frac{1}{40}$ (Ledwell et. al., 2000). To solve for the slip velocity, surface velocities were calculated from the drifter trajectories of surface drifters $\# 9$ and $\# 11$. The surface velocity, $U_{s}$, was calculated to be in the range of $5-8 \mathrm{~cm} \mathrm{~s}^{-1}$ for the time of the study. This resulted in a slip velocity, $U$, of $0.8-1.2 \mathrm{~cm} \mathrm{~s}^{-1}$.

\subsection{Motion Relative to the Front}

The fitted drifter records were used to determine if the drifters moved significantly relative to the front. For each of the four times that the front was located (see Chapter 2), the front and all the drifters that were deployed and functioning at that exact time were plotted (see Figure 3.3). The front was plotted as a line, which intersected the front location, with an angle of $58^{\circ}$ from true north following the formulation of Loder and Wright (1985). While the front most likely 
follows the bathymetry rather than a straight line, as discussed in Chapter 2, the line was used for consistency between the four front locations/times. Each drifter's perpendicular distance from the front was noted for each front

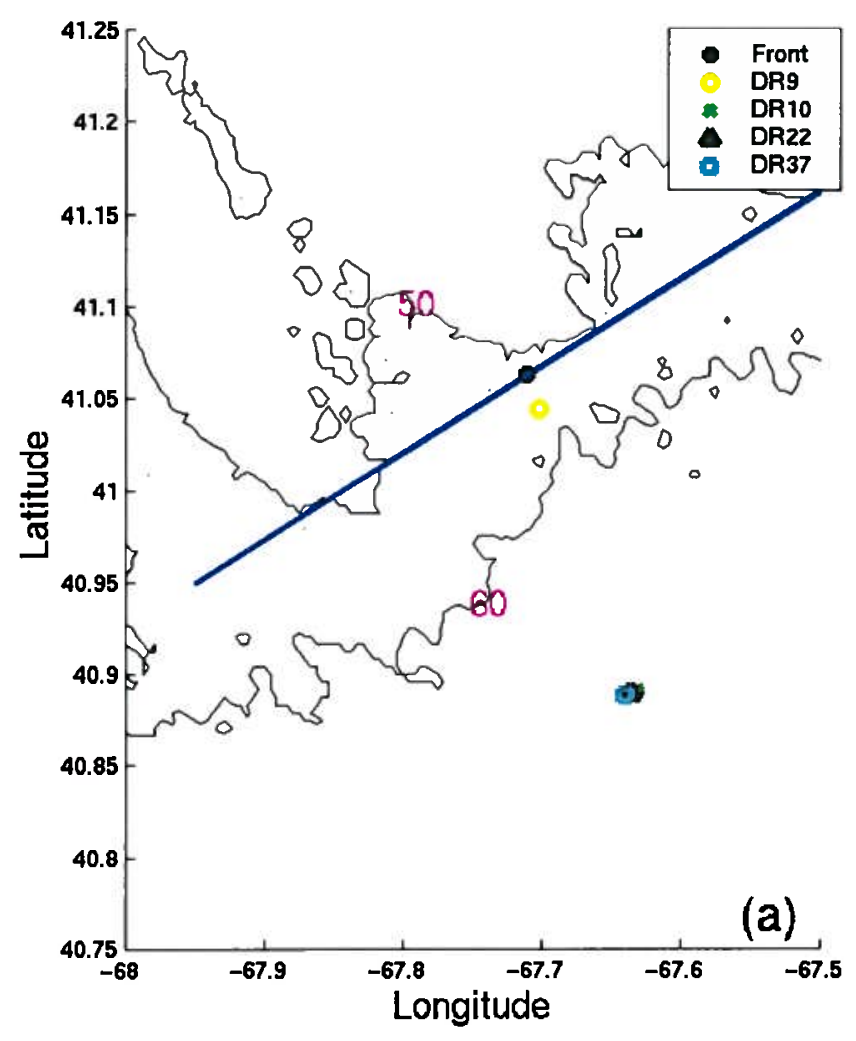

Figure 3.3(a). Plot of drifters and frontal line for front location $\# 1$, at year-day 143.1352 . At this time, all drifters are on the seaward side of the front. 


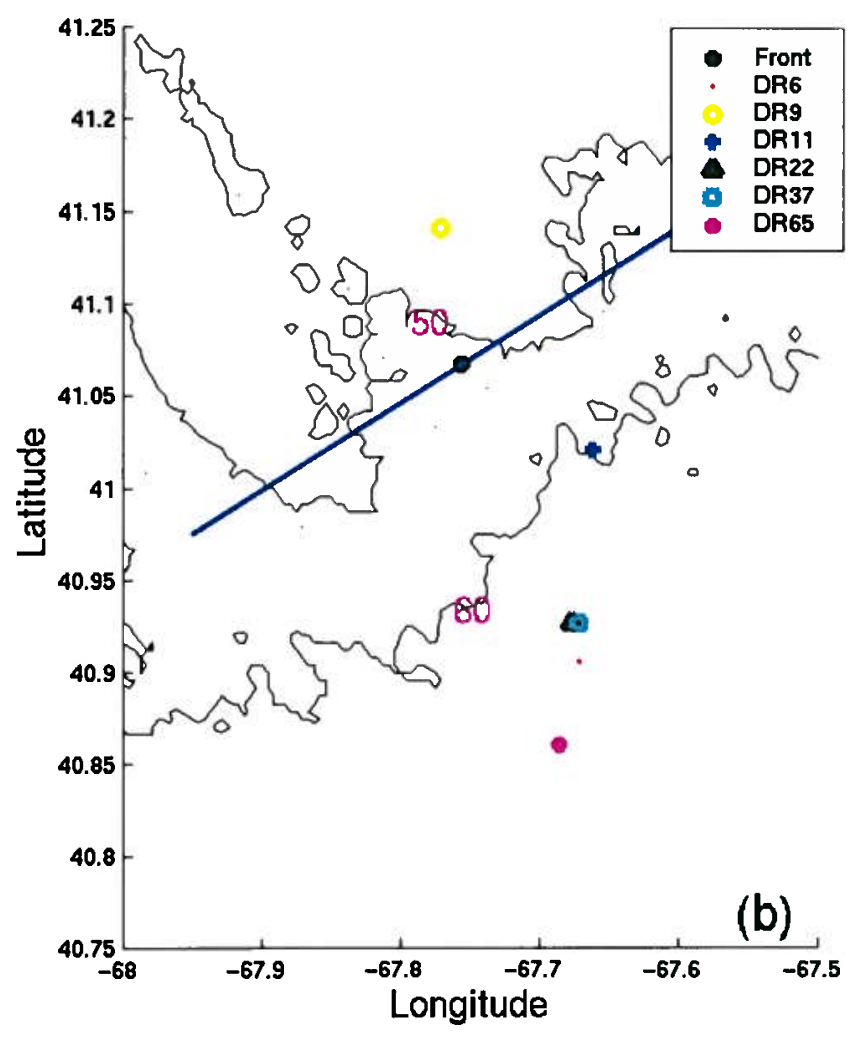

Figure 3.3(b). Plot of drifters and frontal line for front location $\# 2$, at year-day 144.1046. By this time, drifter \#10 has already stopped working. Drifter \#9, a surface drifter, has crossed the front and moved onto the bank. 


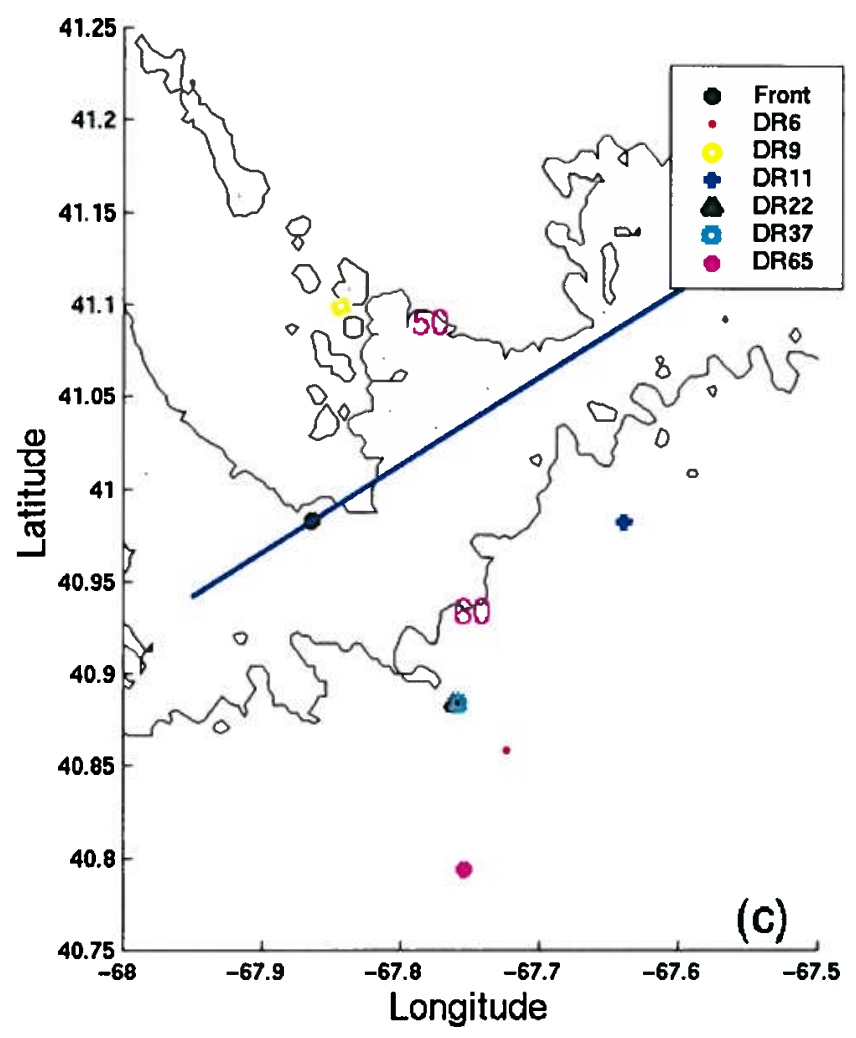

Figure 3.3(c). Plot of drifters and frontal line for front location $\# 3$, at year-day 144.8531 . Only a fraction of a day has passed since location \#2, and the drifters have moved little relative to the front. 


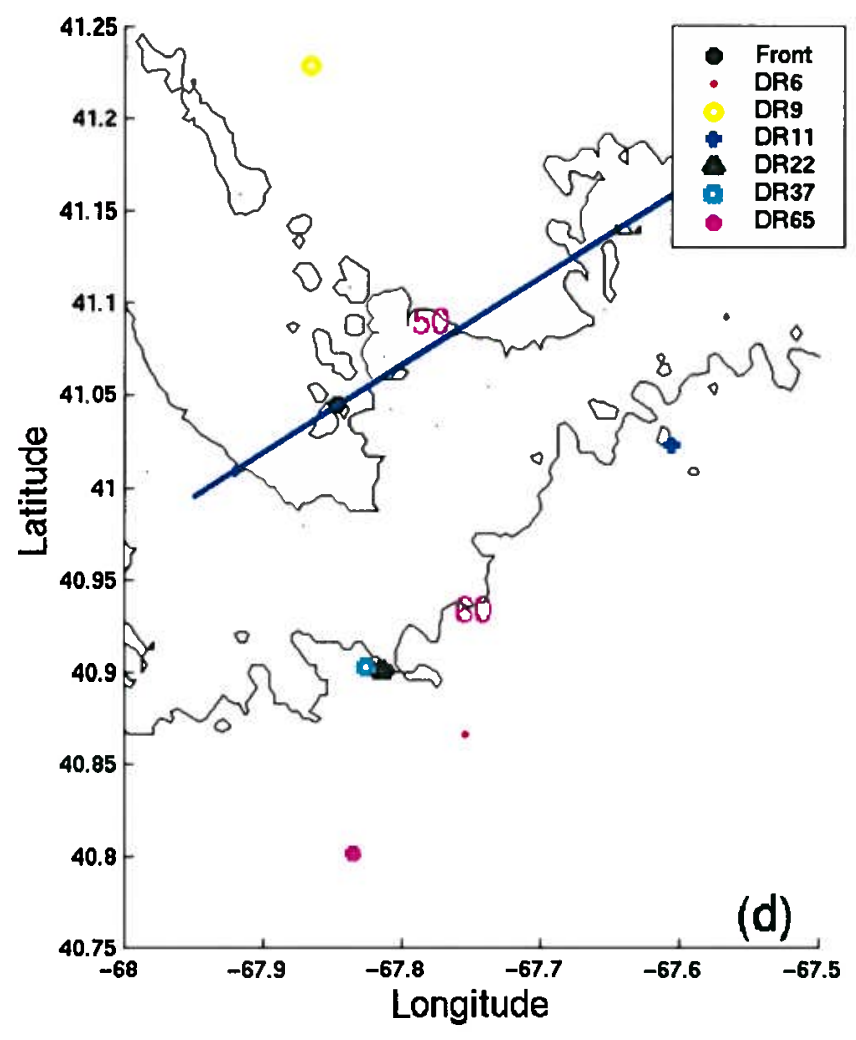

Figure 3.3(d). Plot of drifters and frontal line for front location $\# 4$, at year-day 146.1547 . Drifter \#9 has continued to move onto the bank, while there is little relative movement of the drogued drifters. 
location/time, and was tracked through time to see if there was any discernable motion towards or away from the front. The resulting measurements are plotted in Figure 3.4, and given in Table 3.4. Distances on the open-ocean side of the front are given as positive values, while those on the bank side of the front are given as negative values. Table 3.4 also reports the velocity of the drifters over the period of the study (from the time of Front \#1 to the time of Front \#4) and their general direction. The only drifter to cross the front was Drifter \#9, a surface drifter that was driven by the local winds.

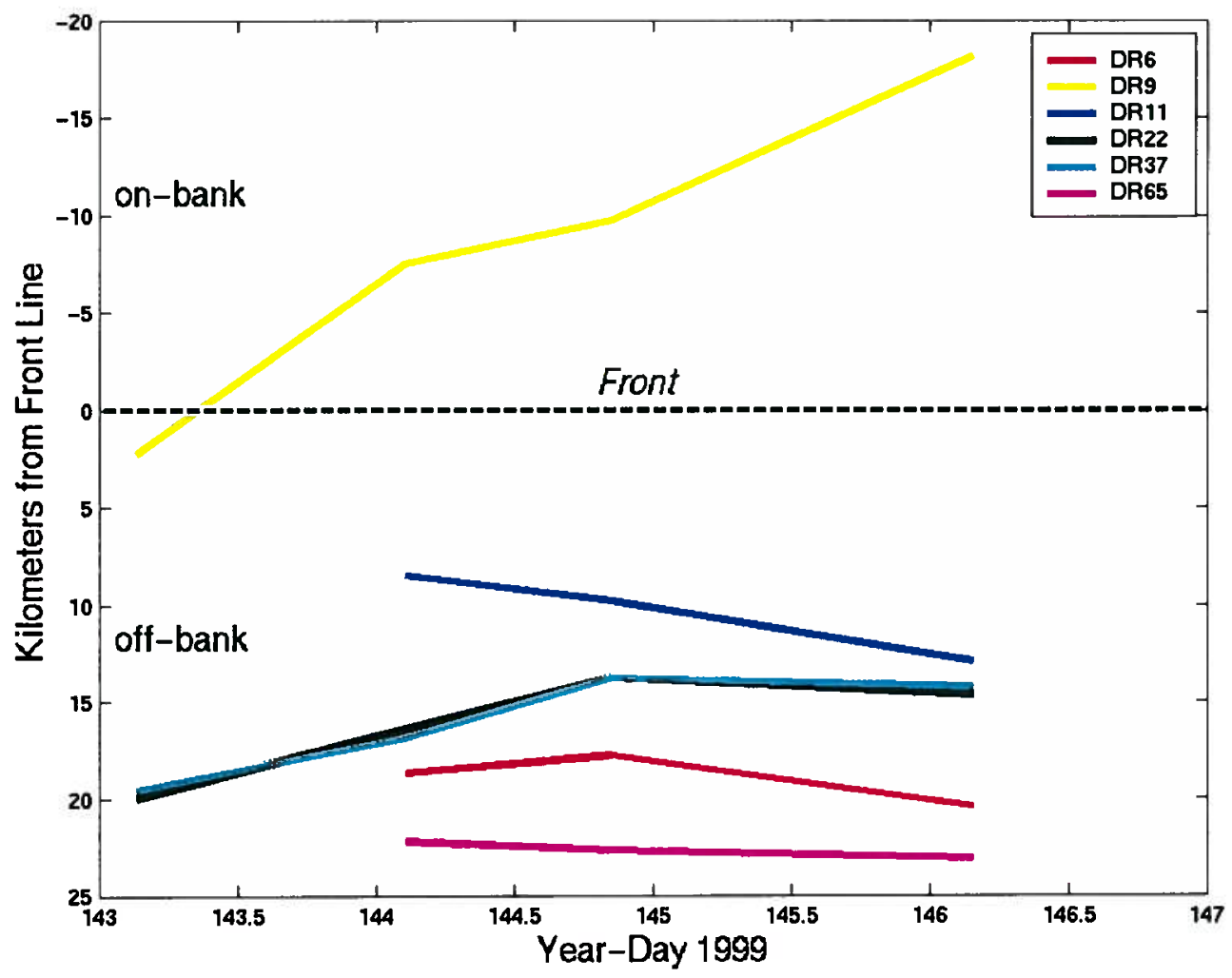

Figure 3.4. Drifter distances relative to the front line. 


\begin{tabular}{|c|c|c|c|c|c|c|c|}
\hline & Style & Front \#1 & Front \#2 & Front \#3 & Front \#4 & $\begin{array}{l}\text { Velocity } \\
\left(\mathrm{cm} \mathrm{s}^{-1}\right)\end{array}$ & $\begin{array}{c}\text { General Direction } \\
\text { of Movement }\end{array}$ \\
\hline DR6 & $\begin{array}{l}\text { Drogued } \\
\text { to } 39.4 \mathrm{~m}\end{array}$ & $n / a$ & 18.6 & 17.8 & 20.4 & 1.0 & $\begin{array}{l}\text { Away from } \\
\text { the front }\end{array}$ \\
\hline DR9 & Surface & 2.2 & -7.5 & -9.8 & -18.2 & 7.8 & $\begin{array}{l}\text { Across the front, } \\
\text { onto the bank }\end{array}$ \\
\hline DR11 & Surface & $\mathrm{n} / \mathrm{a}$ & 8.4 & 9.8 & 12.9 & 2.5 & $\begin{array}{l}\text { Away from } \\
\text { the front }\end{array}$ \\
\hline DR22 & \begin{tabular}{|l|} 
Drogued \\
to $19.4 \mathrm{~m}$ \\
\end{tabular} & 20.0 & 16.4 & 13.8 & 14.7 & 2.0 & $\begin{array}{l}\text { Towards } \\
\text { the front }\end{array}$ \\
\hline DR37 & \begin{tabular}{|l|} 
Drogued \\
to $19.4 \mathrm{~m}$ \\
\end{tabular} & 19.5 & 16.9 & 13.8 & 14.2 & 2.0 & $\begin{array}{l}\text { Towards } \\
\text { the front }\end{array}$ \\
\hline DR65 & $\begin{array}{l}\text { Drogued } \\
\text { to } 19.4 \mathrm{~m}\end{array}$ & $n / a$ & 22.2 & 22.6 & 23.1 & 0.5 & $\begin{array}{l}\text { Away from } \\
\text { the front }\end{array}$ \\
\hline
\end{tabular}

Table 3.4. Relative motion of drifters. The columns labeled "Front \#" give the distance, in $\mathrm{km}$, of each drifter to the respective front line. The velocity value is the average velocity of each drifter from the measurement at Front \#1 (or \#2 if it wasn't deployed at the time of Front \#1) to the measurement at Front \#4.

The motion of the drifters drogued in the pycnocline relative to the front was small, ranging from $0.5-2.0 \mathrm{~cm} \mathrm{~s}^{-1}$. The motion also was both towards and away from the front. This velocity is very near the slip velocity that was calculated in Section 3.3 and therefore can not be considered a real advective motion. 


\section{Chapter 4}

\section{Evaluation of Transport Using Dye Tracer}

\subsection{Data construction}

To further observe transport mechanisms in the area of interest, Rhodamine WT dye, a passive fluorescent tracer, was injected into the pycnocline from a towed sled on May 23, 1999 (Figure 4.1; For injection details, see Ledwell et al., 2000). The target potential density for this dye release was $1025.295 \mathrm{~kg} \mathrm{~m}^{-3}$, which lay within a thin pycnocline. Approximately $65 \mathrm{~kg}$ of dye were injected over 50 minutes, with the injection occurring $16 \mathrm{~km}$ southeast of the tidal mixing front.

The patch was then surveyed with a towed fluorometer three times during the experiment. 35,43 , and $70 \mathrm{~kg}$ of the dye were located in the first, second, and third surveys, respectively (Note: The survey references used throughout the text, Surveys 1, 2, and 3, were used for simplicity and correspond to Surveys 21,25 , and 210 , respectively, in the original labeling of cruise data in Ledwell et. al. (2000)). The mass values for the first two surveys are most likely low due to the spottiness of the distribution, as the mass calculations for these surveys depended on relatively few, high-concentration profiles. It could also be due to relative motion of parts of the patch during the actual surveys. By the time of the third survey, the patch is much larger and more homogeneous, and is therefore not as spotty or so greatly affected by relative motions. However, correcting for the background signal was difficult due to the lower concentrations. The mass value for this survey is larger than the mass injected, though within uncertainty limits, probably because too much of the background was counted as dye.

To obtain "snap-shots" of the dye patch, positions for each survey were adjusted to a single time using the integral of the velocity measured from the 
survey ship at the level of the dye patch between the time of a profile and the reference time. The reference time chosen in each case was near the end of the survey at the time of the maximum off-bank phase of the semidiurnal tide, which was when the front was near the 60-meter isobath (Ledwell et al., 2000). Three advected data sets for dye concentration in 3-dimensions resulted, with reference times of 4,41 , and 117 hours after the initial injection.

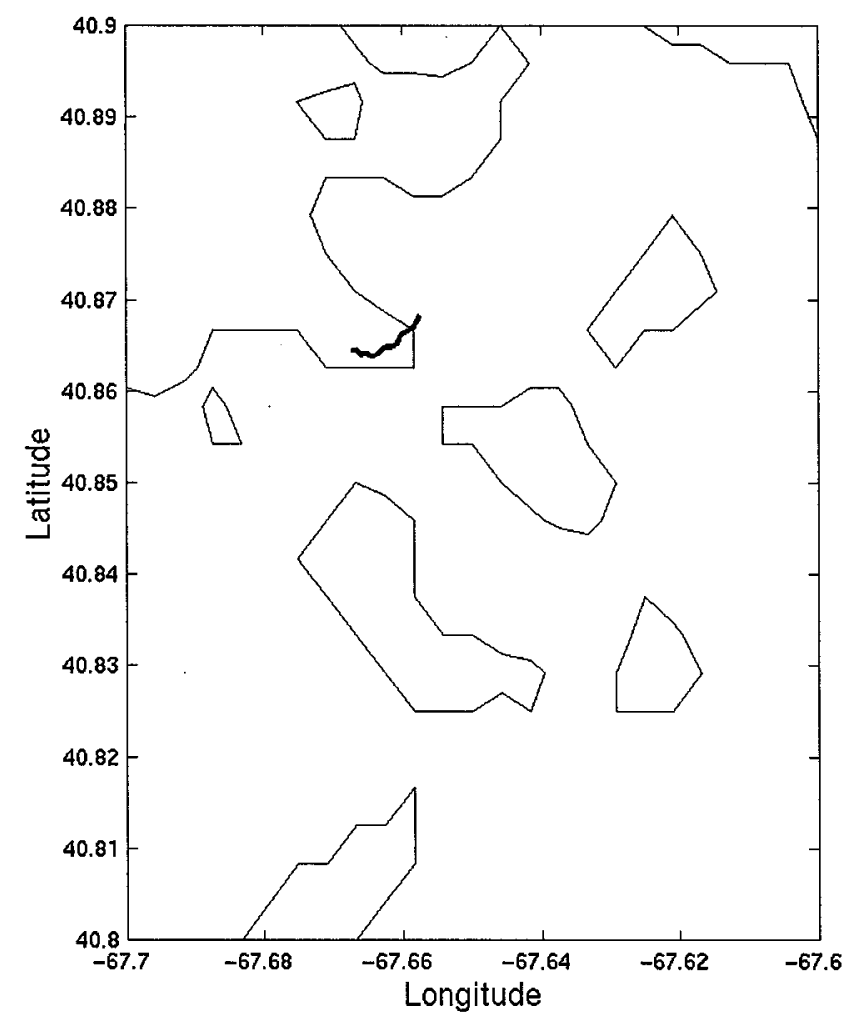

Figure 4.1. Plot of the ship's track (in blue) during the dye injection. This represents the initial dye streak. The black line shown is the 70-meter isobath. 


\subsection{Dye Patch Advection}

The overall advection of the dye patch throughout the experiment can be observed by following the center of mass of the dye patch. The coordinates of the center of mass were calculated from the advected survey data. First, each survey was vertically integrated to yield a map-view of the dye patch (see Figures 4.2a-c). Then, as adapted from Peeters et al. (1993), the locations of the centers of mass of the vertically integrated, advected dye patches are given by:

$$
\begin{aligned}
& x_{o}=\frac{1}{M} \iint x C(x, y) d x d y ; \\
& y_{o}=\frac{1}{M} \iint y C(x, y) d x d y ;
\end{aligned}
$$

where $x$ and $y$ are the meridional and zonal lengths, $M$ is the total tracer mass calculated from:

$$
M=\iint C(x, y) d x d y
$$

and $C(x, y)$ represents the vertically integrated dye concentrations for the advected patch. The centers of mass of the three surveys are depicted in Figure 4.2 . 


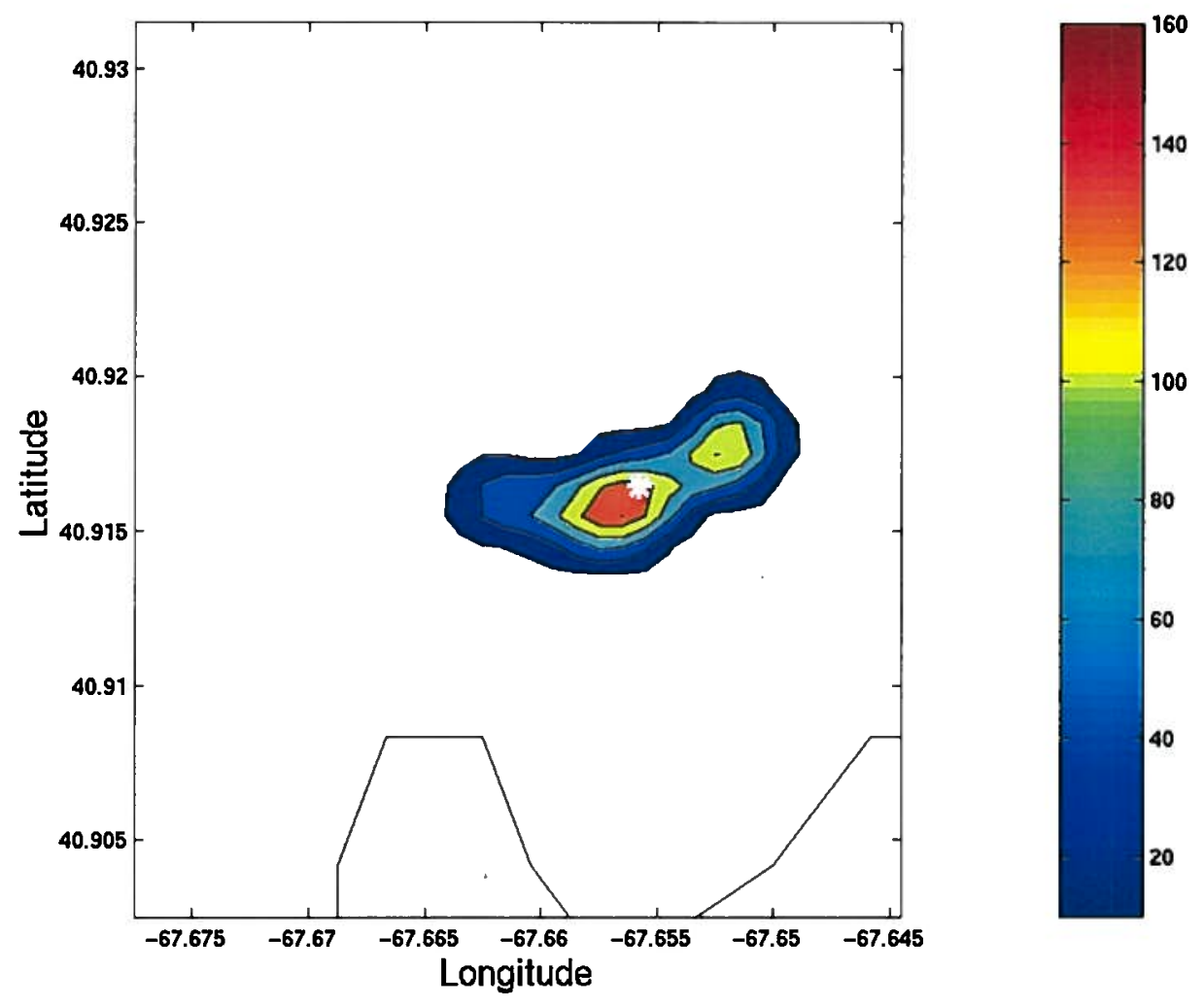

Figure 4.2(a). Vertically integrated map of the dye patch from Survey 1, 4 hours after injection. Rhodamine concentrations are given in units of $\mathrm{kg} \mathrm{km}^{-2}$. The white star represents the center of mass of the dye patch. The black line is the 70meter isobath. Figure 4.6 shows the sampling track. 

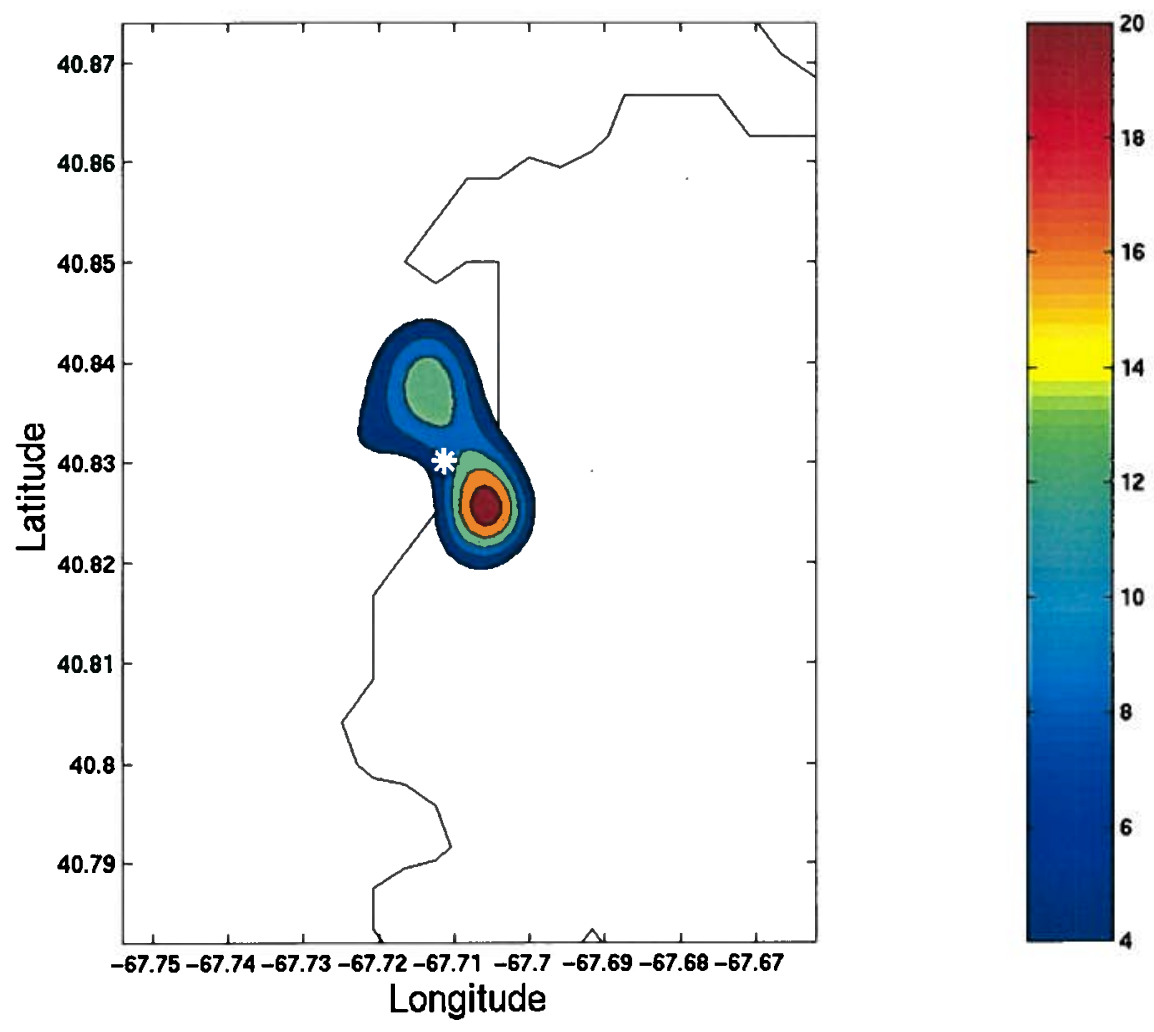

Figure 4.2(b). Vertically integrated map of the dye patch from Survey 2, 41 hours after injection. Rhodamine concentrations are given in units of $\mathrm{kg} \mathrm{km}^{-2}$. The white star represents the center of mass of the dye patch. The black line is the 70meter isobath. Figure C.2 shows the sampling track. 

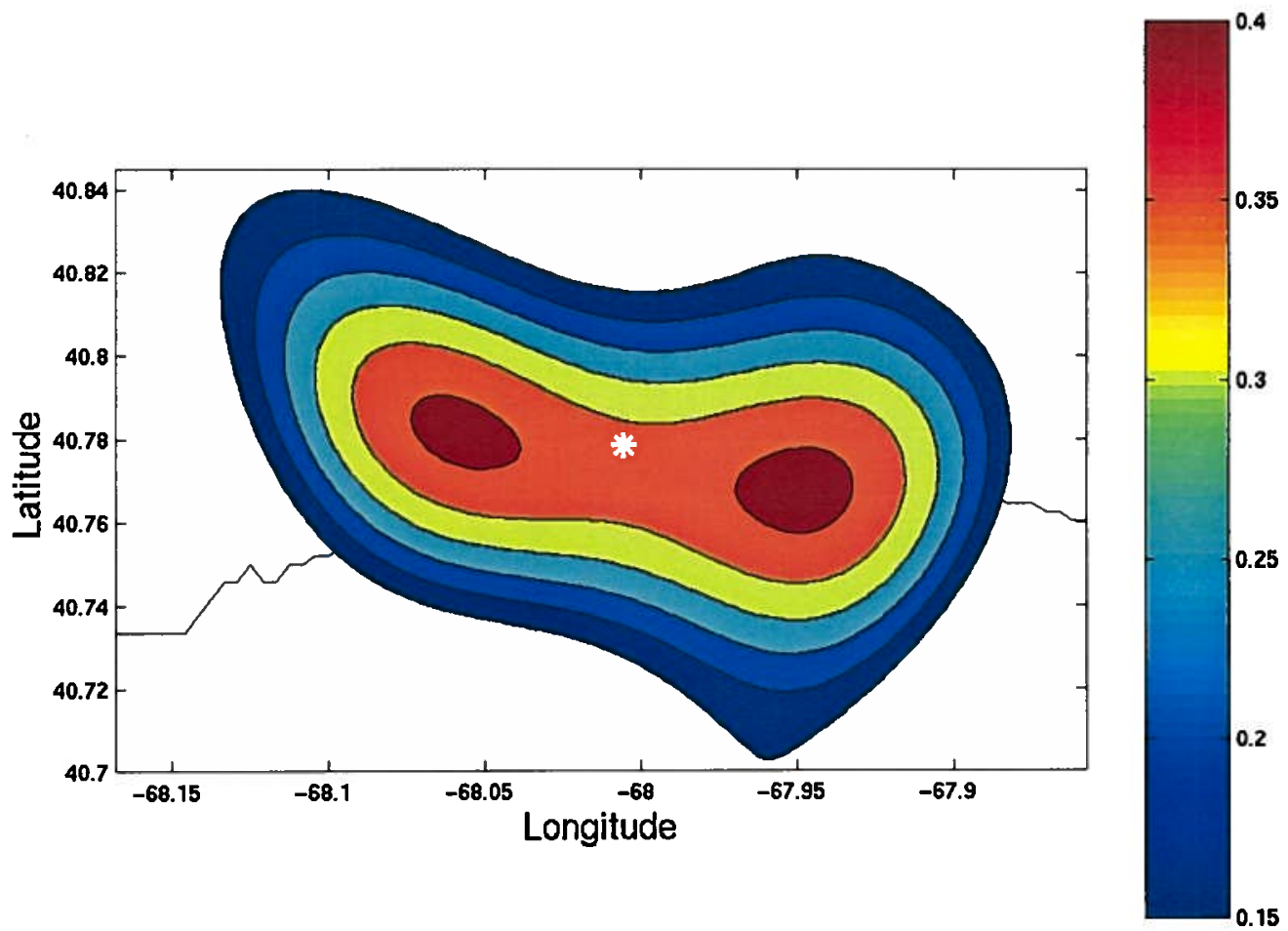

Figure 4.2(c). Vertically integrated map of the dye patch from Survey 3,117 hours after injection. Rhodamine concentrations are given in units of $\mathrm{kg} \mathrm{km}^{-2}$. The white star represents the center of mass of the dye patch. The black line is the 70-meter isobath. Figure C.3 shows the sampling track.

The dye was injected near the 70-meter isobath and, as seen in Figures 4.2 and 4.3, its center of mass doesn't depart from this isobath throughout the experiment (NOTE: The dye injection is south of the 4 hour dye survey due to the elliptical nature of the tides on Georges Bank.). While we can't see where the dye went between the surveys, it appears that it has traveled along this isobath, only departing from it as part of the semidiurnal tidal excursion. As this 
is the same motion demonstrated by the front itself, the dye does not seem to be advected relative to the front, but rather only along the isobaths. The center of mass of the dye patch perhaps moves relative to the front only as a result of the isobaths getting closer together.

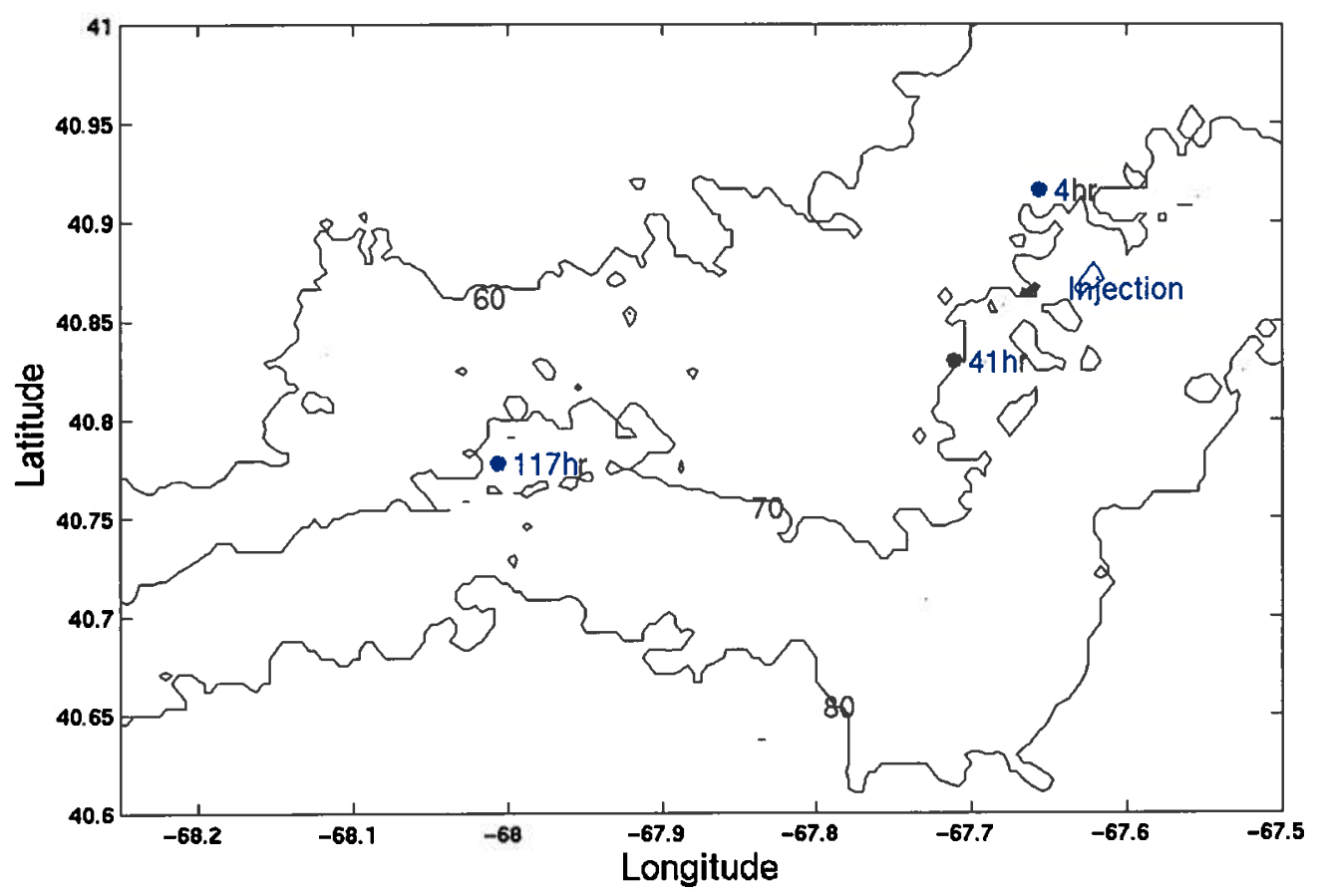

Figure 4.3. Advection of the dye's center of mass from 4 to 117 hours. The $60-, 70-$, and $80-$ meter isobaths, as well as the injection location, are also plotted. 


\subsection{Dye Patch Diffusion}

While the dye does not seem to be advected relative to the front, Figure 4.2 clearly shows that it is spreading laterally both towards and away from the front. As this dispersion transport may be the main mechanism for getting materials to Georges Bank, a closer examination of its characteristics is worthwhile.

The vertically integrated, advected, dye patch data were used to calculate the area of the patch containing $95 \%$ of the total dye mass for each survey. From the time of the first survey (4 hours after injection) to the time of the second survey (41 hours after injection), this area grew at a rate of $700 \mathrm{~m}^{2} \mathrm{~s}^{-1}$. Between the second and third (117 hours after injection) surveys, that rate increased to $1800 \mathrm{~m}^{2} \mathrm{~s}^{-1}$. Clearly this is not a linear growth.

The variance and covariance of each surveyed patch could then be calculated from the vertically integrated data and compared to previous dye studies. Removing the centers of mass to redefine $x$ and $y$ as:

$$
\begin{aligned}
& x=x-x_{o} \\
& y=y-y_{o},
\end{aligned}
$$

the variances are then given by:

$$
\begin{aligned}
& \sigma_{x}^{2}=\frac{1}{M} \iint x^{2} C(x, y) d x d y \\
& \sigma_{y}^{2}=\frac{1}{M} \iint y^{2} C(x, y) d x d y .
\end{aligned}
$$

The covariance is given by: 


$$
\sigma_{x y}=\frac{1}{M} \iint x y C(x, y) d x d y
$$

where $M$ and $C(x, y)$ remain as described in Section 4.2 (Peeters et al., 1993). The values obtained for each survey are displayed in Table 4.1.

\begin{tabular}{|c|c|c|c|c|}
\multicolumn{5}{|c|}{ Survey } \\
Survey Time(hrs) $\sigma_{x}^{2}\left(\mathrm{~km}^{2}\right) \sigma_{y}^{2}\left(\mathbf{k m}^{2}\right)$ & $\sigma_{x y}\left(\mathbf{k m}^{2}\right)$ \\
\hline 1 & 4 & 0.09 & 0.03 & 0.02 \\
\hline 2 & 41 & 0.59 & 1.3 & -0.38 \\
\hline 3 & 117 & 33 & 13 & -4.9 \\
\hline
\end{tabular}

Table 4.1. Computed dispersion statistics for the advected dye patches.

Figure 4.2 clearly shows that the dye does not spread isotropically, but rather in a somewhat ellipsoid form. While the above statistics describe the spreading of the dye patch in the $x$ and $y$ directions, it is much more valuable to examine the spreading along the patch's major and minor principal axes.

\subsubsection{Rotating the Axes}

Rotating the axes to the dye patch's major and minor axes requires a rotation about the center of mass $\left(x_{o}, y_{o}\right)$ of angle $\theta$ such that the covariance, $\sigma_{x y}$, of the rotated patch is equal to or very close to zero. This method is applied 
to each surveyed dye patch independently (Okubo, 1971), yielding a different angle $\theta$ for each of the three surveys. First, using the definitions of $x$ and $y$ from equations (4.4) and (4.5), we define coordinates in the rotated frame as:

$$
\begin{array}{r}
x^{\prime}=x \cos \theta+y \sin \theta \\
y^{\prime}=y \cos \theta-x \sin \theta
\end{array}
$$

where $x^{\prime}$ and $y^{\prime}$ will now always refer to the rotated axes. The covariance is then:

$$
\sigma_{x^{\prime} y^{\prime}}=\frac{1}{M} \iint x^{\prime} y^{\prime} C(x, y) d x^{\prime} d y^{\prime}
$$

By inserting (4.9) and (4.10) into (4.11) and applying trigonometric identities, (4.11) can be written:

$$
\sigma_{x^{\prime} y^{\prime}}=\left(2 \cos ^{2} \theta-1\right) \sigma_{x y}+\sin \theta \cos \theta\left(\sigma_{y}^{2}-\sigma_{x}^{2}\right)
$$

Setting (4.12) equal to zero and again applying trigonometric identities, (4.12) can be rewritten in the form:

$$
\begin{array}{r}
\sigma_{x^{\prime} y^{\prime}}=0=\cos ^{4} \theta\left[4\left(\sigma_{x y}\right)^{2}+\left(\sigma_{y}^{2}-\sigma_{x}^{2}\right)^{2}\right]-\ldots \\
\cos ^{2} \theta\left[4\left(\sigma_{x y}\right)^{2}+\left(\sigma_{y}^{2}-\sigma_{x}^{2}\right)^{2}\right]+\left(\sigma_{x y}\right)^{2}
\end{array} .
$$

Solution of this quadratic equation using the values for $\sigma_{x}^{2}, \sigma_{y}^{2}$, and $\sigma_{x y}$ given in Table 4.1 will produce two roots of $\cos ^{2} \theta$ for each survey. Taking the square root of these roots produces four possible values for $\cos \theta$. Restricting $\theta$ to the 
right half-plane, where $-\pi / 2<\theta<\pi / 2$, gives us two pair of angles that are $\pi / 2$ radians apart. One pair represents the major and minor axes, while the other pair is spurious due the ambiguity introduced by expressing $\sin \theta=\sqrt{1-\cos ^{2} \theta}$ in the formulation of (4.13). One member of each pair was tested in equations (4.9)--(4.11) to see which resulted in $\sigma_{x^{\prime} y^{\prime}}=0$. The variances for the rotated axes, given by:

$$
\begin{aligned}
& \sigma_{x^{\prime}}^{2}=\frac{1}{M} \iint x^{\prime 2} C(x, y) d x d y \\
& \sigma_{y^{\prime}}^{2}=\frac{1}{M} \iint y^{\prime 2} C(x, y) d x d y
\end{aligned}
$$

were calculated for the pair of angles that yielded $\sigma_{x^{\prime} y^{\prime}}$ closest to zero. The angle of that pair that yielded the greatest value for $\sigma_{x^{\prime}}^{2}$ was designated at the major axis, and the other member of the pair was then the minor axis. The resulting angles and the diffusion characteristics of the patches on their rotated axes are given in Table 4.2.

Survey $\begin{gathered}\text { Major } \\
\text { Axis }\end{gathered}$
\begin{tabular}{|c|c|c|c|c|c|}
\hline Survey Time(hrs) & Angle $\sigma^{2}{ }^{\prime}\left(\mathbf{k m}^{2}\right)$ & $\sigma^{2}{ }^{\prime}{ }^{\prime}\left(\mathbf{k m}^{2}\right)$ & $\sigma_{x^{\prime} \mathbf{y}^{\prime}}\left(\mathbf{k m}^{2}\right)$ \\
\hline 1 & 4 & $72^{\circ}$ & 0.10 & 0.02 & $9.0 \mathrm{E}-07$ \\
\hline 2 & 41 & $157^{\circ}$ & 1.5 & 0.43 & $4.5 \mathrm{E}-05$ \\
\hline 3 & 17 & $103^{\circ}$ & 35 & 12 & $7.3 \mathrm{E}-05$ \\
\hline
\end{tabular}

Table 4.2. Axes rotation angles and dispersion statistics for the advected dye patches computed on their rotated axes. Angles are reported in degrees from true north. 


\subsubsection{Calculation of Diffusion Statistics}

To understand the diffusion characteristics of the area, the data were compared with the work of Okubo (1971) who described the diffusion characteristics of the upper mixed layer of the ocean. For an asymmetrical dye patch with a Gaussian distribution, the variance for a radially symmetric equivalent radius can be given by:

$$
\sigma_{r c}^{2}=2 \sigma_{x^{\prime}} \sigma_{y^{\prime}}
$$

where $\sigma_{x^{\prime}}^{2}$ and $\sigma_{y^{\prime}}^{2}$ are the variances in the major and minor axes (Okubo, 1971; Peeters et al., 1993). This value was calculated for the three-pycnocline dye surveys.

For a collection of 20 data sets obtained by various investigators with time scales ranging from 2 hours to 1 month and length scales of $30 \mathrm{~m}$ to $100 \mathrm{~km}$, Okubo (1971) found the variance to increase with time with the non-Fickian (nonlinear) relationship:

$$
\sigma_{r c}^{2}=0.0108 t^{2.34}
$$

This relationship is shown in Figure 4.4 in a basic diffusion diagram displaying $\sigma_{r c}^{2}$ versus diffusion time, $t$. To compare the Okubo diffusion relationship to the three GLOBEC dye surveys, the time of the GLOBEC surveys was shifted such that the first survey exactly agreed with Okubo. The shifted $\sigma_{r c}^{2}$ of the GLOBEC pycnocline data, also shown in Figure 4.4, are in good agreement with Okubo's relationship for the surface mixed layer (1971). 


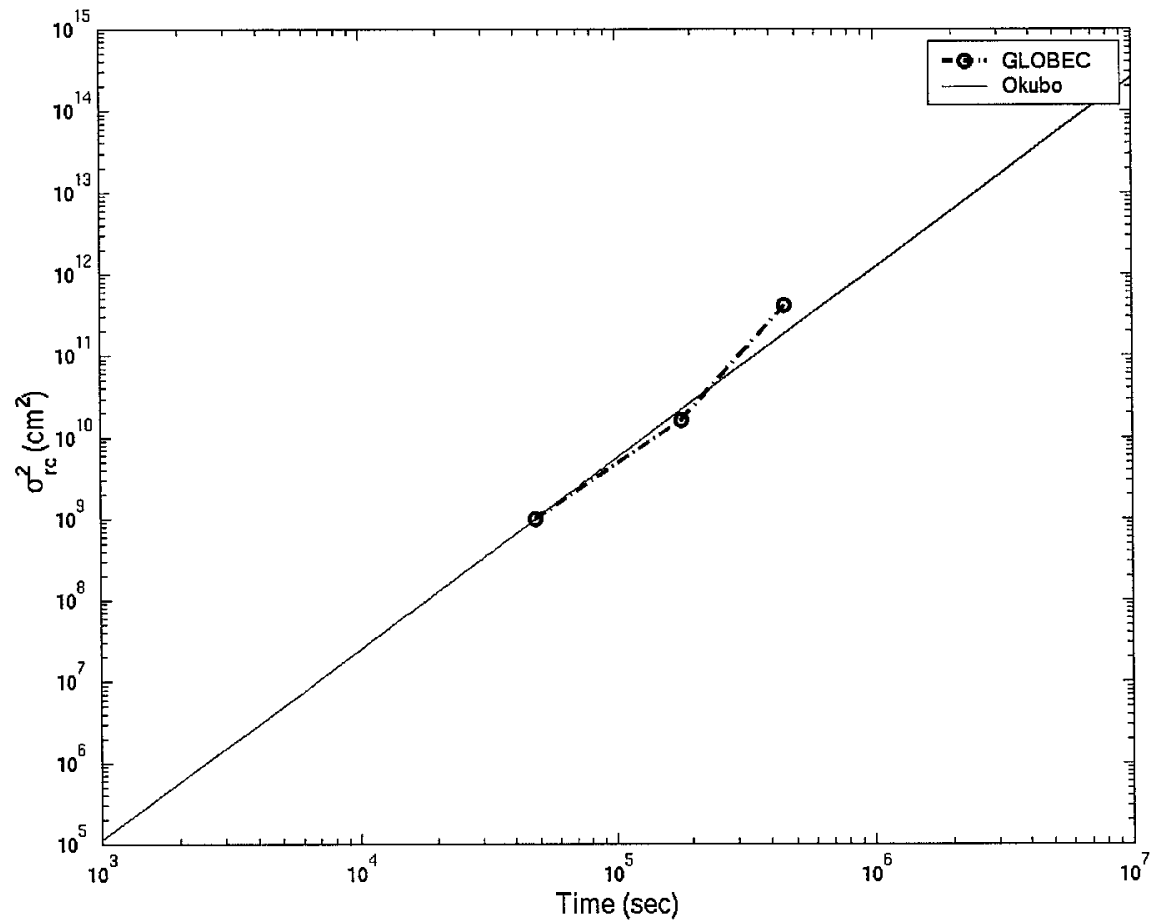

Figure 4.4. Comparison of the growth of the variance $\sigma_{r c}^{2}$ with Okubo (1971).

The relationship of the apparent diffusivity, $K_{a}$, to the diffusion length scale, $l$, of the GLOBEC dye patches was also compared to Okubo's 1971 work. For each survey, the apparent diffusivity was given by:

$$
K_{a}=\frac{\sigma_{r c}^{2}}{4 t} .
$$

Letting $l$ be given by:

$$
l=3 \sigma_{r c},
$$


Okubo (1971) fit a relationship for the apparent diffusivity and diffusion length scale of 20 data sets such that:

$$
K_{a}=0.0103 l^{1.15} \text {. }
$$

Given the variance values from the GLOBEC data, $l$ and $K_{a}$ are calculated using (4.19) and (4.20) according to Okubo's findings. Figure 4.5 shows both Okubo's trend for $K_{a}$ as well as the GLOBEC $K_{a}$ as calculated from (4.18). Again, the data from the southern flank pycnocline dye experiment agree fairly well with Okubo's findings.

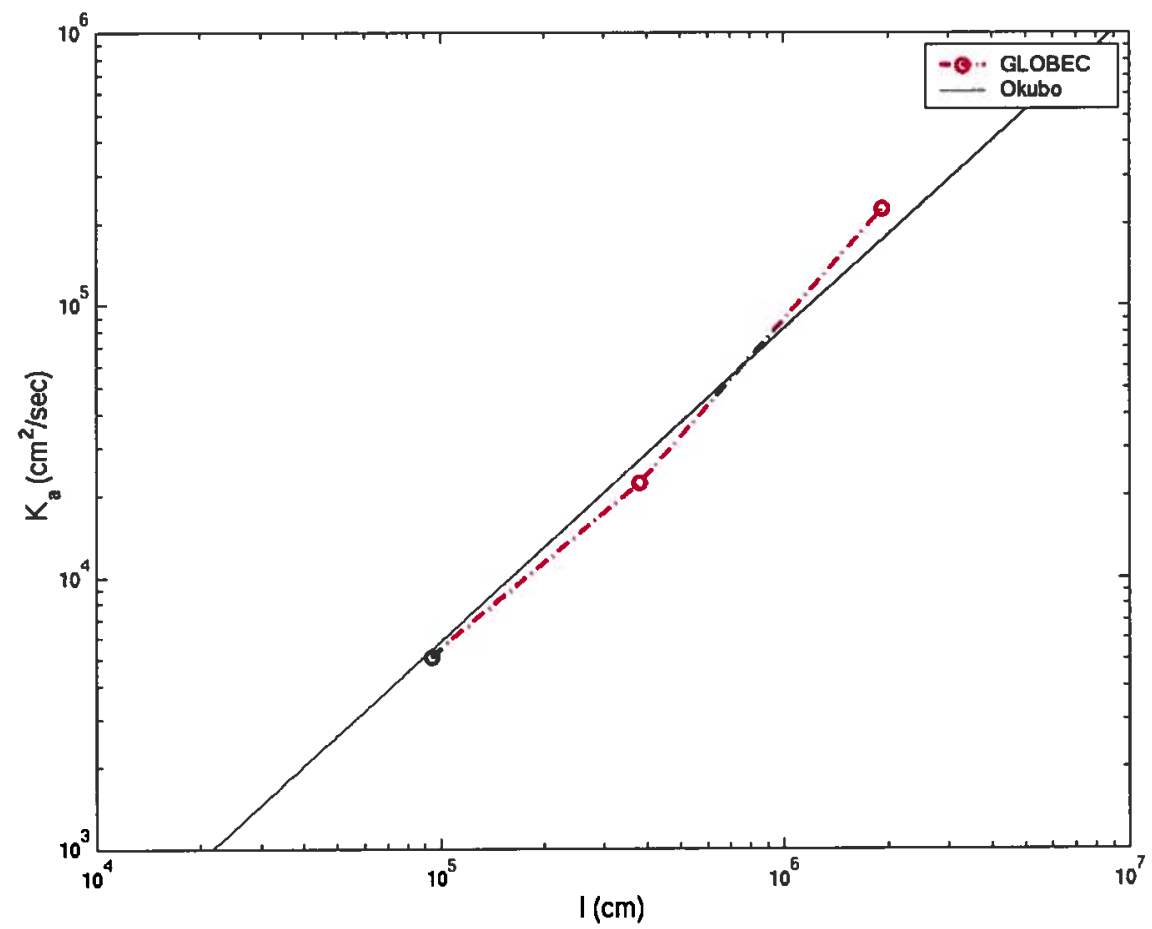

Figure 4.5. A diffusion diagram relating apparent diffusivity to the length scale of the dye patch, and comparison with Okubo (1971). 


\subsection{Advective Dispersion}

\subsubsection{Dye Versus Depth}

While the analysis so far has considered the dye patches in their 2dimensional map-views, looking at the dye distribution versus depth can help further describe how the patch disperses. Looking at the vertical distribution of the dye may also help describe the secondary circulation in the area.

For each survey, sections along the advected ship's track were chosen to be contoured. Sections chosen lay within the dye, preferably crossing completely through it, and were oriented such that they were aligned roughly with the isobaths or perpendicular to them. Figure 4.6 demonstrates the choices that were made for the first survey (see Appendix $C$ for figures from Surveys 2 and 3 ). Each section was contoured on a grid of depth versus either latitude or longitude. The choice of geographic coordinate depended on the orientation of each individual section. For example, contour sections 1-6 for Survey 1 were plotted on a depth/latitude grid, while contour sections 7 and 8 were plotted on a depth/longitude grid (Figure 4.6).

An objective analysis program which assumes a Gaussian correlation function was then performed on the both the dye and the density data for each section (for details, see Appendix $\mathrm{C}$ ). For all three surveys, the amplitude of the correlation function at the origin (variable $R O$ in the program) was 0.95 . The decay scale of the function (variable corrlen in the program) was different for each survey and depended on the overall size of the patch. The decay scale value used for the first, second, and third surveys, was $0.5,2.5$, and $5 \mathrm{~km}$, respectively. The output of the objective analysis of the dye data was then plotted as a filled contour, with the output of the density analysis plotted as contour lines overlaying the dye contour. Eight such sections were made for 
Survey 1 , seven for Survey 2, and three for Survey 3, all of which are contained in Appendix C.

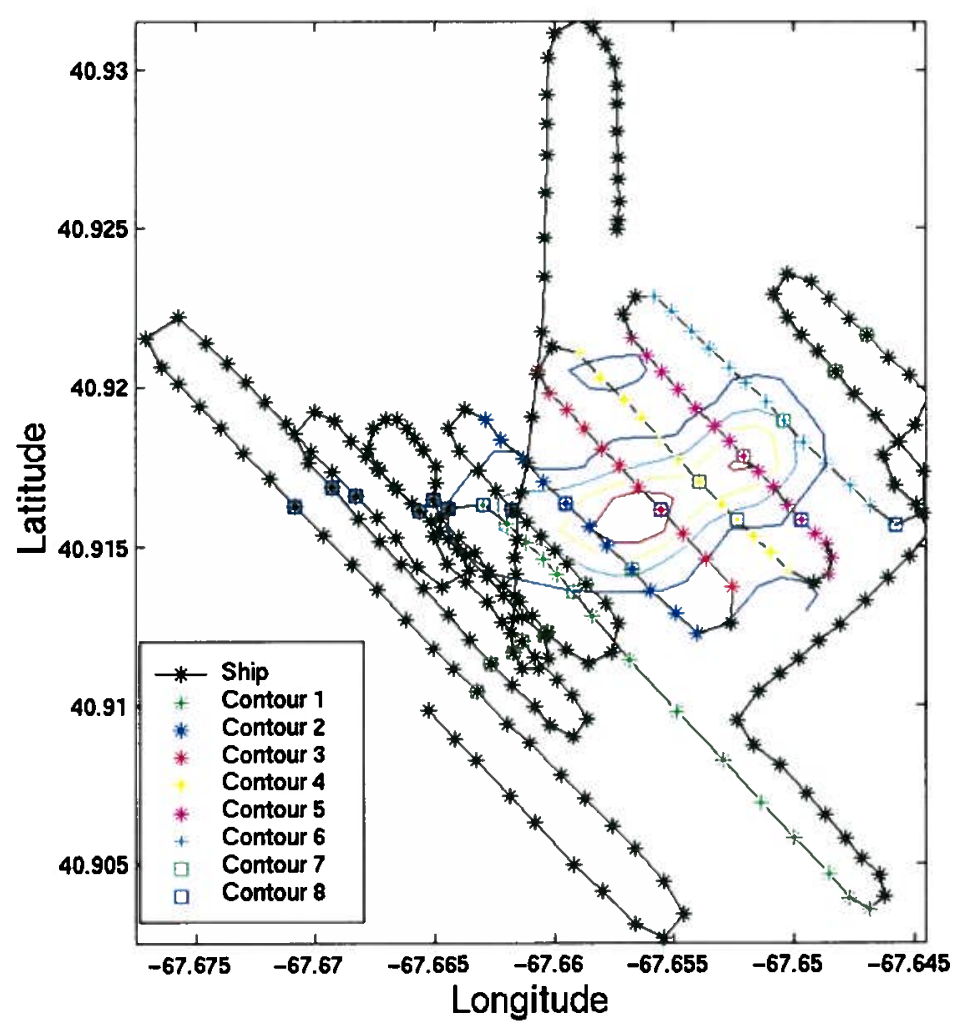

Figure 4.6. Survey 1 advected ship's track with dye sections for vertical contouring labeled.

The sections were then evaluated to see if shearing or secondary circulation in the dye patch could be observed. 


\subsubsection{Shear Dispersion}

As can be seen in Figure 4.2 and inferred from the major axis angles given in Table 4.2, the dye patch orientation is not constant throughout the study. While the center of mass of the patch remains near the 70-meter isobath throughout the experiment (Figure 4.3), the dye patch itself seems to rotate somewhat. For all three surveys, the major principal axis of the dye patch is oriented more or less in the direction of the underlying bathymetry. This enhanced along-isobath dispersion could be a result of vertical shear in the along-isobath velocity.

The terms of a dispersion equation can be compared to determine the importance of horizontal and vertical shear in a system. For a system with steady flow, the second moment in the along-isobath direction (along the major axis of the dye patch in this case), $\sigma_{1}^{2}$, is given by (Smith, 1982):

$$
\sigma_{1}^{2}=2 K_{1}\left(t-t_{o}\right)+\frac{2}{3}\left(\frac{\partial u}{\partial y}\right)^{2} K_{2}\left(t-t_{o}\right)^{3}+\frac{2}{3}\left(\frac{\partial u}{\partial z}\right)^{2} K_{3}\left(t-t_{0}\right)^{3}
$$

where $x$ and $y$ represent the along- and across-isobath directions, respectively, $z$ is the vertical coordinate, $K_{1}$ is the along-isobath diffusivity, $K_{2}$ is the crossisobath diffusivity, $K_{3}$ is the vertical diffusivity, and $t$ is time, with $t_{o}$ being the time of injection of a small patch. The third survey was used for the analysis, such that $t_{o}=0$ and $t=117$ hours. For this region, $K_{3} \cong 0.2 \mathrm{~cm}^{2} \mathrm{~s}^{-1}$ (Ledwell, personal communication), and for this amount of elapsed time $K_{1}=K_{2}=2.4 \times 10^{5}$ $\mathrm{cm}^{2} \mathrm{~s}^{-1}$ as calculated in Section 4.3.2 (see Figure 4.5). $K_{1}$ and $K_{2}$ actually vary with the size of the patch and hence with the time of sampling if the patch is growing. $\frac{\partial u}{\partial y}$ was estimated to be on the order of $10^{-5} \mathrm{~s}^{-1}$ (Schlitz and Smith, 
2001; Chen and Beardsley, 1998). An upper limit on $\frac{\partial u}{\partial z}$ was calculated from shipboard ADCP data between depths of 15 and $23 \mathrm{~m}$, which centers on the dye patch's average vertical position, to be $0.006 \mathrm{~s}^{-1}$.

Using the values given above, the first, second, and third terms of equation (4.21) are then calculated to be $2.0 \times 10^{11}, 1.2 \times 10^{12}$, and $3.7 \times 10^{11} \mathrm{~cm}^{2}$, respectively, for a total $\sigma_{1}^{2}$ of $1.8 \times 10^{12} \mathrm{~cm}^{2}$. This value is larger than the $3.5 \times 10^{11}$ $\mathrm{cm}^{2}$ calculated for the dispersion along the major axis in Survey 3 (see Section 4.3.1, Table 4.2). However, the value used for $K_{1}$ and $K_{2}$ accounts for all types of dispersion and may have been overestimated due to the uncertainty in the size of the patch for Survey 3.

The dispersion in the cross-isobath direction is evaluated to obtain a better estimate for $K_{1}$ and $K_{2}$. The second moment in the cross-isobath direction is given by:

$$
\sigma_{2}^{2}=2 K_{2}\left(t-t_{o}\right)+\frac{2}{3}\left(\frac{\partial v}{\partial x}\right)^{2} K_{1}\left(t-t_{o}\right)^{3}+\frac{2}{3}\left(\frac{\partial v}{\partial z}\right)^{2} K_{3}\left(t-t_{0}\right)^{3}
$$

For the southern flank of Georges Bank, $\frac{\partial v}{\partial x}$ is assumed to be small and $\frac{\partial v}{\partial z}$ is on the order of $4 \times 10^{-4} \mathrm{~s}^{-1}$ (Schlitz, 2001). The third term of equation (4.22) is then calculated to be $1.6 \times 10^{9} \mathrm{~cm}^{2}$, which is about 100 times smaller than the total value calculated for the minor axis dispersion in Section 4.3.1. The third term is thus considered negligible, and equation (4.22) becomes:

$$
\sigma_{2}^{2} \cong 2 K_{2}\left(t-t_{o}\right)
$$


$K_{2}$ can then be estimated from the slope of a line describing the cross-isobath dispersion. Values for the dispersion along the minor axis (cross-isobath) from Surveys 1 and 2 (see Table 4.2) were used to estimate $K_{2}$ to be $1.5 \times 10^{4} \mathrm{~cm}^{2} \mathrm{~s}^{-1}$.

Recalculating the second moment in the along-isobath direction with the new $K_{1}$ and $K_{2},\left(K_{1}\right.$ is assumed to equal $\left.K_{2}\right)$, the first, second, and third terms of equation (4.21) are $1.3 \times 10^{10}, 7.5 \times 10^{10}$, and $3.7 \times 10^{11} \mathrm{~cm}^{2}$, respectively, for a sum of $4.5 \times 10^{11} \mathrm{~cm}^{2}$. This value more closely matches that reported in Table 4.2. Calculating the second moment in the cross-isobath direction from equation (4.22) yields values of $1.3 \times 10^{10}, 0$, and $1.6 \times 10^{9} \mathrm{~cm}^{2}$ for the first, second, and third terms, respectively.

These values imply that vertical shear in the along-isobath direction, from the $\frac{\partial u}{\partial z}$ term, is the dominant shear mechanism. The contoured vertical sections of dye were evaluated to see if evidence of this shear is present. Figure 4.7, which is a vertical section dye contour that parallels the underlying bathymetry, demonstrates this shear. The western lobe of the patch is deeper, relative to the isopycnals, than the eastern lobe. The along-isobath current in this area runs towards the southwest, or towards the left in the figure, and with a maximum velocity occurring at about $20 \mathrm{~m}$ (Schlitz, 2000) could have pulled the deep dye to the west. 


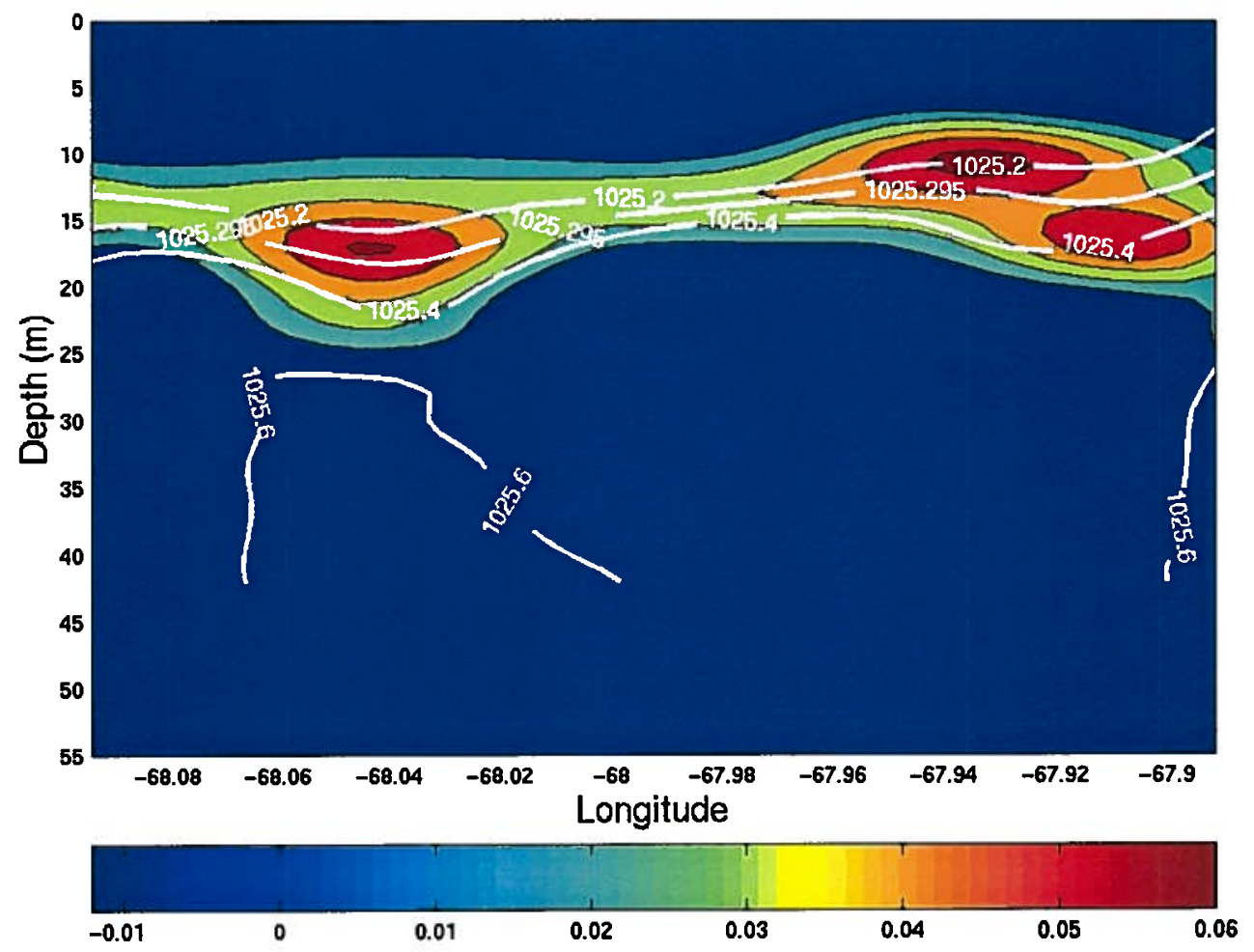

Figure 4.7. Survey 3 , Contour 1 vertical section dye contour. Rhodamine dye concentrations are given in units of $\mu \mathrm{g} \mathrm{L}^{-1}$. Density contours are plotted as white lines/labels in units of $\mathrm{kg}$ $\mathrm{m}^{-3}$.

\subsubsection{The Effect of Strain on Dispersion}

While vertical shear is an acceptable cause of the enhanced along-isobath dispersion, strain is also a possible contributor. Consider a two-dimensional field ( $x \equiv$ along-isobath, $y \equiv$ cross-isobath) with the strain rate $\gamma=\frac{\partial u}{\partial x}=-\frac{\partial v}{\partial y}$, where small-scale dispersion can be described by an effective diffusivity constant, $\kappa_{a}$ (Sundermeyer, 1998). If we assume that the tracer initially had a Gaussian 
distribution and $\gamma>0$ (Townsend, 1951), the variance in the along-isobath direction is given by (Sundermeyer, 1998):

$$
\sigma_{x}^{2}=\sigma_{x o}^{2} e^{2 \Gamma}+e^{2 \Gamma} \int_{0}^{t} 2 \kappa_{a} e^{-2 \Gamma} d t
$$

and in the cross-isobath direction is given by:

$$
\sigma_{y}^{2}=\sigma_{y o}^{2} e^{-2 \Gamma}+e^{-2 \Gamma} \int_{0}^{t} 2 \kappa_{a} e^{2 \Gamma} d t
$$

We consider the case of steady $\gamma$ and therefore let the exponential growth rate be given by:

$$
\Gamma=\int_{0}^{i} \gamma(t) d t=\gamma t
$$

Inserting (4.26) into (4.24) and computing the integral yields:

$$
\sigma_{x}^{2}=\sigma_{x o}^{2} e^{2 \gamma t}+\frac{\kappa_{a}}{\gamma}\left(e^{2 \gamma t}-1\right)
$$

which increases exponentially with time. Likewise, the variance in the crossisobath direction becomes:

$$
\sigma_{y}^{2}=\sigma_{y o}^{2} e^{-2 \gamma t}+\frac{\kappa_{a}}{\gamma}-\frac{\kappa_{a}}{\gamma} e^{-2 \gamma}
$$


As time increases the first and third terms of (4.28) go to zero, and the patch approaches a finite cross-isobath width of $\frac{\kappa_{a}}{\gamma}$ while $\sigma_{x}^{2}$ continues to increase. Given this formulation, a positive strain $\frac{\partial u}{\partial x}$ would be an alternative to vertical shear in explaining the along-isobath elongation of the dye patch. However, as we have no way of estimating the magnitude of $\frac{\partial u}{\partial x}$, we are unable to conclusively identify this as an elongating mechanism for this study.

\subsection{Secondary Circulation}

Models discussed in the Introduction (Chapter 1) offered suggestions for the mean cross-isobath, or secondary, circulation on southern Georges Bank. Chen et. al. (1995) predicted a single cross-isobath circulation cell on the southern flank while Loder (1980) predicted double-cell circulation. Other models of the circulation of Georges Bank have even predicted multiple cross-isobath circulation cells on the southern flank (Chen and Beardsley, 1998; Chen et. al., 2001). If secondary circulation cells exist in the region where the dye was injected, vertical sections through the patch should demonstrate the circulation pattern.

Sections that were aligned across the isobaths (see Section 4.4.1 and Appendix C) showed little evidence of cell-like secondary circulation. Figure 4.8, a cross-isobath section, suggests deeper dye moving off-bank relative to shallower dye. Models predict the cross-isobath velocity associated with the cells is $0.5-3 \mathrm{~cm} \mathrm{~s}^{-1}$ (Chen and Beardsley, 1998), which could account for the dye displacement seen in Figure 4.8. However, as this section is unique in showing this feature and it comes from the survey where the dye patch is least certain, it 
is not considered to be strong supporting evidence of cross-isobath circulation cells. While they may exist, the data contained herein do not offer enough information to confirm it.

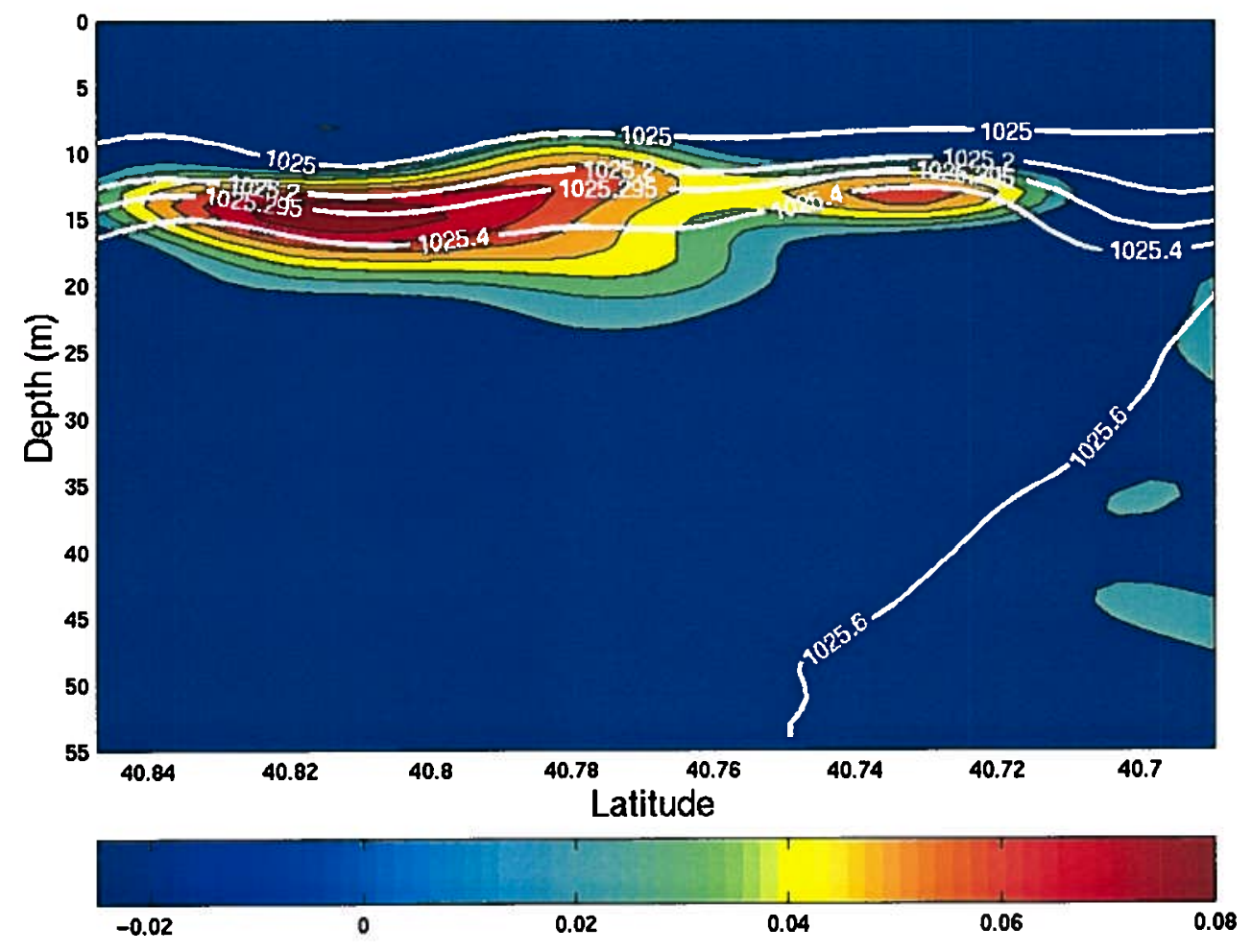

Figure 4.8. Survey 3 , Contour 3 vertical section dye contour. Rhodamine dye concentrations are given in units of $\mu \mathrm{g} \mathrm{L}^{-1}$. Density contours are plotted as white lines/labels in units of $\mathrm{kg}$ $\mathrm{m}^{-3}$. 


\section{Chapter 5}

\section{Summary and Discussion}

The overall goal of this research was to determine if advection and/or diffusion within the pycnocline is responsible for transport relative to the tidal mixing front on southern Georges Bank. The work was done as part of Phase III of the U.S. Global Ocean Ecosystem Dynamics (GLOBEC) Northwest Atlantic Georges Bank Program during May-June 1999. I used hydrographic data to first locate the tidal mixing front for the time of the cruise. Then drogued drifter trajectories were used to assess advective transport, and tracking of dye injected into the pycnocline was used to assess both advective and diffusive transport, advective dispersion, and secondary circulation.

There was no conclusive evidence to support a mean, advective flow relative to the front within the pycnocline. The motion of the drifters drogued in the pycnocline relative to the front was small, ranging from $0.5-2.0 \mathrm{~cm} \mathrm{~s}^{-1}$ (Table 3.4), and was both towards and away from the front (Figure 3.4). This velocity was on the order of the slip velocity that is imparted on the drogued drifters as a result of their design, and is therefore not a conclusive result. The center of mass of the dye that was injected into the pycnocline also did not move relative to the front. Throughout the study, the center of mass of the patch remained very near the $70 \mathrm{~m}$ isobath (see Figure 4.3). Having accepted that the tidal mixing front follows the local bathymetry (Loder, 1980; Loder and Wright, 1985; Chen and Beardsley, 1995; Chen et. al., 2001) and noting that the dye remained centered near the $70 \mathrm{~m}$ isobath, one can conclude that the dye may only move relative to the front as a result of the relative distance between isobaths 
changing. So if the topography steepens in the direction of flow along the bank, one would expect the dye center of mass to move closer to the tidal mixing front.

Diffusion relative to the front does occur. Figure 4.2(a)-(c) shows the dye spreading laterally both towards and away from the front. The diffusion of the dye is not purely Fickian, but rather spreads non-linearly with a time dependence close to $t^{2.34}$, the relationship found by Okubo (1971) for diffusion in the surface ocean (Figure 4.4). Given this relationship, it is possible to predict how far the dye will spread in a given period of time.

Elongation of the dye patch along the isobaths was also noted and can be seen in Figure 4.2(a)-(c). This can be attributed to vertical shear in the alongisobath current (see Figure 4.7), but may also be a result of positive strain in the along-isobath direction.

Vertical section dye contours (see Appendix C) did not show conclusive evidence of cross-isobath secondary circulation cells. While Figure 4.8 suggests that a cross-isobath current may be carrying deeper dye off-bank, there is simply not enough information from our data as a whole to really tell if the cell-like circulation exists in the area where the dye was. However, the dye patch was over $10 \mathrm{~km}$ away from the front. It is likely that if the circulation cells do exist, they may be closer to the front.

In summary, evidence now exists for an on-bank, diapycnal bottom flow through the tidal mixing front on the southern flank of $1.6 \mathrm{~cm} \mathrm{~s}^{-1}$ (Houghton, submitted) and for diffusion relative to the front within the pycnocline. While we can observe a rate of diffusion from the open ocean towards the front, these data still do not reveal what occurs at the front. Predicting diffusion rates from the relationship found by Okubo (1971) and knowing there is little advection toward the front in the pycnocline, one could better place a dye patch for study of processes at the front in future experiments. 


\section{References}

Butman, B. and R.C. Beardsley. 1987. Physical Oceanography, in Georges Bank, R.H. Backus, ed., MIT Press, Cambridge, MA, pp. 88-98.

Butman, B., J.W. Loder, and R.C. Beardsley. 1987. The Seasonal Mean Circulation: Observation and Theory, in Georges Bank, R.H. Backus, ed., MIT Press, Cambridge, MA, pp. 125-138.

Chen, C. and R.C. Beardsley. 1995. A numerical study of stratified tidal rectification over finite-amplitude banks. Part I: Symmetric Banks. J. Phys. Oceanogr., 25, 2090-2110.

----1998. Tidal mixing and cross-frontal particle exchange over a finite amplitude asymmetric bank: A model study with application to Georges Bank. J. Mar. Res., 56, 1163-1201.

Chen, C., R. Beardsley, and P.J.S. Franks. 2001. A 3-D prognostic numerical model study of the Georges Bank ecosystem. Part I: physical model. Deep-Sea Res. II, 48, 419-456.

Chen, C., R.C. Beardsley, and R. Limeburner. 1995. A numerical study of stratified tidal rectification over finite-amplitude banks. Part II: Georges Bank. J. Phys. Oceanogr., 25, 2111-2128.

Cohen, E.B., and M.D. Grosslein. 1987. Production on Georges Bank Compared with Other Shelf Ecosystems, in Georges Bank, R.H. Backus, ed., MIT Press, Cambridge, MA, pp. 383-391.

Csanady, G.T. and B.A. Magnell. 1987. Mixing Processes, in Georges Bank, R.H. Backus, ed., MIT Press, Cambridge, MA, pp. 163-169.

Flagg, C. 1987. Hydrographic Structure and Variability, in Georges Bank, R.H. Backus, ed., MIT Press, Cambridge, MA, pp. 108-124.

Fogarty, M.J., M.P. Sissenwine, and M.D. Grosslein. 1987. Fish Population Dynamics, in Georges Bank, R.H. Backus, ed., MIT Press, Cambridge, MA, pp. 494-507.

Geyer, W.R. 1989. Field calibration of mixed-layer drifters. J. Atmos. Oc. Tech., $6,333-342$. 
Houghton, R.W. Diapycnal flow through a tidal front: A dye tracer study on Georges Bank. J. Marine Science (submitted).

Ledwell, J.R., A.J. Watson, and C.S. Law. 1998. Mixing of a tracer in the pycnocline. J. Geophys. Res., 103, 21, 499-21,529.

Ledwell, J.R., T.G. Donoghue, C.J. Sellers, J.H. Churchill, D. Torres, D. McGillicuddy, V. Kosnyrev, C.S. Davis, S.M. Gallagher, C.J. Ashjian, A.P. Girard, P. Alatalo, Q. Hu. 2000. R/V Endeavor cruises 323 and 324. Lagranian studies of the tidal mixing front on Georges Bank, GLOBEC Phaselll, 5 May-7 June 1999. Cruise report, Woods Hole Oceanographic Institute.

Lewis, C.V.W., C. Chen, and C.S. Davis. 2001. Effect of winter wind variability on plankton transport over Georges Bank. Deep-Sea Res. II, 48, 137158.

Loder, J.W. 1980. Topographic rectification of tidal currents on the sides of Georges Bank. J. Phys. Oceanogr., 10, 1399-1416.

Loder, J.W. and D.G. Wright. 1985. Tidal rectification and frontal circulation on the sides of Georges Bank. J. Mar. Res., 43, 581-604.

Moody, J.A., B. Butman, R.C. Beardsley, W.S. Brown, P. Daifuku, J.D. Irish, D.A. Mayer, H.O. Mofjeld, B. Petrie, S. Ramp, P. Smith, and W.R. Wright. 1984. Atlas of tidal elevation and current observations on the northeast American Continental Shelf and Slope. U.S. Geol. Surv. Bull. 1611, 122pp.

Noble, M. and B. Butman. 1985. Wind-Current Coupling on the Southern Flank of Georges Bank: Variation with Season and Frequency. J. Phys. Oc., $15,606-620$.

Open University. 1989. Ocean Circulation. G. Bearman, ed., Pergamon Press, New York.

Okubo, A. 1971. Oceanic diffusion diagrams. Deep Sea Res., 18, 789-802.

Peeters, F., A. Wüest, and D.M. Imboden. 1993. Comparison of the results of tracer experiments in lakes with predictions based on horizontal mixing models. Verh. Internat. Verein. Limnol., 25, 69-74. 
Ryan, J.P., J.A. Yoder, and D.W. Townsend. 2001. Influence of a Gulf Stream warm-core ring on water mass and chlorophyll distributions along the southern flank of Georges Bank. Deep-Sea Res. II, 48, 159-178.

Schlitz, R. 2001May28. Moored Current Meter Array: Physical and Biological Processes at the Tidally Mixed Front on Southern Georges Bank (See http://globec.whoi.edu/globec-dir/reports/data_workshops/crossfrontal_exchange/cfe-ssc_report_2000/schlitz_1ms.html).

Schlitz, R. and K. Smith. 2001Jul07. Southern flank velocity and temperature movies (Use links "SF_vel_temp" and "velocity and temperature data movies" on http://globec.whoi.edu/jg/dir/globec/gb/mooring/1999/).

Smith, R. 1982. Dispersion of tracers in the deep ocean. J. Fluid Mech, 123, 131-142.

Sundermeyer, M. A. 1998. Studies of Lateral Dispersion in the Ocean. Doctoral Dissertation, Massachusetts Institute of Technology/Woods Hole Oceanographic Institution, 215pp.

Townsend, A.A. 1951. The diffusion of heat spots in isotropic turbulence. Proc. R. Soc. London, Ser. A, 209, 418-430.

Walsh, J.J., T.E. Whitledge, J.E. O'Reilly, W.C. Phoel, and A.F. Draxler. 1987. Nitrogen Cycling on Georges Bank and the New York Shelf: A Comparison between Well-Mixed and Seasonally Stratified Waters, in Georges Bank, R.H. Backus, ed., MIT Press, Cambridge, MA, pp. 234255.

Weibe, P.H., R.C. Beardsley, A. Bucklin, and D.G. Mountain. 2001. Coupled biological and physical studies of plankton populations in the Georges Bank region and related North Atlantic GLOBED study sites. Deep-Sea Res. II, 48, 1-2. 


\section{Appendix A}

\section{Front-Finding Program}

As stated in Section 2.2, the first step in finding the front location from the in situ hydrographic data was interpolating the density values on uniform grids of latitude and longitude versus depth. The interpolation was accomplished using a combination of readily available Matlab functions. First, uniform grids of time, latitude, and longitude, each versus pressure, were created using the meshgrid function. The uniform grids of longitude and latitude were then separately used as input to the griddata function. Griddata fits a uniform surface of the form $Z=F(X, Y)$ to data in non-uniformly spaced vectors. Here, $X$ represents either the latitude or longitude, and $Y$ represents the pressure (depth). Griddata interpolates the surface at the points specified by the uniform grid that was created in meshgrid using triangle-based linear interpolation. The surface and deep potential density values are then compared and if they meet the front definition, the location is plotted.

The following program accomplishes all of these tasks, and its output is seen in Figure 2.2.

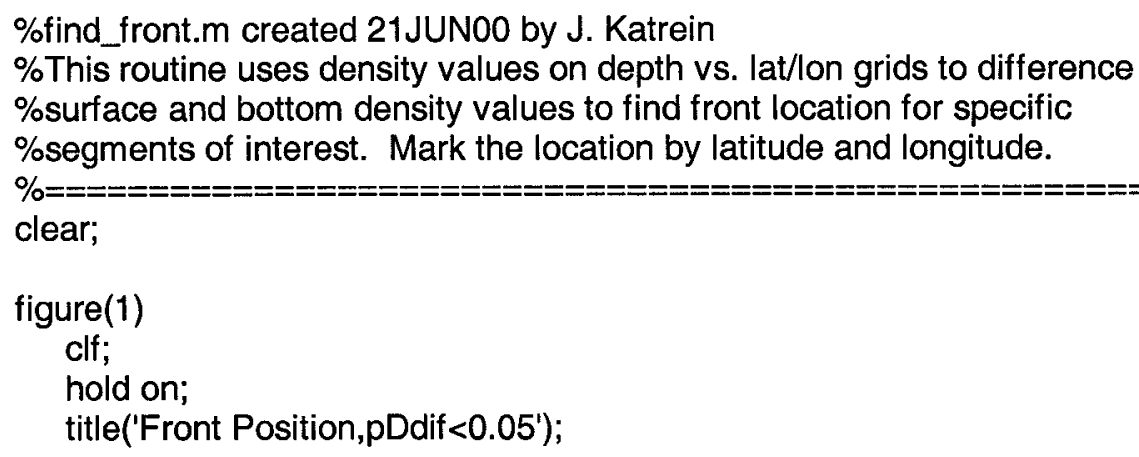




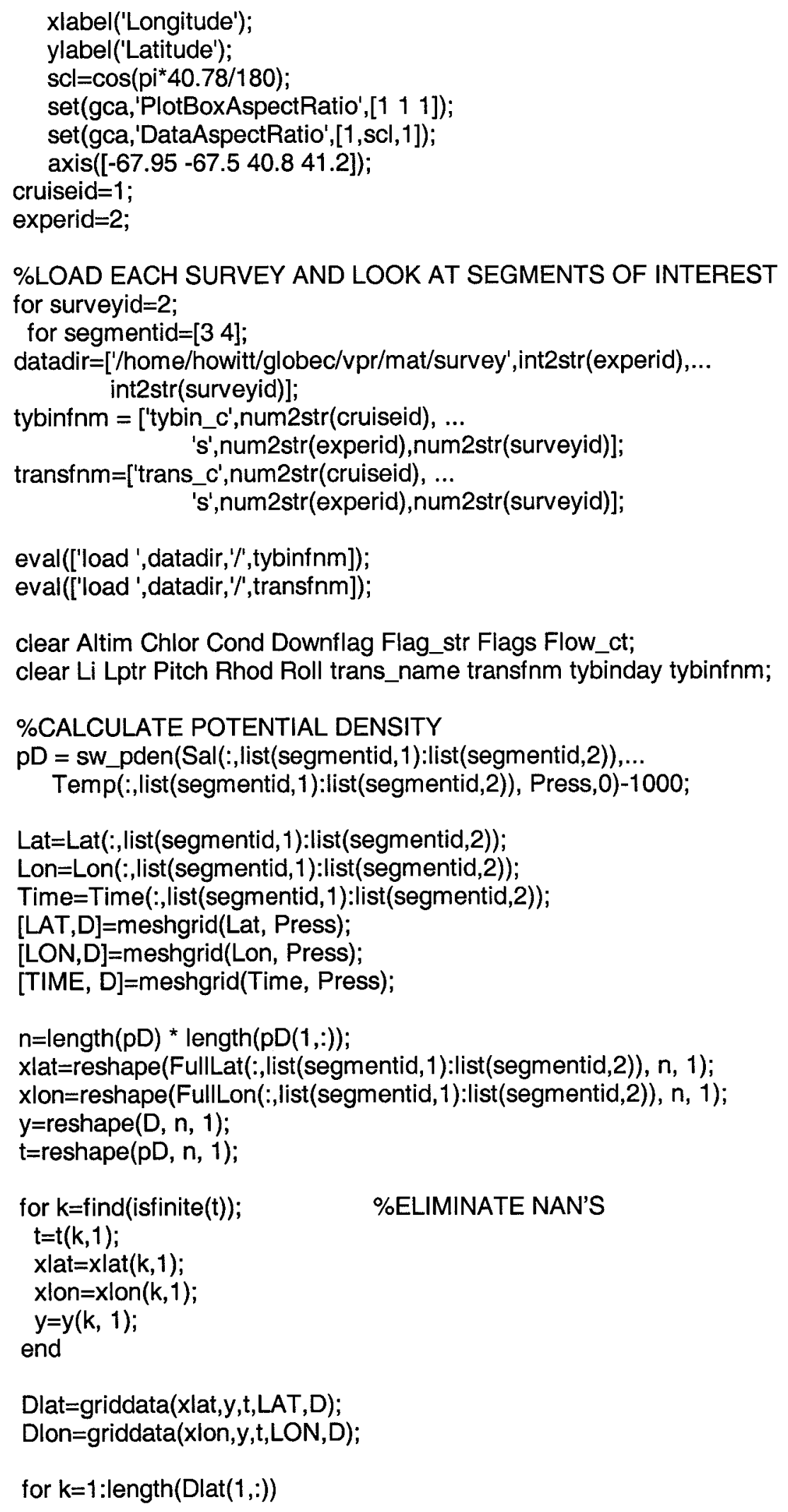




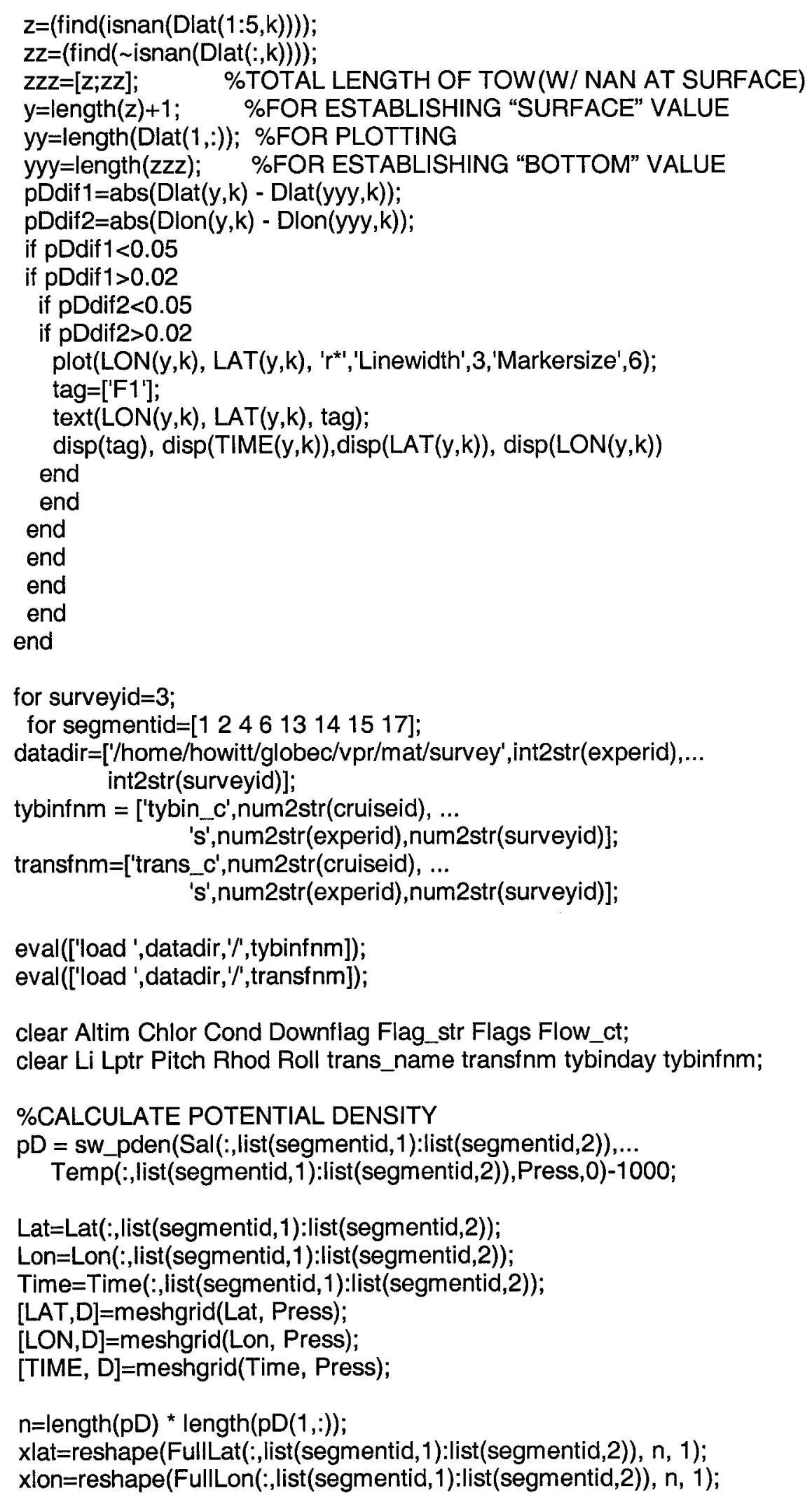




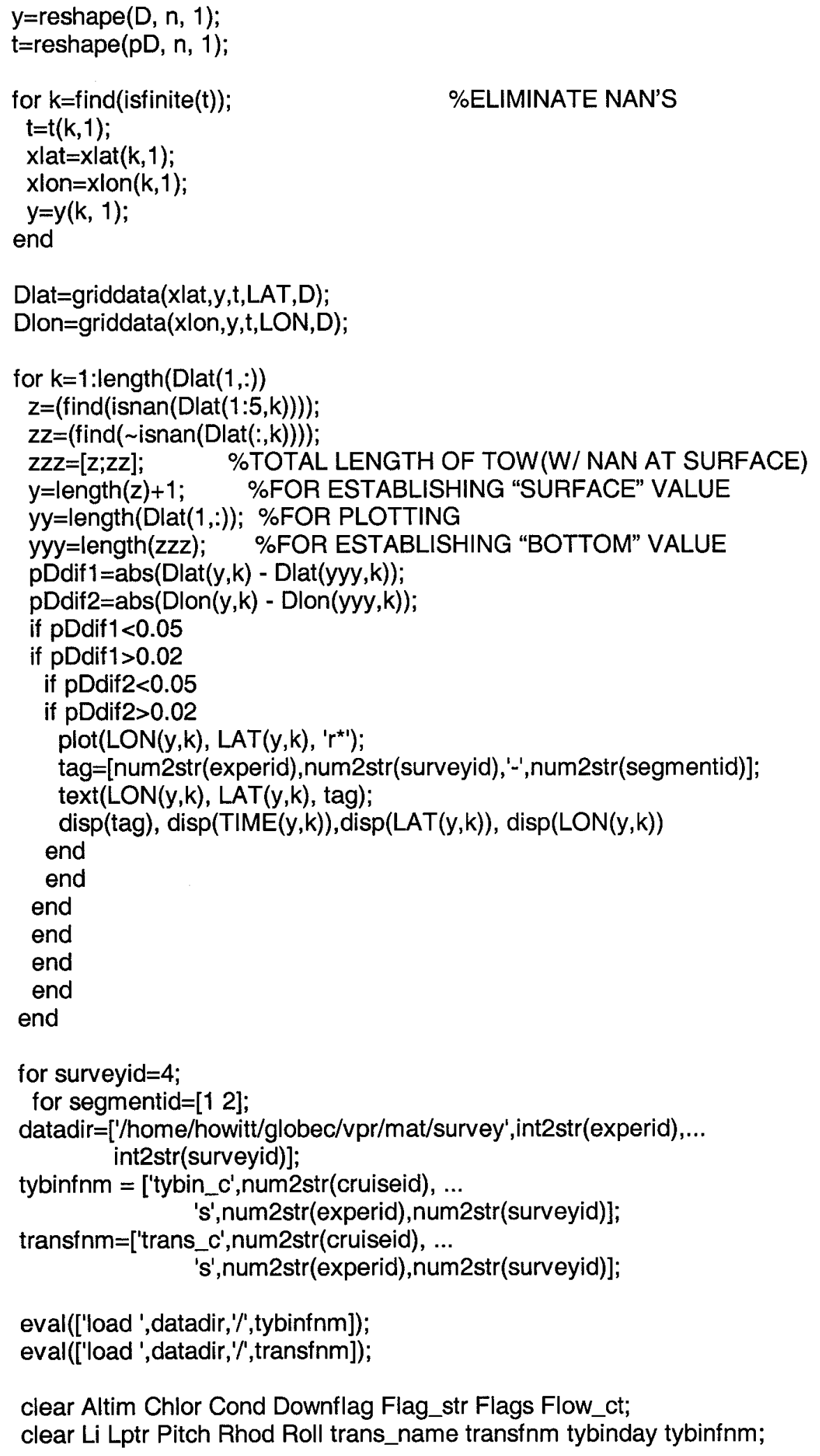




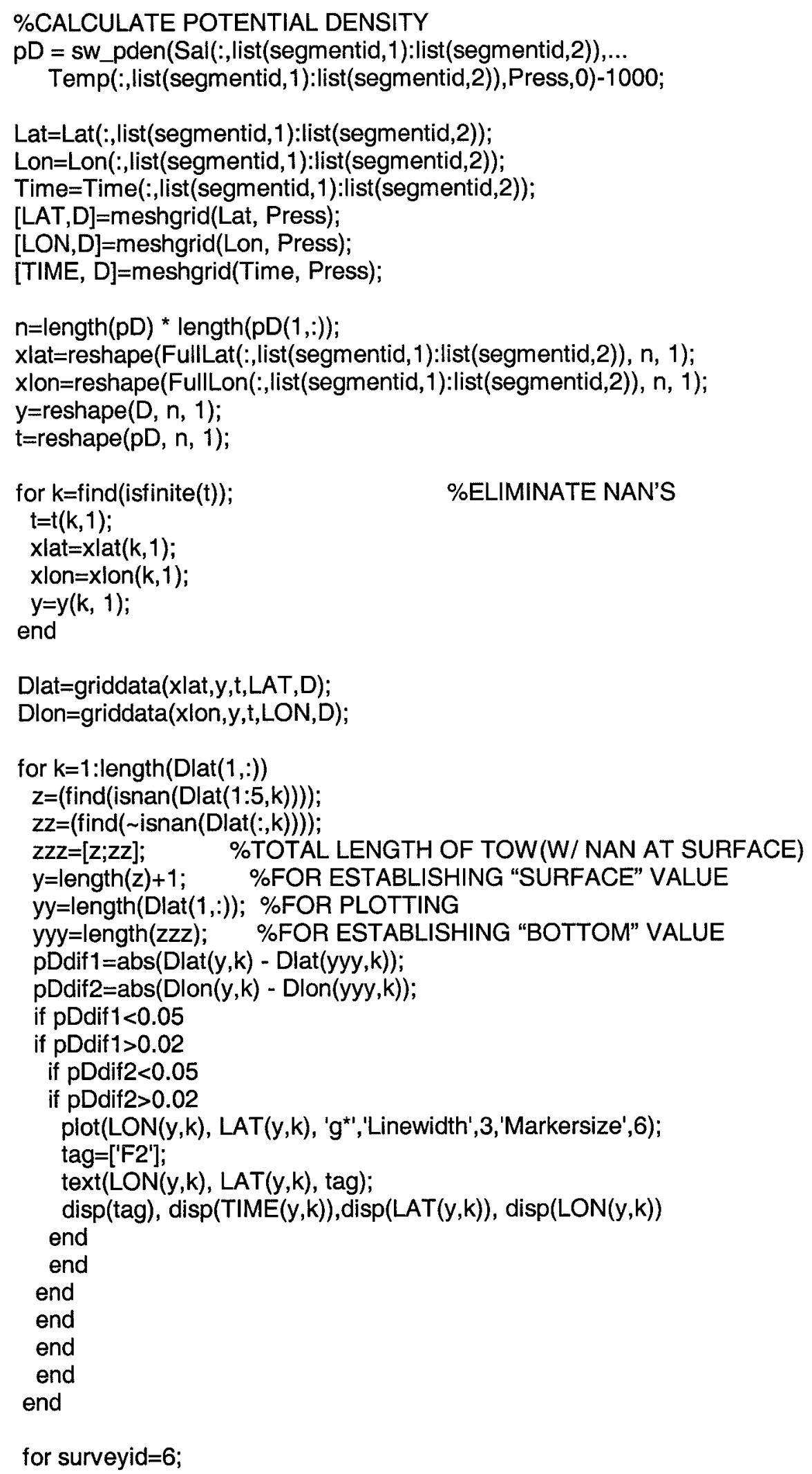




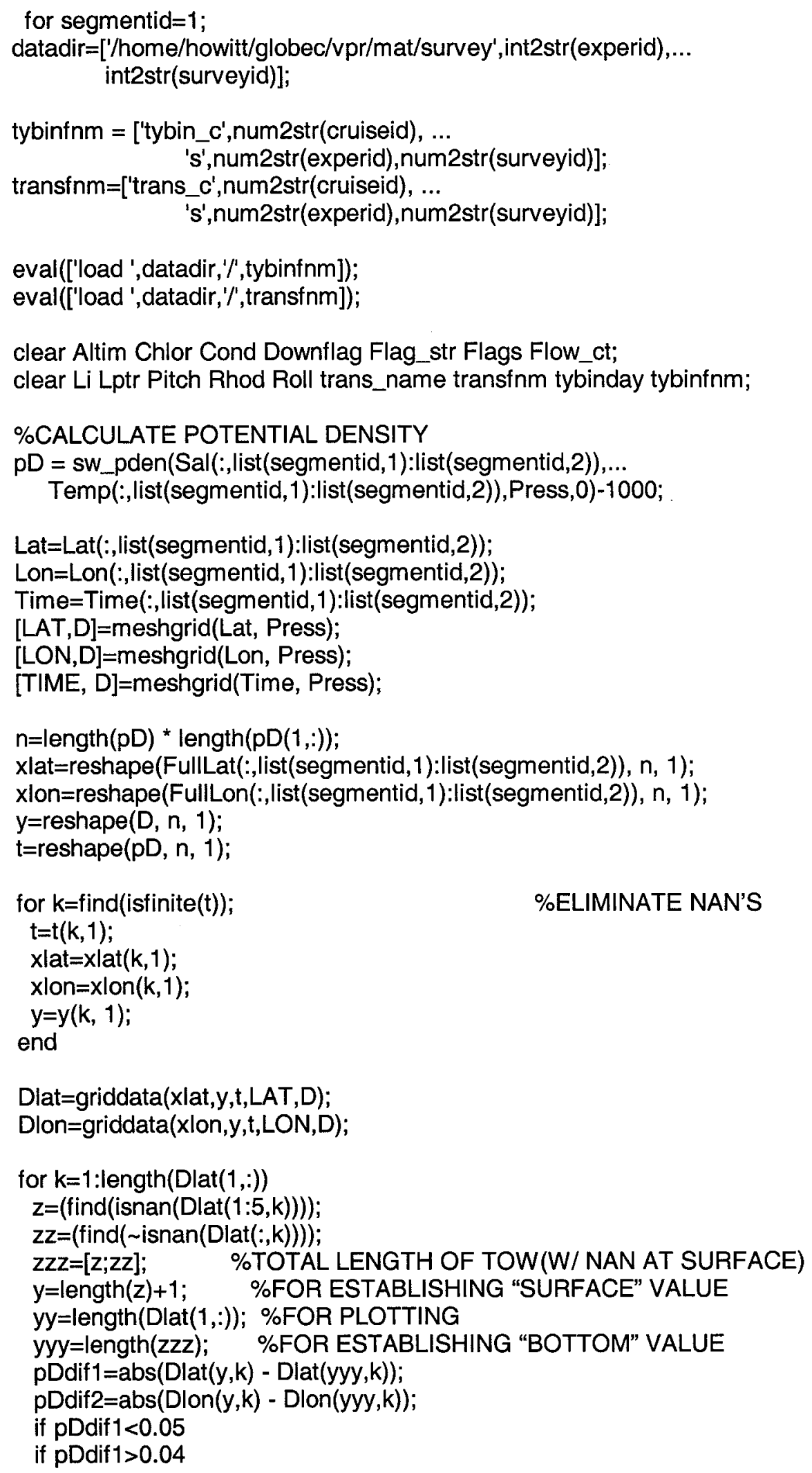




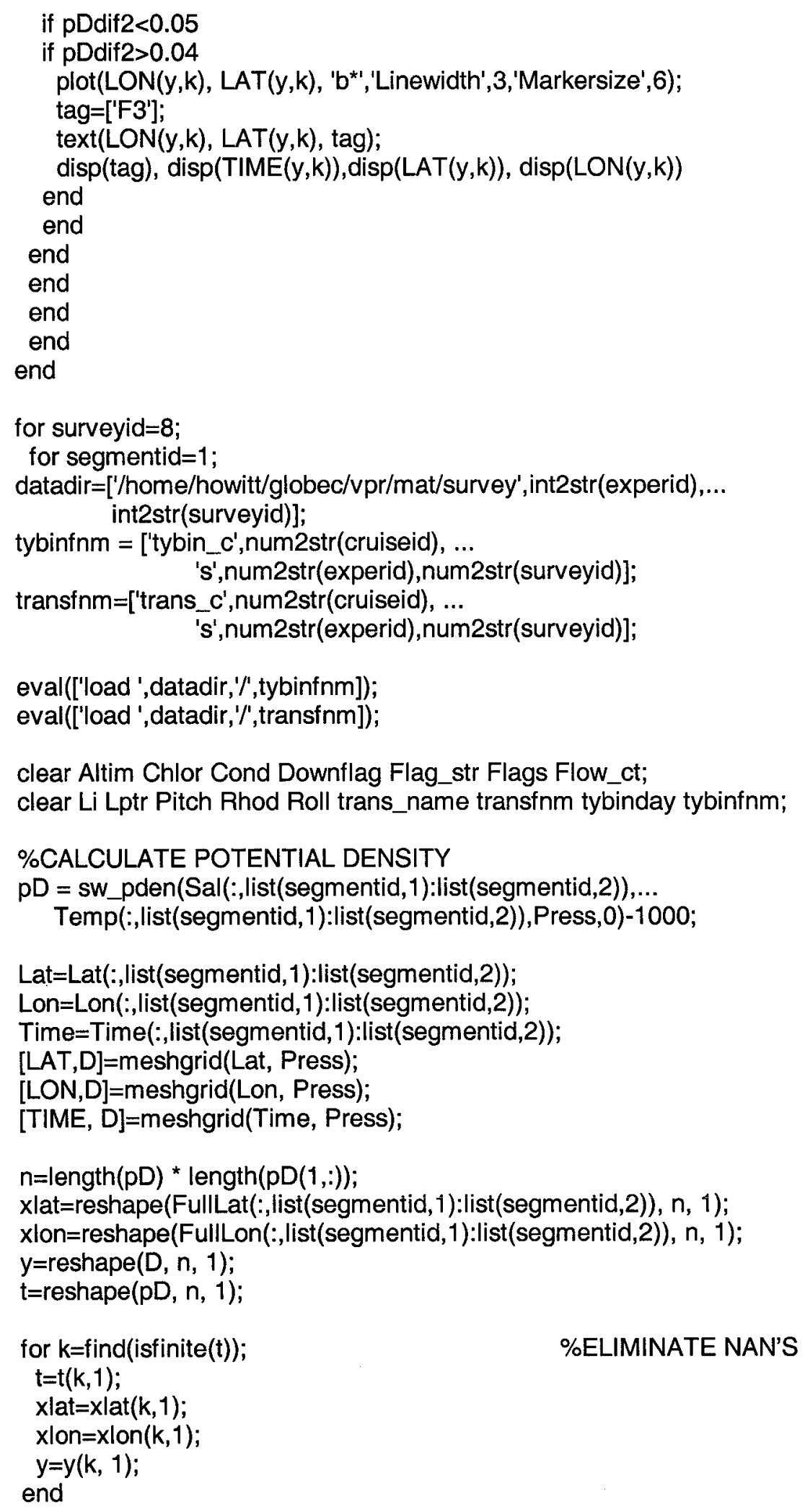




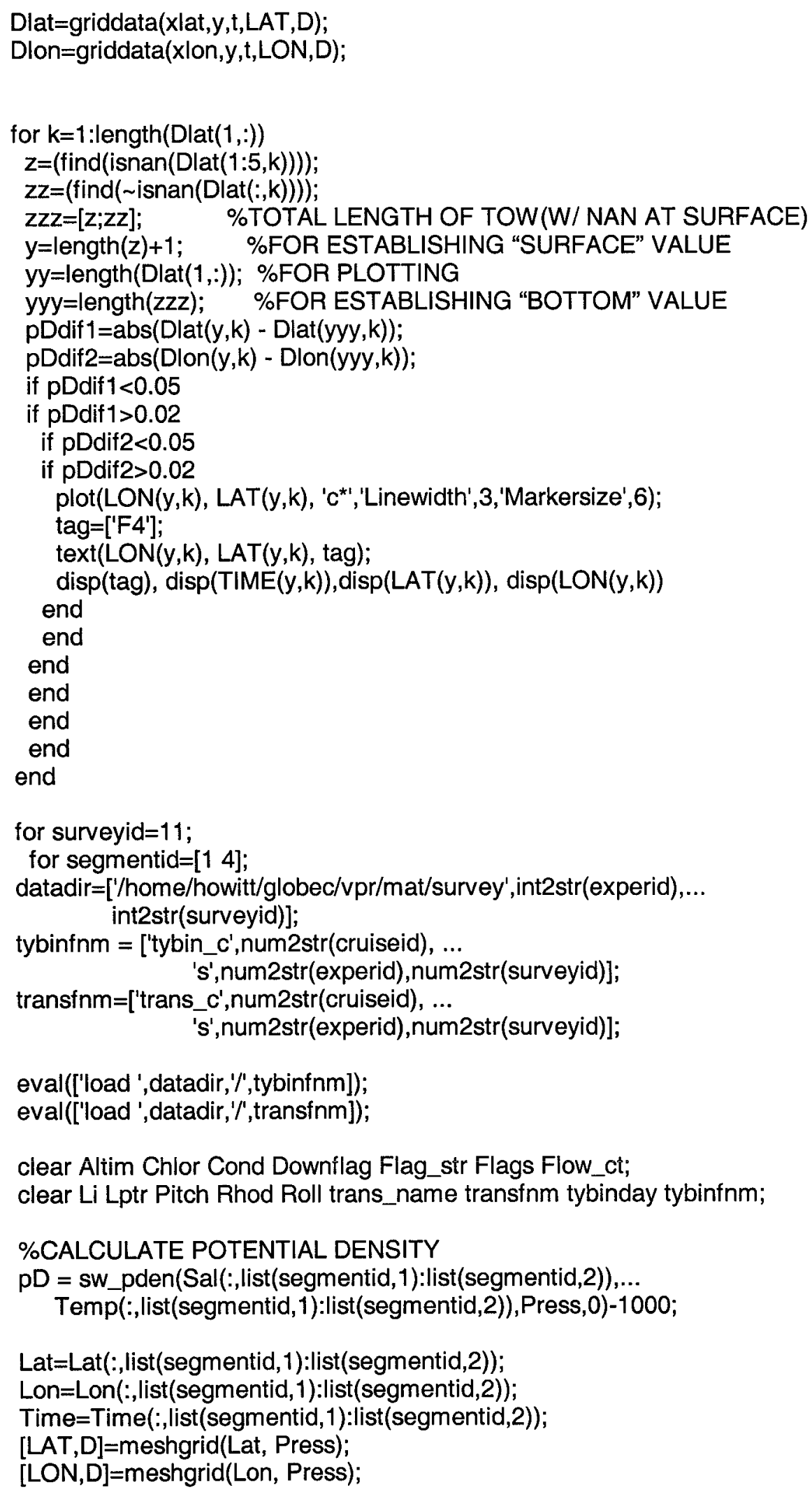


$[T I M E, D]=$ meshgrid(Time, Press);

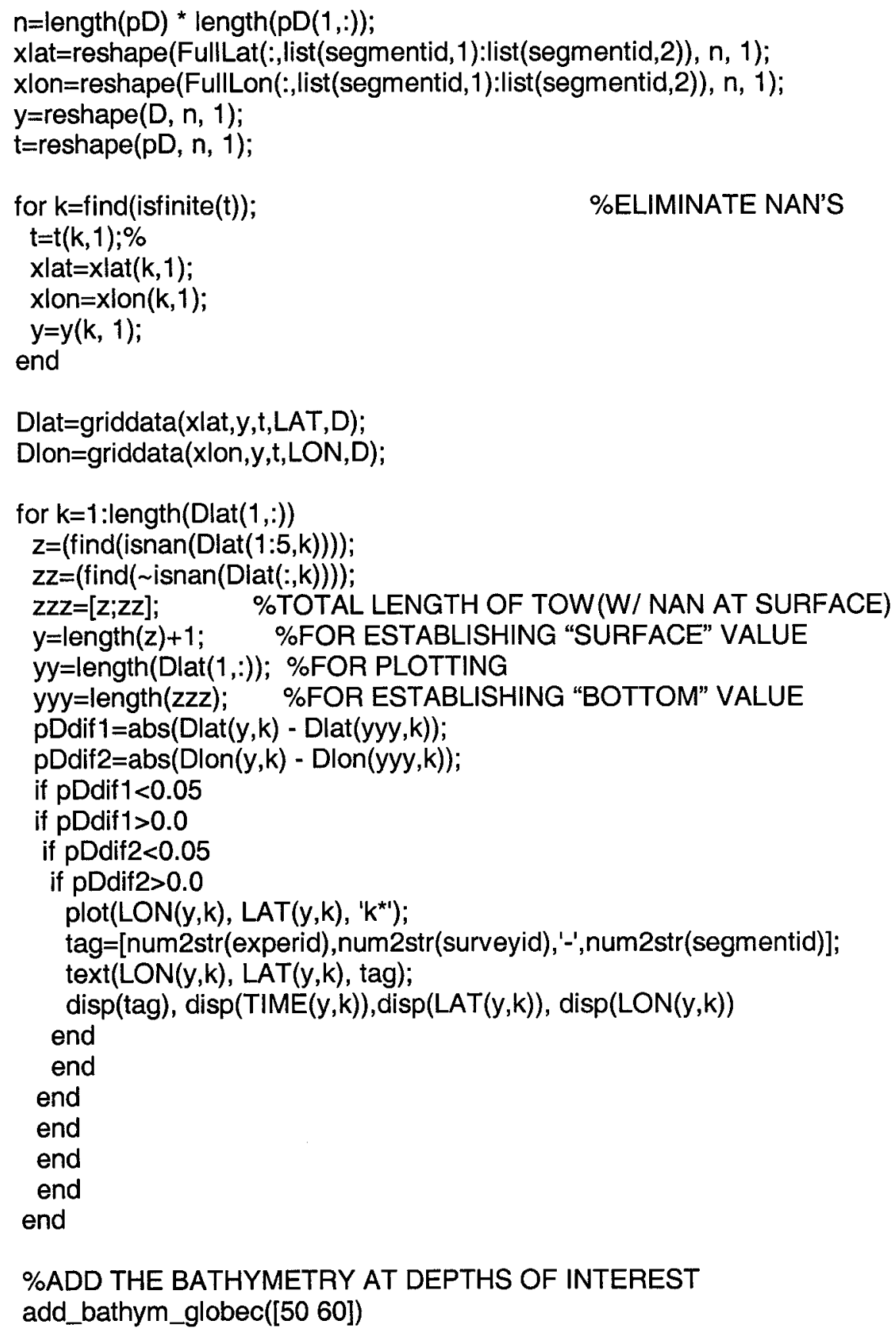




\section{Appendix B}

\section{More on Drifters}

\section{B.1 Drifter Data Files}

The drifter data from the southern flank pycnocline release were acquired from Jim Churchill of the Woods Hole Oceanographic Institute. Table B.1 gives the drifter numbers that were used throughout the proceeding text and their corresponding data files. The file names are given for reference as they are used in the programs given below. Each drifter's file contained one variable matrix of six columns and several rows corresponding to its length of deployment. The data contained in the six columns, in order, are as follows: time (year-day), longitude (degrees), latitude (degrees), blank column, blank column, and temperature at instrument package.

\begin{tabular}{|c|c|}
\hline $\begin{array}{l}\text { Drifter Number } \\
\text { Used in Thesis }\end{array}$ & Original File Name \\
\hline 6 & dr006b.dft \\
\hline 9 & dr009b.dft \\
\hline 10 & dr010b.dft \\
\hline 11 & dr011b.dft \\
\hline 22 & dr022c.dft \\
\hline 37 & dr037c.dft \\
\hline 65 & dr065m.dft \\
\hline
\end{tabular}

Table B.1. Data files for drifters used in this study. 


\section{B.2 Fitting the Drifter Record}

\section{B.2.1 The Fit Program}

The following is an example of the Matlab program for fitting the drifter record (see Chapter 3.2), named fit_dro06b.m. While this program is for Drifter \#6, is works for all drifters by just changing the input file.

\%fit_dr006b.m created 28JUN00 by J. Katrein

\%Routine to fit a curve to the drifter position data to fill in gaps in the drifter data $\%$ records. There will be a fit for the latitude and the longitude for each drifter.

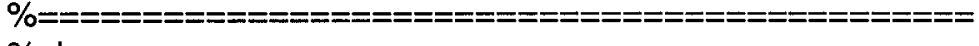

$\%$ clear;

\%LOAD THE DRIFTER DATA

eval(['load /home/jody/drifter/depl3/dfts/dr006b.dft']);

\%LOOK AT PLOT OF ORIGINAL DATA SET

figure(1);

clf;

time $=\operatorname{dr006b}(:, 1)$;

lon=dr006b(:, 2);

lat=dr006b(:, 3);

subplot(2,1,1);

plot(time, lat, '.');

ylabel('Latitude');

title('Drifter: dr006b');

hold on;

subplot $(2,1,2)$;

plot(time, lon, '.');

ylabel('Longitude');

xlabel('Time $\left.(y-d)^{\prime}\right)$;

hold on;

\%TRY TO COMPLETE THE DRIFTER RECORD USING MATLAB'S REGRESS $\%$ MODEL $(y=X b)$ AS FOLLOWS:

$\%$

$\%\left|L_{-} 1\right|\left|\sin \left(\left(s \_d i\right) t \_1\right) \cos \left(\left(s_{\_} d i\right) t \_1\right) \sin \left((d i) t \_1\right) \ldots 1 t \_1\left(t \_1\right)^{\wedge} 2\right||a|$

$\%\left|L \_2\right|\left|\sin \left(\left(s \_d i\right) t \_2\right) \cos \left(\left(s \_d i\right) t \_2\right) \sin \left((d i) t \_2\right) \ldots 1 t \_2\left(t \_2\right)^{\wedge} 2\right||b|$

$\%\left|L \_3\right| \mid \sin \left(\left(s \_d i\right) t \_3\right) \cos \left(\left(s \_d i\right) t \_3\right) \sin \left((d i) t \_3\right) \ldots 1 t$.. 1 (t_3 $)^{\wedge} 2|| c \mid$

$\% \mid . \quad I=1 . \quad$. . . .

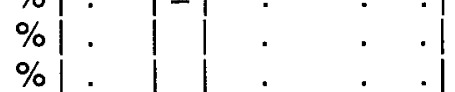

$\%$ : 


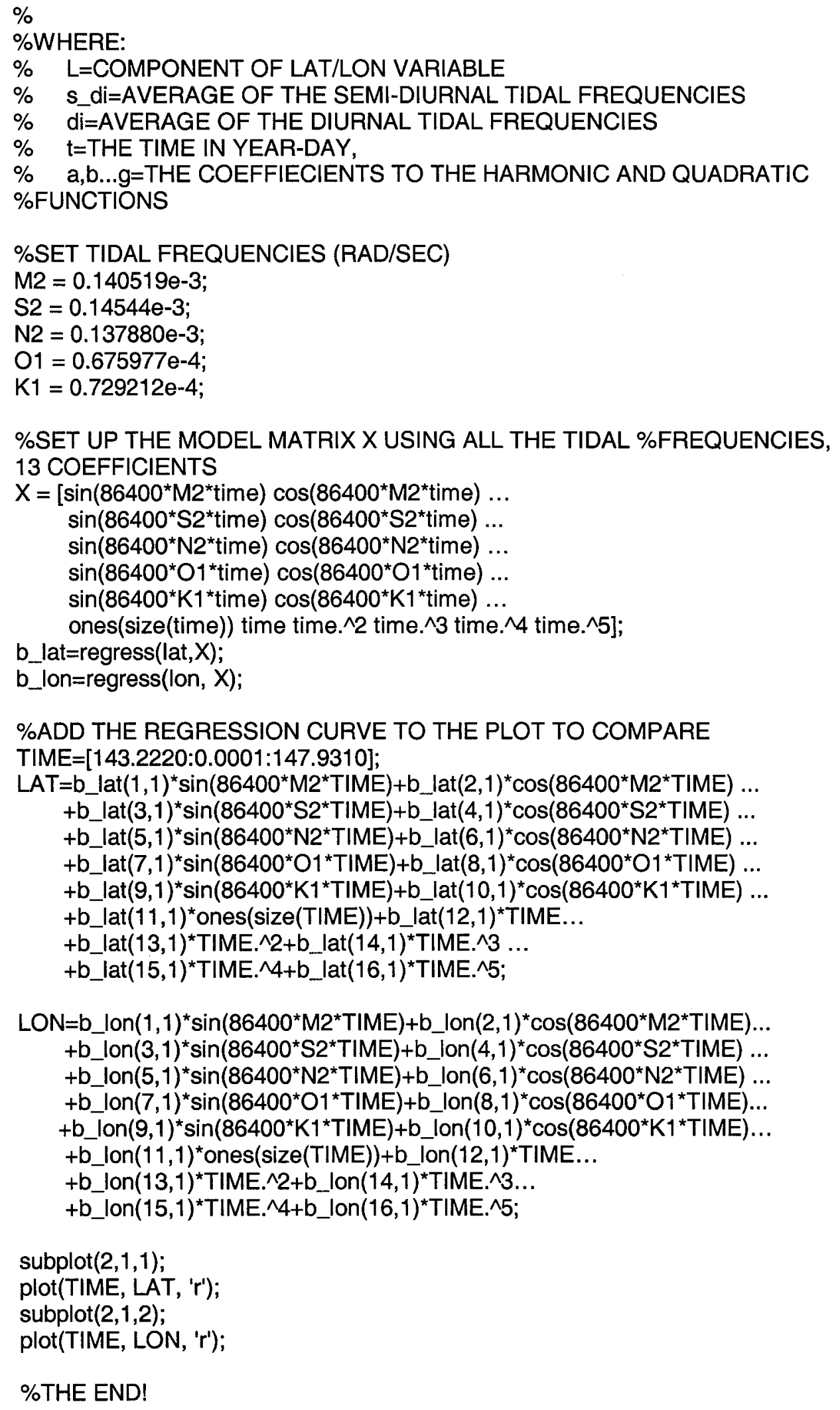

LON=b_Ion $(1,1)^{\star} \sin \left(86400^{*} \mathrm{M} 2^{\star} \mathrm{TIME}\right)+\mathrm{b} \_\operatorname{lon}(2,1)^{*} \cos \left(86400^{*} \mathrm{M} 2^{*} \mathrm{TIME}\right) .$. $+b$ _lon $(3,1)^{\star} \sin \left(86400^{\star} S 2^{*} \mathrm{TIME}\right)+b$ _lon $(4,1)^{\star} \cos \left(86400^{*} \mathrm{~S} 2^{\star} \mathrm{TIME}\right) . .$. $+b \_\operatorname{lon}(5,1)^{\star} \sin \left(86400^{\star} \mathrm{N} 2^{\star} \mathrm{TIME}\right)+\mathrm{b} \_\operatorname{lon}(6,1)^{\star} \cos \left(86400^{\star} \mathrm{N} 2^{\star} \mathrm{TIME}\right) .$. + b_lon $(7,1)^{*} \sin \left(86400^{*} \mathrm{O} 1^{*} \mathrm{TIME}\right)+\mathrm{b} \_\operatorname{lon}(8,1)^{*} \cos \left(86400^{*} \mathrm{O} 1^{*} \mathrm{TIME}\right) \ldots$ +b_lon $(9,1)^{\star} \sin \left(86400^{*} \mathrm{~K} 1^{*} \mathrm{TIME}\right)+\mathrm{b} \_\operatorname{lon}(10,1)^{*} \cos \left(86400^{*} \mathrm{~K} 1^{*} \mathrm{TIME}\right) .$. +b_Ion $(11,1)^{\star}$ ones(size (TIME))+b_Ion $(12,1)^{*}$ TIME... +b_lon $(13,1)^{\star}$ TIME.^2+b_Ion $(14,1)^{\star}$ TIME.^3...

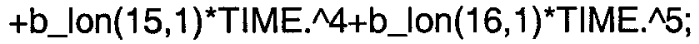

subplot $(2,1,1)$;

plot(TIME, LAT, 'r');

subplot $(2,1,2)$;

plot(TIME, LON, 'r');

\%THE END! 
Once the drifter records were fitted, the RMS (root-mean-square) error for each drifter's latitude and longitude fit was calculated using the following Matlab program. While this program is for Drifter \#6, it can be applied to any of the fitted drifter records by just changing the name of the input file. The resulting values for all drifters are displayed in Table 3.3.

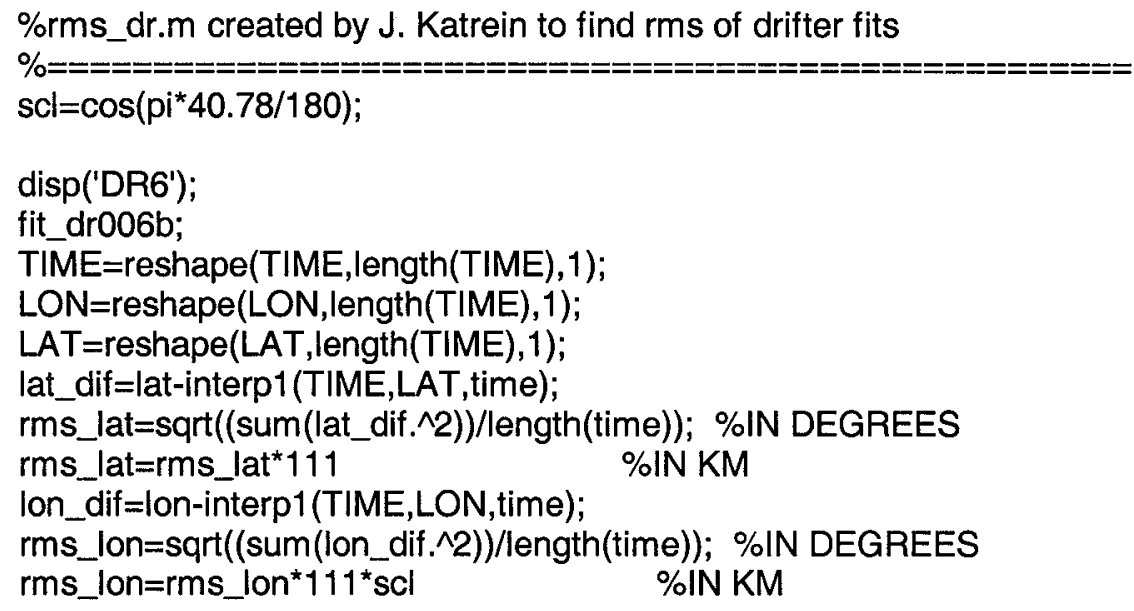

\section{B.2.2 Fit Results}

The following pages contain figures for all drifters showing their original data and their fitted data, as well as the resulting fitted drifter track that was used in the analysis of the drifter motions. 

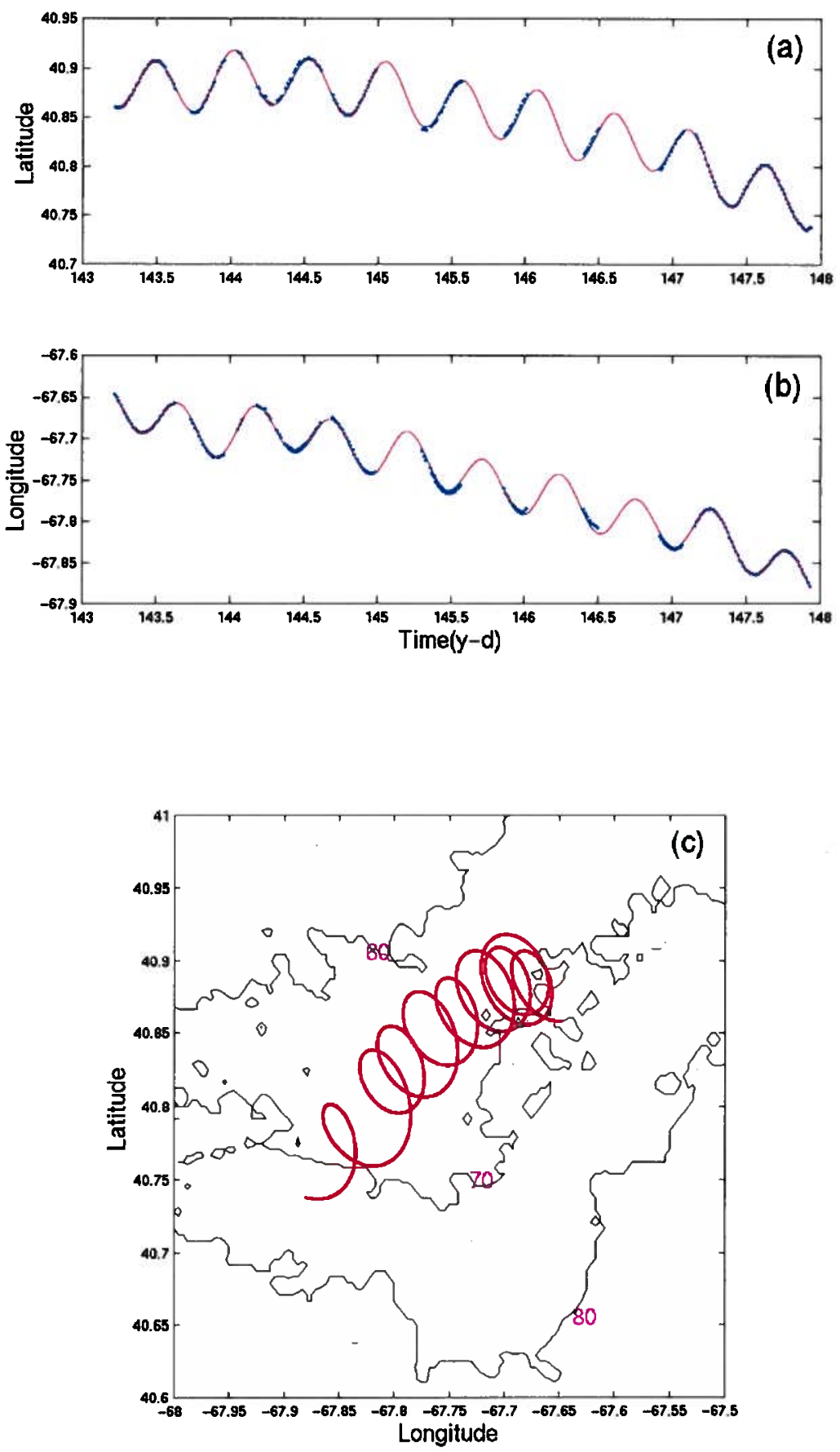

Figure B.1. a) Latitude and b) longitude data from Drifter \#6, with the original data plotted as blue dots and the fitted data shown as a red line. c) Resulting complete drifter trajectory. 

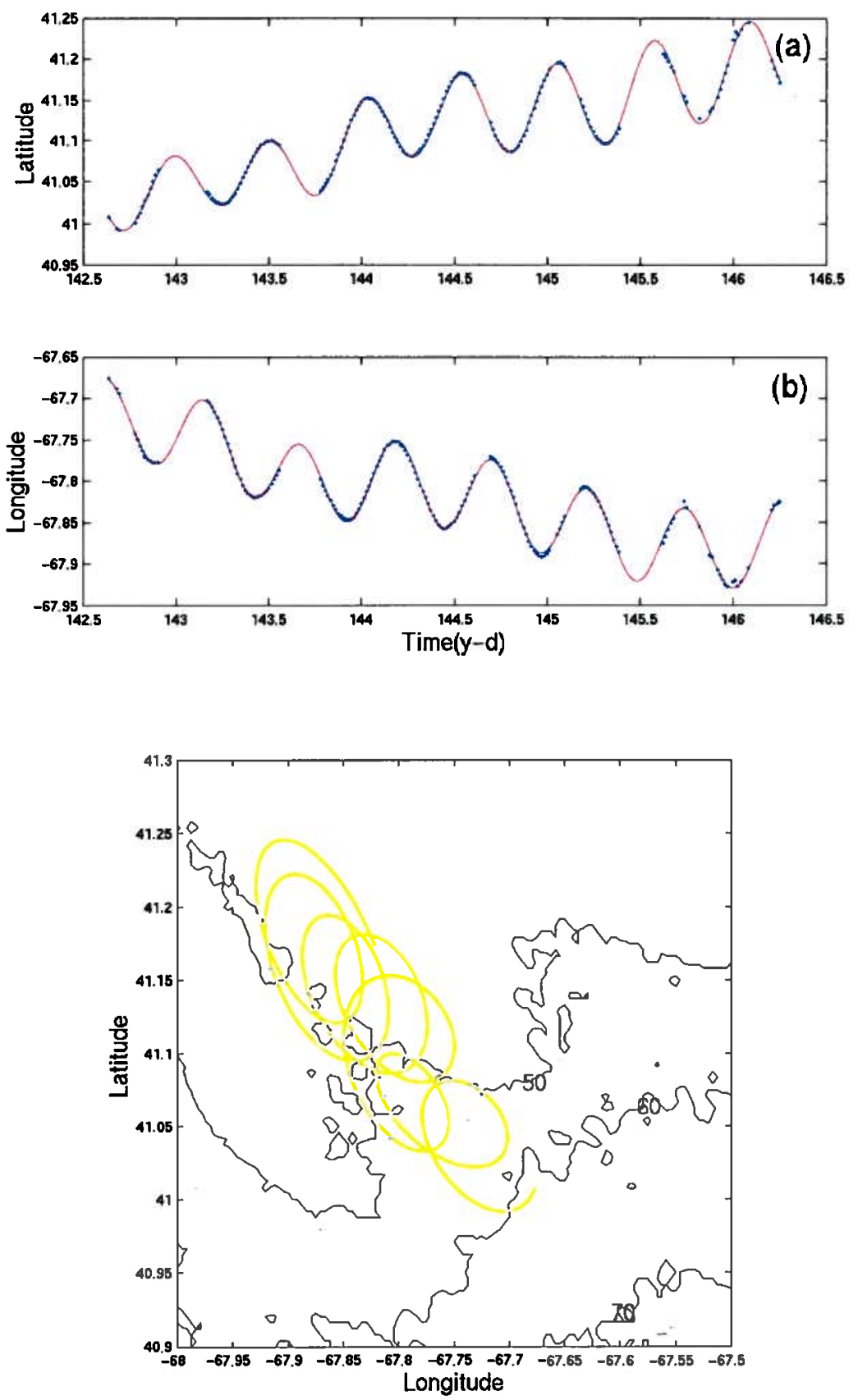

Figure B.2. a) Latitude and b) longitude data from Drifter \#9, with the original data plotted as blue dots and the fitted data shown as a red line. c) Resulting complete drifter trajectory. 

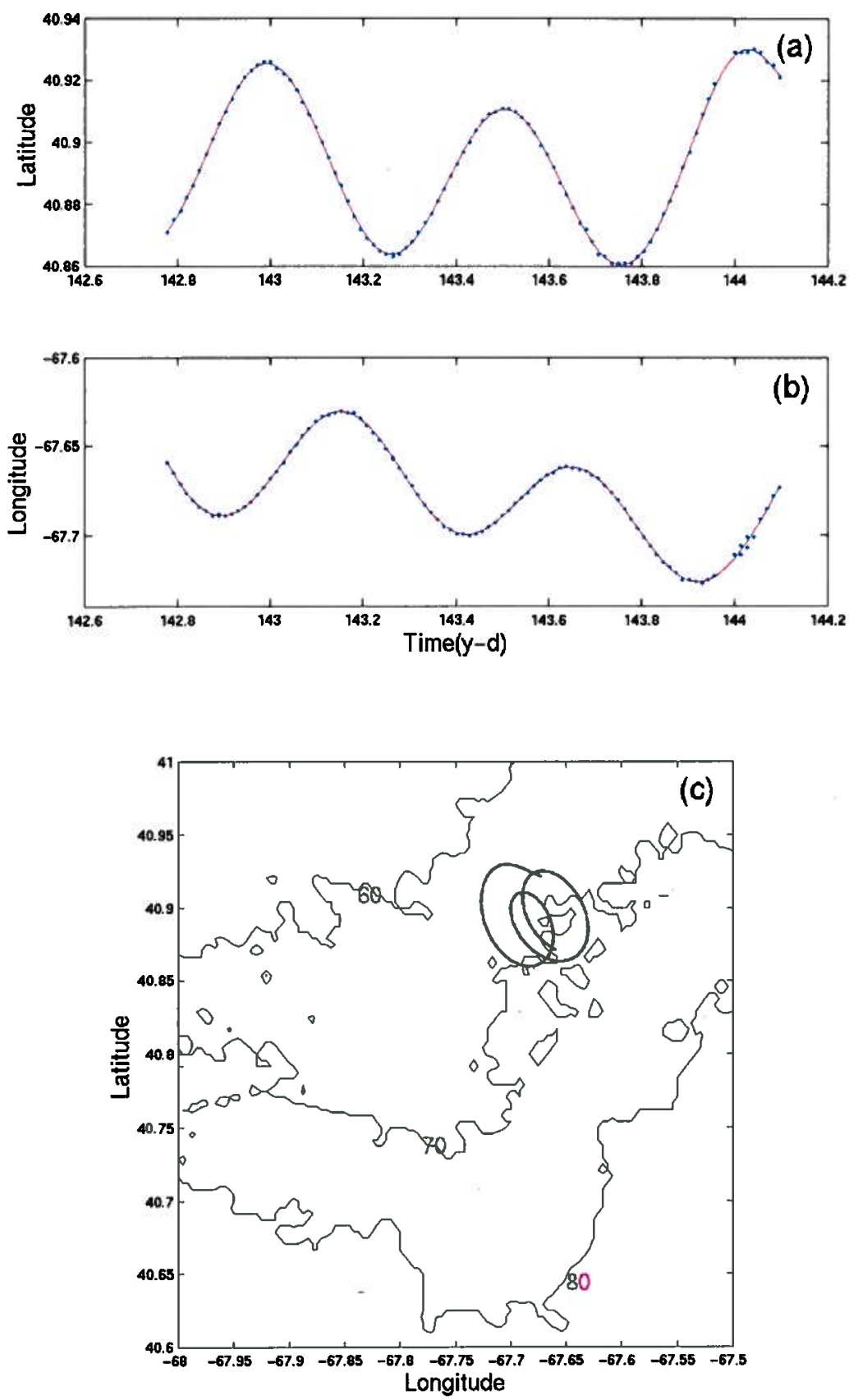

Figure B.3. a) Latitude and b) longitude data from Drifter \#10, with the original data plotted as blue dots and the fitted data shown as a red line. c) Resulting complete drifter trajectory. 

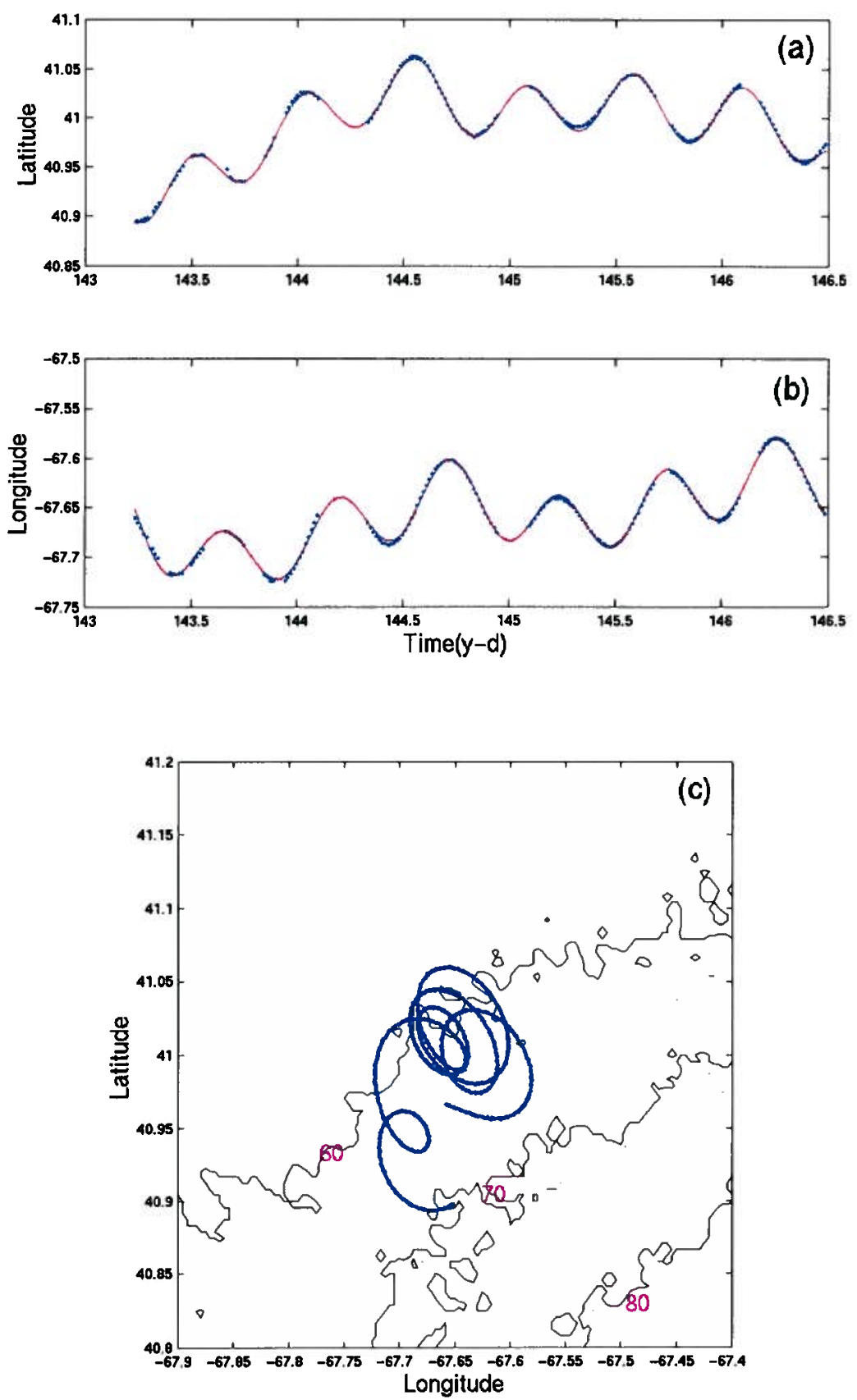

Figure B.4. a) Latitude and b) longitude data from Drifter \#11, with the original data plotted as blue dots and the fitted data shown as a red line. c) Resulting complete drifter trajectory. 

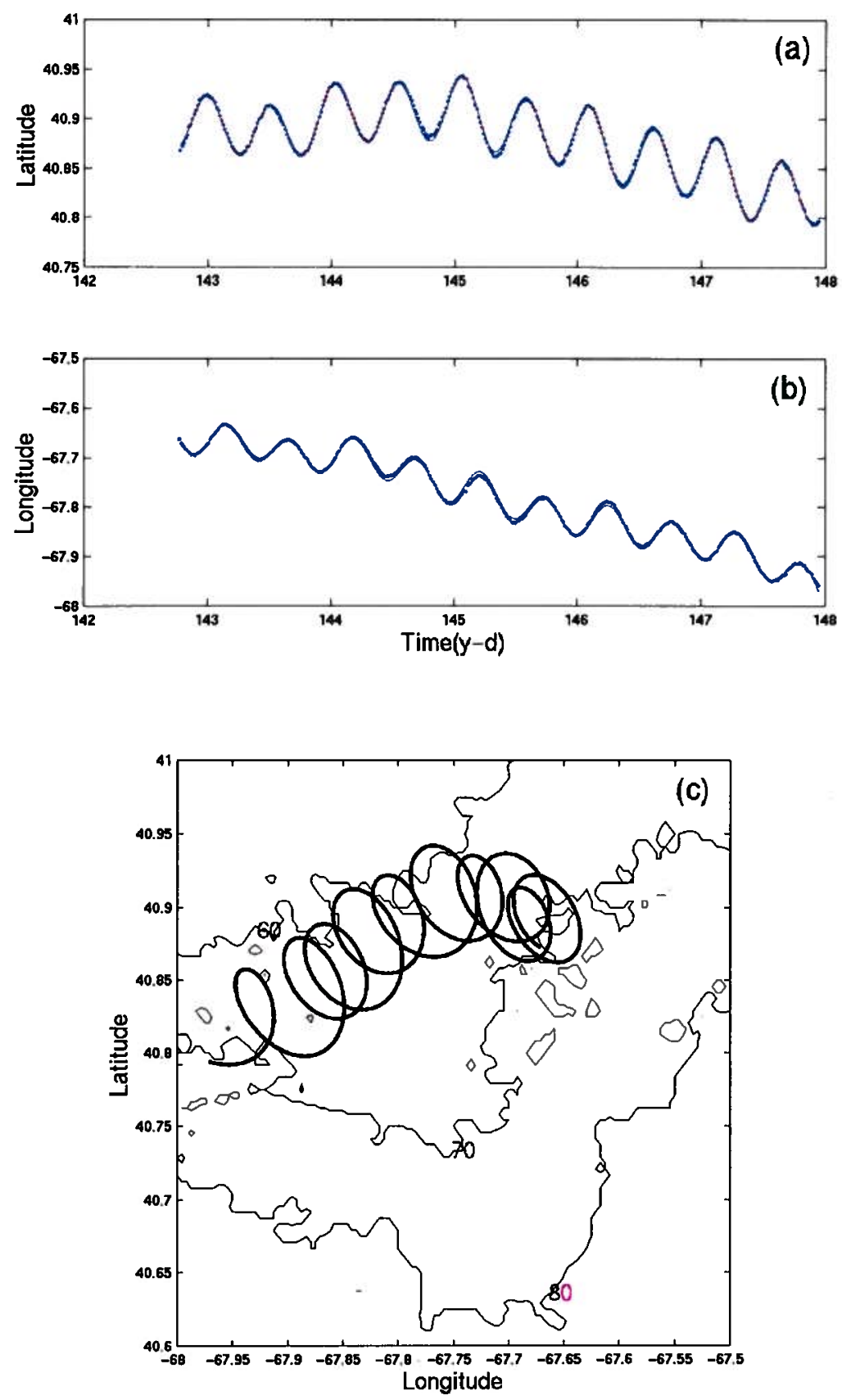

Figure B.5. a) Latitude and b) longitude data from Drifter \#22, with the original data plotted as blue dots and the fitted data shown as a red line. c) Resulting complete drifter trajectory. 

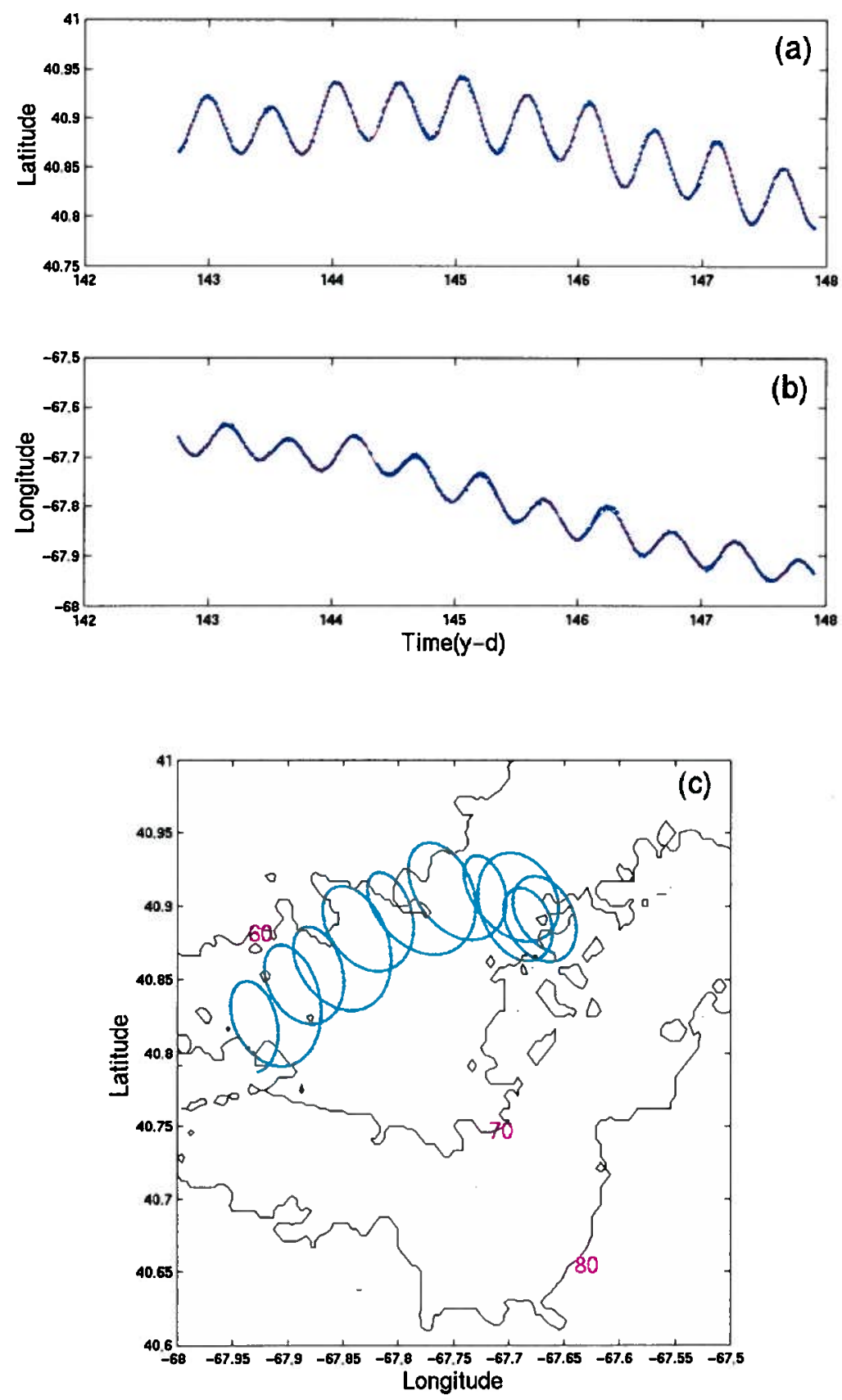

Figure B.6. a) Latitude and b) longitude data from Drifter \#37, with the original data plotted as blue dots and the fitted data shown as a red line. c) Resulting complete drifter trajectory. 

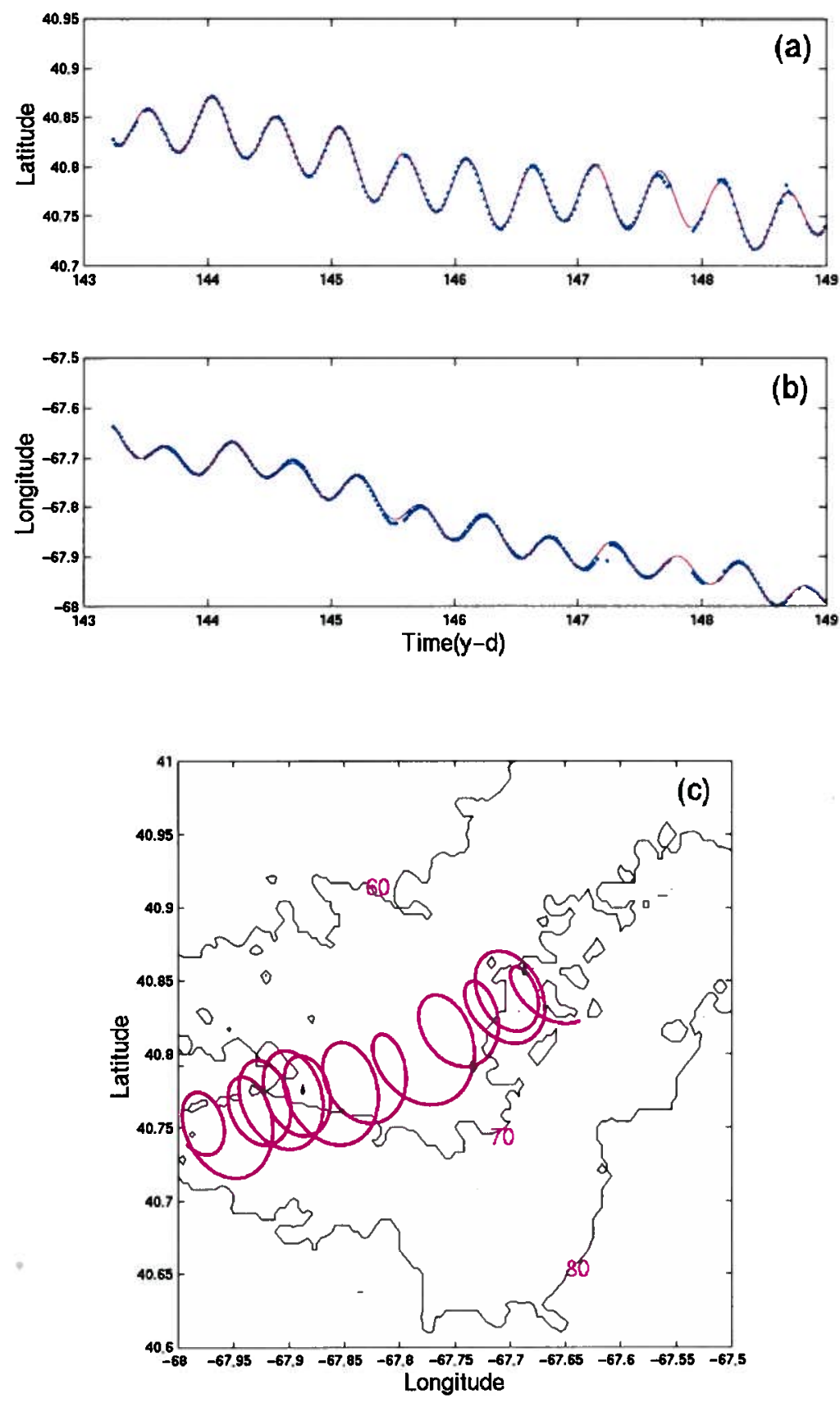

Figure B.7. a) Latitude and b) longitude data from Drifter \#65, with the original data plotted as blue dots and the fitted data shown as a red line. c) Resulting complete drifter trajectory. 


\section{Appendix C}

\section{More on Dye}

\section{C.1 Dye Programs}

The following is a sampling of the programs that were used in the dye studies presented in Chapter 4. Again, note that the survey names used throughout the text, Surveys 1,2 , and 3 , were used for simplicity and correspond to Surveys 21,25 , and 210 , respectively, in the original labeling of cruise data in Ledwell et. al. (2000).

\section{C.1.1 Dye Mapping}

The Matlab program below was used to create the dye maps shown in Figures 4.2(a)-(c). The input data has been advected and the dye concentrations have been vertically integrated. This program also calculates and plots the center of mass ( $0^{\text {th }}$ moment) of the dye patch.

\%mk_map_dye.m created 10AUG01 by J. Katrein

\%Routine from J. Ledwell (WHOI) to map column integrals from GLOBEC dye

$\%$ surveys and make smooth, filled contour. Added Oth moment.

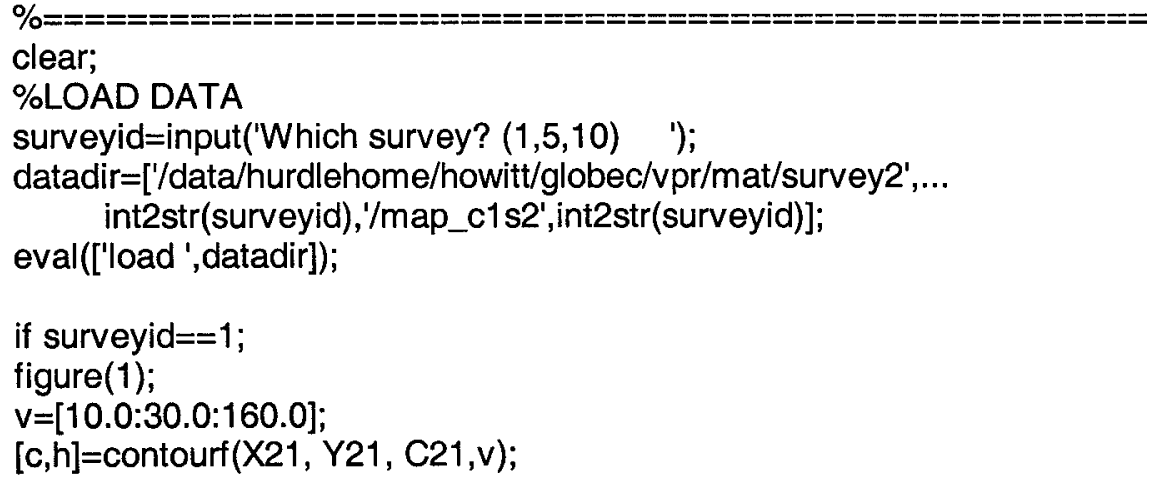


$s c l=\cos \left(\mathrm{pi}^{*} 40.78 / 180\right)$;

set(gca,'PlotBoxAspectRatio',[[1 111$]$ );

set(gca,'DataAspectRatio',[1,scl, 1]);

clabel(c,h,'manual');

$\mathrm{CC}=\mathrm{C} 21$;

\%PRESERVES ORIG. CONCENTRATION

$X=X 21 ;$

$\mathrm{Y}=\mathrm{Y} 21$;

\%ADDING THIS TO GET THINGS IN KM FIRST!!!! MAKES ONE

$\%$ VALUE OF X/Y 0, THEN OTHERS INCREASE FROM THAT. KEEP IN

$\%$ KM FOR VARIANCE CALCS SINCE RHOD CONC IS IN

$\% \mathrm{KG} / \mathrm{KM}^{\wedge} 2$...LEAVES VARIANCE IN KM

$\min x=\min (X)$;

$\mathrm{X}=\mathrm{X}-\min \mathrm{x}$;

$X=X^{*} 111^{*} \mathrm{scl} ; \%$ GETS LON IN KM

$\min y=\min (Y)$;

$\mathrm{Y}=\mathrm{Y}$-miny;

$Y=Y^{*} 111 ; \quad \%$ GETS LAT IN KM

elseif surveyid $==5$;

figure(1);

$v=[4.0: 4.0: 20.0]$;

$[\mathrm{c}, \mathrm{h}]=$ contourf $(\mathrm{X} 25, \mathrm{Y} 25, \mathrm{C} 25, \mathrm{v})$;

$\mathrm{scl}=\cos \left(\mathrm{pi}^{\star} 40.78 / 180\right)$;

set(gca,'PlotBoxAspectRatio',[[1 11 1]);

set(gca,'DataAspectRatio',[1,scl,1]);

clabel(c,h,'manual');

$\mathrm{CC}=\mathrm{C} 25$;

\%PRESERVES ORIGINAL CONCENTRATION

$X=X 25$;

$\mathrm{Y}=\mathrm{Y} 25$;

\%ADDING THIS TO GET THINGS IN KM FIRST!!!! MAKES ONE

$\%$ VALUE OF XYY 0, THEN OTHERS INCREASE FROM THAT. KEEP IN

\%KM FOR VARIANCE CALCS SINCE RHOD CONC IS IN

$\%$ KG/KM^2...LEAVES VARIANCE IN KM

$\min x=\min (X)$;

$\mathrm{X}=\mathrm{X}-\min \mathrm{x}$

$X=X^{*} 111^{*}$ scl; \%GETS LON IN KM

$\min y=\min (Y)$;

$\mathrm{Y}=\mathrm{Y}$-miny;

$Y=Y^{*} 111 ; \quad$ \%GETS LAT IN KM

elseif surveyid==10;

figure(1);

$v=[0.15: 0.05: 0.45]$

$[\mathrm{c}, \mathrm{h}]=$ contourf $(\mathrm{X} 210, \mathrm{Y} 210, \mathrm{C} 210, \mathrm{v})$;

$\mathrm{scl}=\cos \left(\mathrm{pi}^{*} 40.78 / 180\right)$;

set(gca,'PlotBoxAspectRatio',[[1 111$])$;

set(gca,'DataAspectRatio',[1,scl,1]);

clabel(c,h,'manual');

$\mathrm{CC}=\mathrm{C} 210$;

\%PRESERVES ORIGINAL CONCENTRATION

$X=X 210$

$Y=Y 210$

\%ADDING THIS TO GET THINGS IN KM FIRST!!!! MAKES ONE

\%VALUE OF XY 0, THEN OTHERS INCREASE FROM THAT. KEEP IN 
\%KM FOR VARIANCE CALCS SINCE RHOD CONC IS IN $\% \mathrm{KG} / \mathrm{KM}{ }^{\wedge} 2 \ldots$...EAVES VARIANCE IN KM

$\min x=\min (X)$;

$X=X-\min x ;$

$X=X^{\star} 111^{*}$ scl; \%GETS LON IN KM

$\min y=\min (Y)$;

$Y=Y$-miny;

$Y=Y^{*} 111$

\%GETS LAT IN KM

end;

\%ADD FIRST AND SECOND MOMENTS

$[\mathrm{m}, \mathrm{n}]=\mathrm{size}(\mathrm{CC})$;

$X X=$ ones $(m, 1)^{\star} X$;

$Y Y=Y^{\prime *}$ ones $(1, n)$;

$X v e c=$ reshape $\left(X X, m^{\star} n, 1\right)$;

$Y v e c=\operatorname{reshape}\left(Y Y, m^{\star} n, 1\right)$;

Cvec=reshape $\left(\mathrm{CC}, \mathrm{m}^{*} \mathrm{n}, 1\right)$;

hold on; \%CALCULATE CENTER OF MASS

$\mathrm{XO}=$ nansum(Cvec. $\left.{ }^{*} \mathrm{Xvec}\right) /$ nansum(Cvec);

YO=nansum (Cvec. $\left.{ }^{\star} Y v e c\right) /$ nansum(Cvec);

\%CALCULATE THE STATS IN KM

sig_sq_X=(nansum (Cvec. $\left.{ }^{*}(X v e c-X 0) . \wedge 2\right) /$ nansum $($ Cvec));

sig_sq_y $=$ (nansum $\left(C v e c .{ }^{*}(Y v e c-Y 0) . \wedge 2\right) /$ nansum $($ Cvec));

sig_xy=(nansum $\left.\left(C_{\text {Cvec. }}{ }^{*}(X v e c-X 0) .{ }^{*}(Y v e c-Y 0)\right)\right) /$ nansum $(C v e c)$;

\%NOW CONVERT CENTER OF MASS BACK TO DEGREES FOR PLOT $\operatorname{plot}\left(\left(\mathrm{XO} /\left(111^{*} \mathrm{scl}\right)\right)+\operatorname{minx},(\mathrm{YO} / 111)+\mathrm{miny}^{\prime}, \mathrm{wh}^{* 1},{ }^{\prime}\right.$ 'Markersize', 10,'Linewidth',2);

colorbar;

xlabel('Longitude');

ylabel('Latitude');

hold off;

\%THE END! 


\section{C.1.2 Objective Analysis and Vertical Contouring}

The following two Matlab programs were used to make vertical section contours of the dye patch. The first, scaloa.m, runs objective analysis on the input data. The second, mk_contour_dye.m, incorporates scaloa.m and contours its output for the chosen contours on a grid of depth versus a horizontal coordinate. While this program works for plotting sections against latitude, adding a scaling function on the horizontal coordinate makes longitude sections.

function[tp,ep]=scaloa(xc, yc, $x, y, t, R 0$, corrlen)

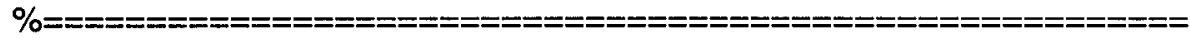

$\%$ Function from $\mathrm{J}$. Ledwell for objective analysis to be used

$\%$ on GLOBEC data. His comments follow:

$\%$

\%assumes a gaussian correlation function: see $\mathrm{A}$ below

$\%$ where corrlen gives decay scale and $\mathrm{RO}$ is amplitude $(<1)$ at origin

$\% x c$ and $y c$ are vectors of the $x$ and $y$ coordinates

$\%$ of the points at which one wants estimates of the field

$\% x$ and $y$ are vectors of the $x$ and $y$ coordinates of the observations

$\% t$ is a vector of the observations, same size as $x$ and $y$

$\%$ is is a vector of the estimates of the field, same size as xc and yc

$\%$ ep is an estimate of the scaled variance associated with tp

$\%$ the validity of ep depends on the validity of R0 and corrlen and

$\%$ the presumed shape of the covariance function. ep must be

$\%$ multiplied by the variance of the data at 0 lag to convert to a true variance.

\%Reference:

\%Bretherton, F.P., R.E. Davis, and C.B. Fandry, A technique for

$\%$ objective analysis and design of oceanographic experiments applied

\%to MODE-73, Deep Sea Res., 23, 559-582, 1976.

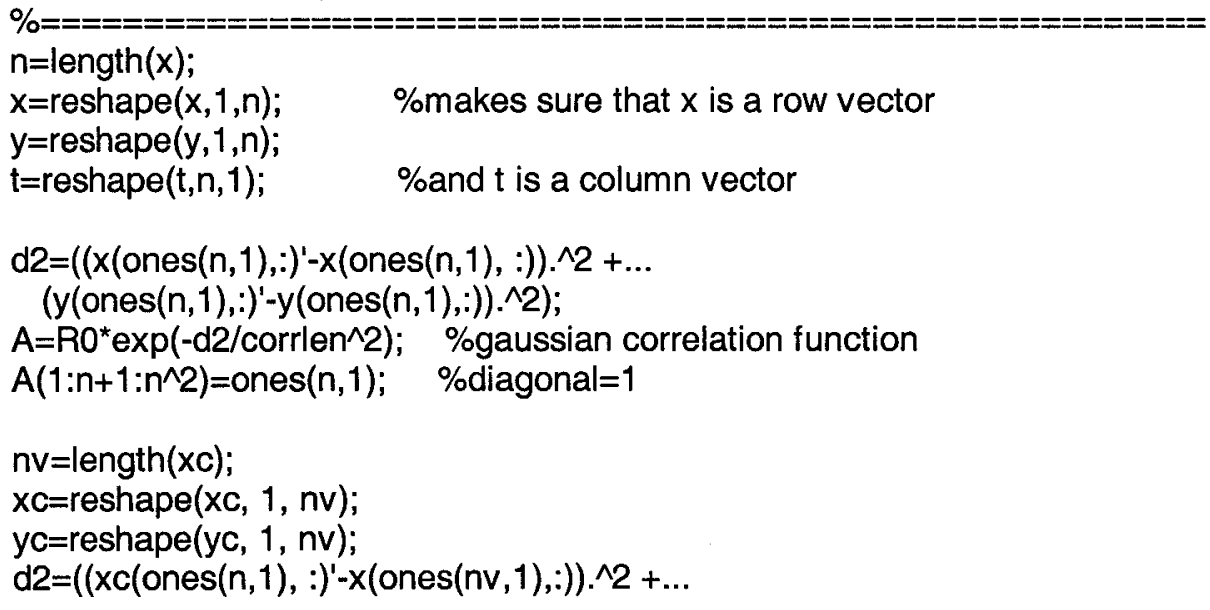




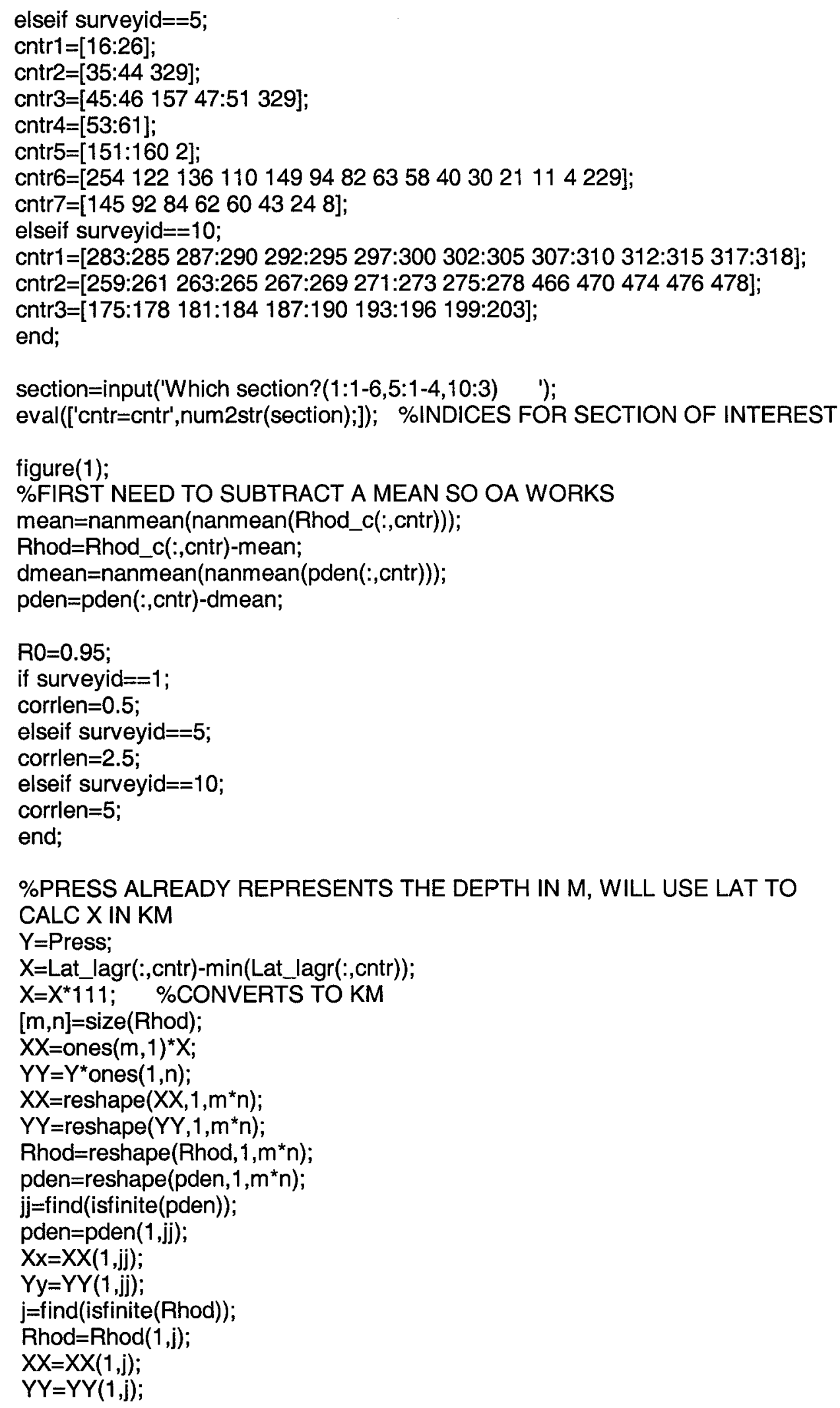




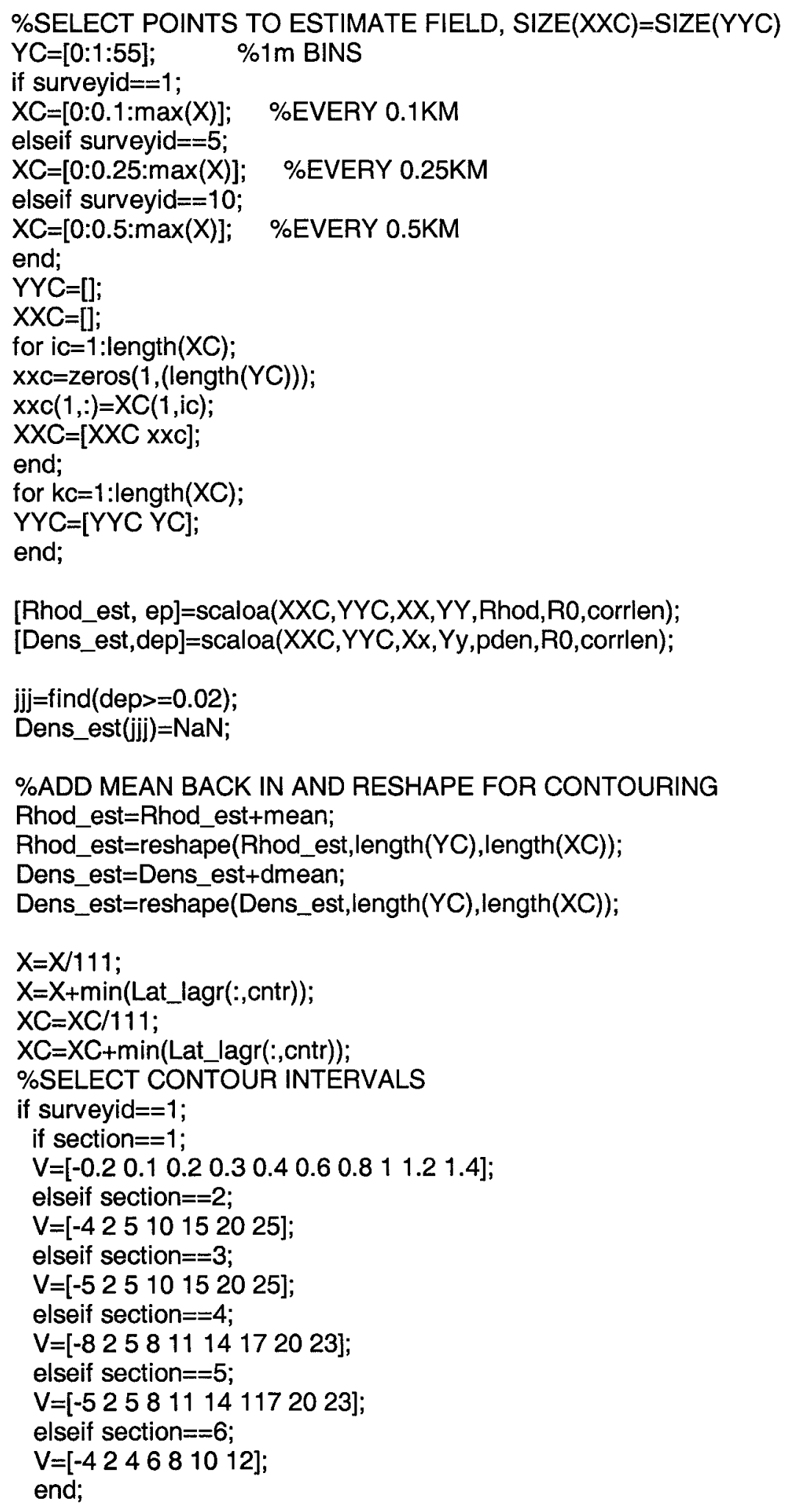




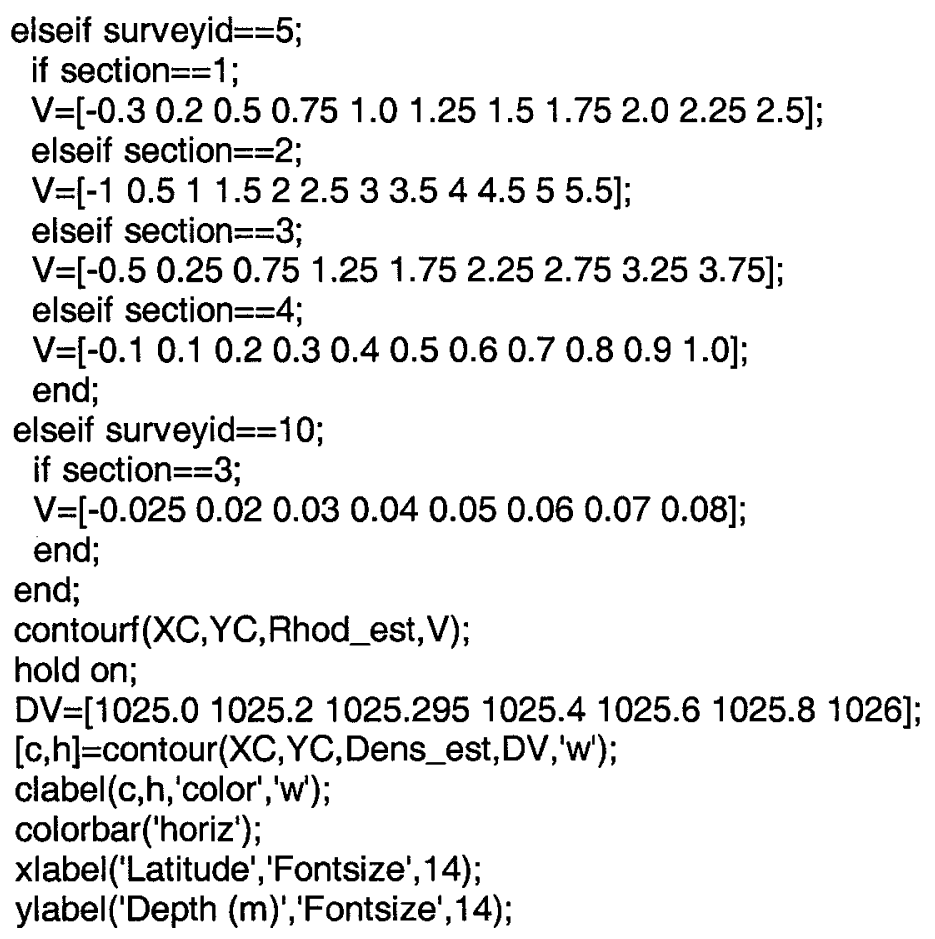




\section{C.2 Additional Figures}

\section{C.2.1 Dye Section Choices}

The following three figures are maps of the sections that were chosen for the vertical contours of dye. The maps are of the advected ship's track with the sections labeled, and overlay the vertically integrated dye patch maps (see Figures 4.2(a)-(c) for corresponding contour levels).

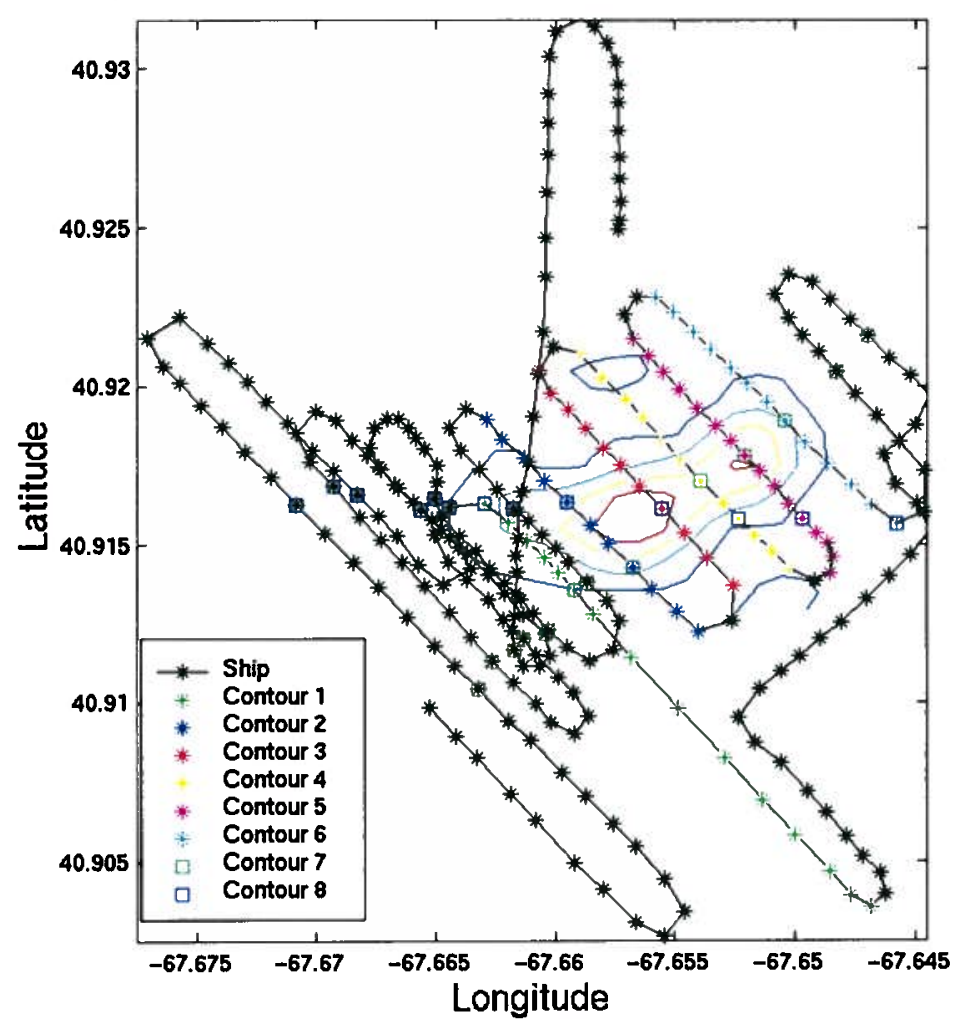

Figure C.1. Survey 1 advected ship's track with dye sections for vertical contouring labeled. 


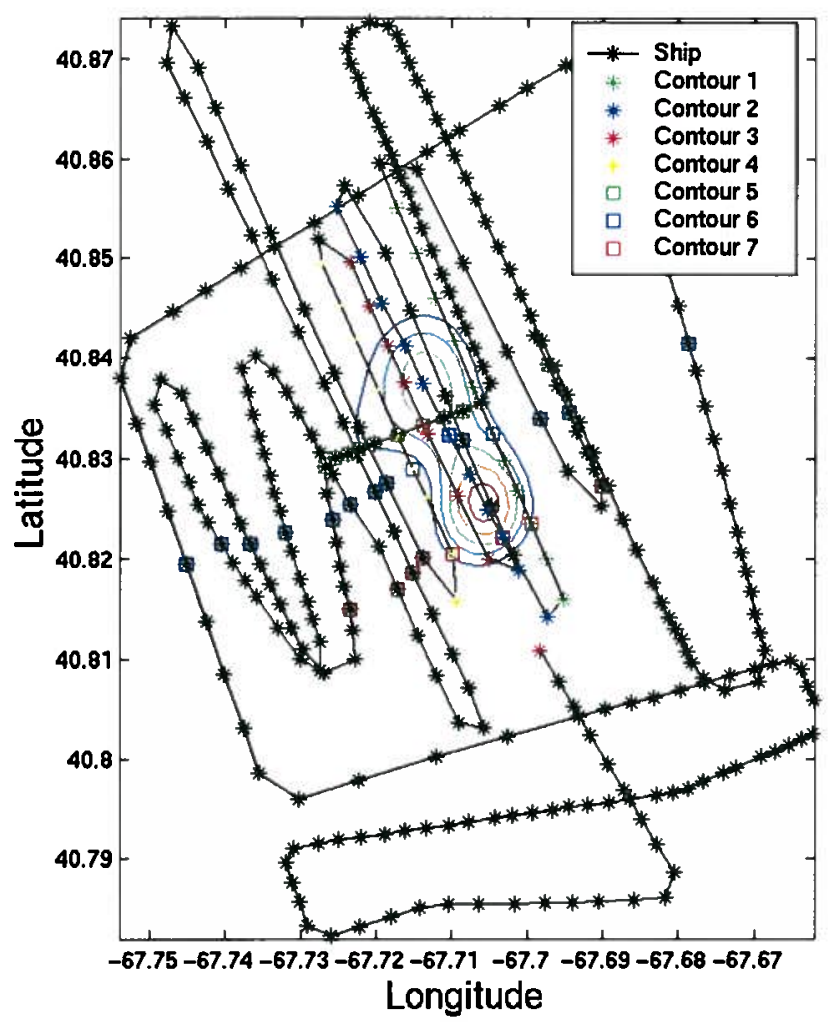

Figure C.2. Survey 2 advected ship's track with dye sections for vertical contouring labeled. 


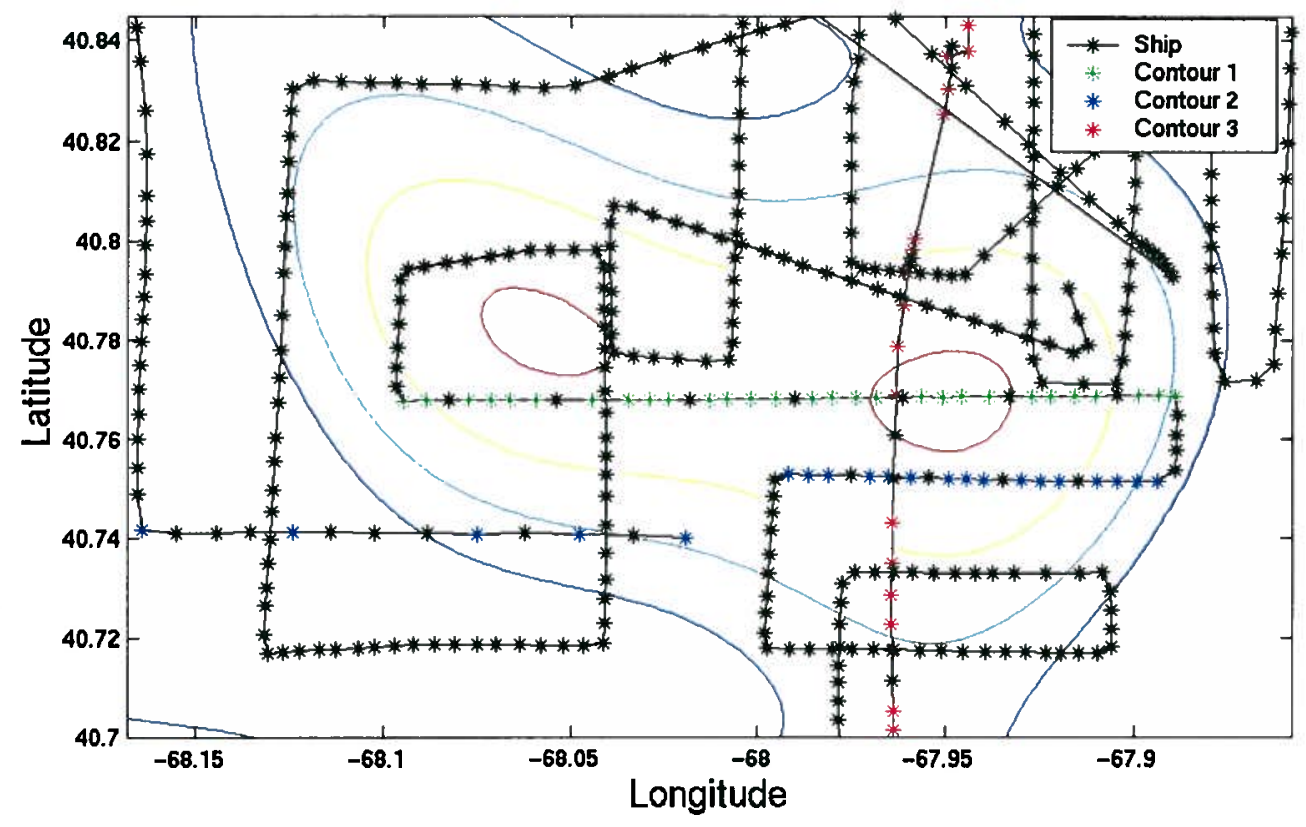

Figure C.3. Survey 3 advected ship's track with dye sections for vertical contouring labeled. 


\section{C.2.2 Dye Contours}

The following figures are contoured vertical sections of dye. Depending on their orientation (see section C.2.1), they were plotted against latitude or longitude. Note that on plots versus latitude that the northernmost point is on the left side of the plot. Refer to Figures C.1, C.2, and C.3 to get a better idea of where the sections are located in relation to the entire dye patch. The density is also contoured to track the dye location relative to the isopycnals.

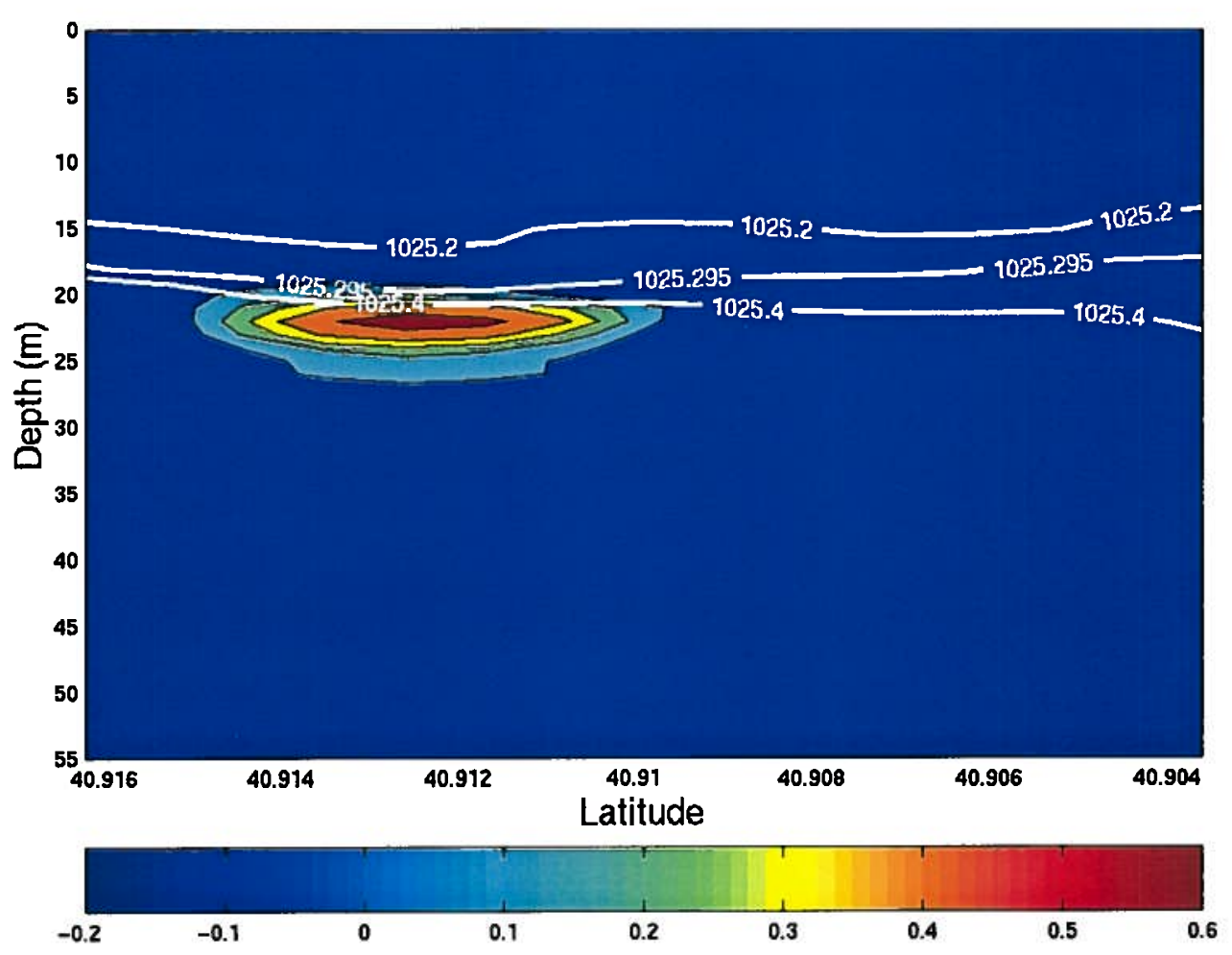

Figure C.4. Survey 1 , Contour 1 vertical section dye contour. Rhodamine dye concentrations are given in units of $\mu \mathrm{g} \mathrm{L}^{-1}$. Density contours are plotted as white lines/labels in units of $\mathrm{kg}$ $\mathrm{m}^{-3}$. 


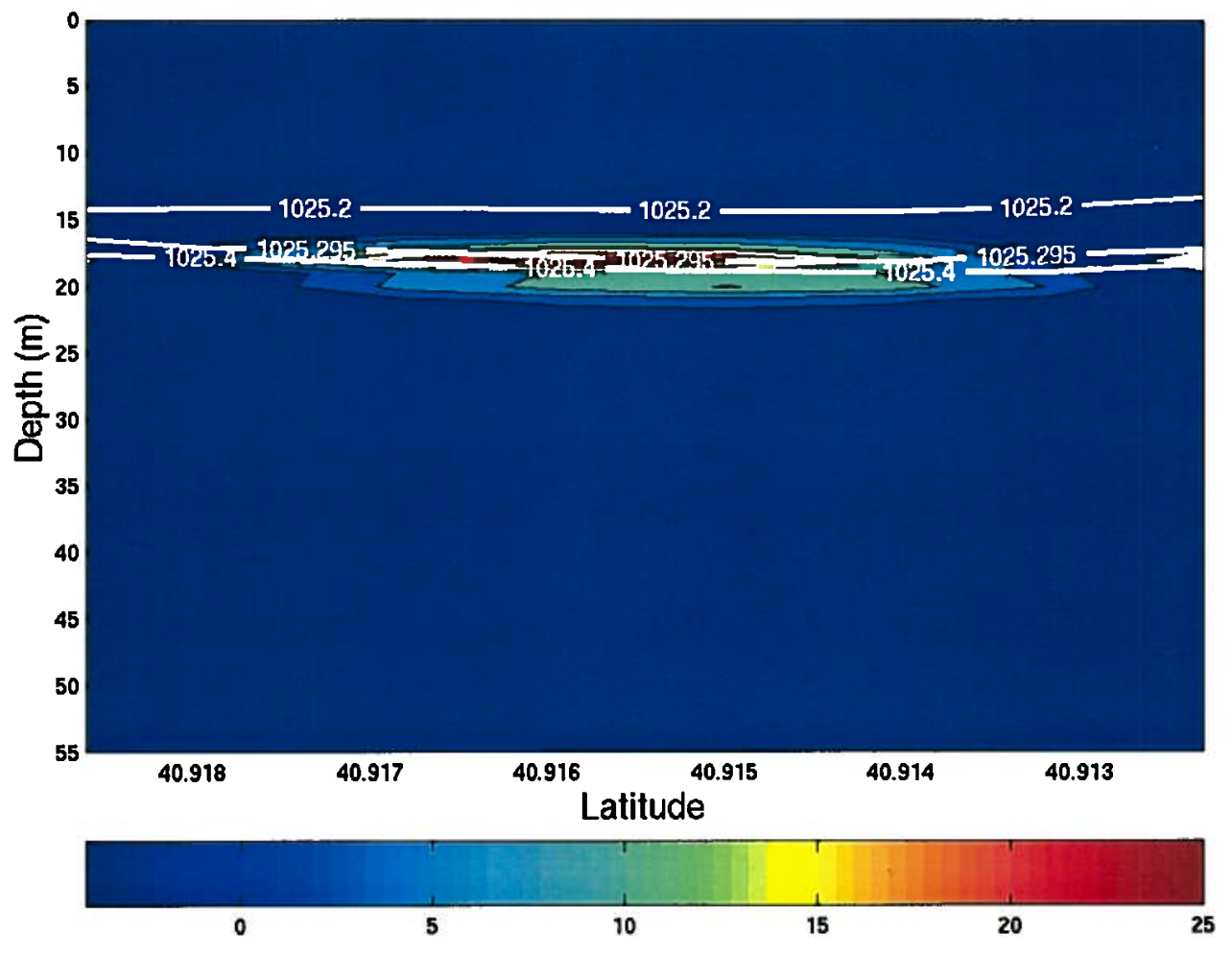

Figure C.5. Survey 1 , Contour 2 vertical section dye contour. Rhodamine dye concentrations are given in units of $\mu \mathrm{g} \mathrm{L}^{-1}$. Density contours are plotted as white lines/labels in units of $\mathrm{kg}$ $\mathrm{m}^{-3}$. 


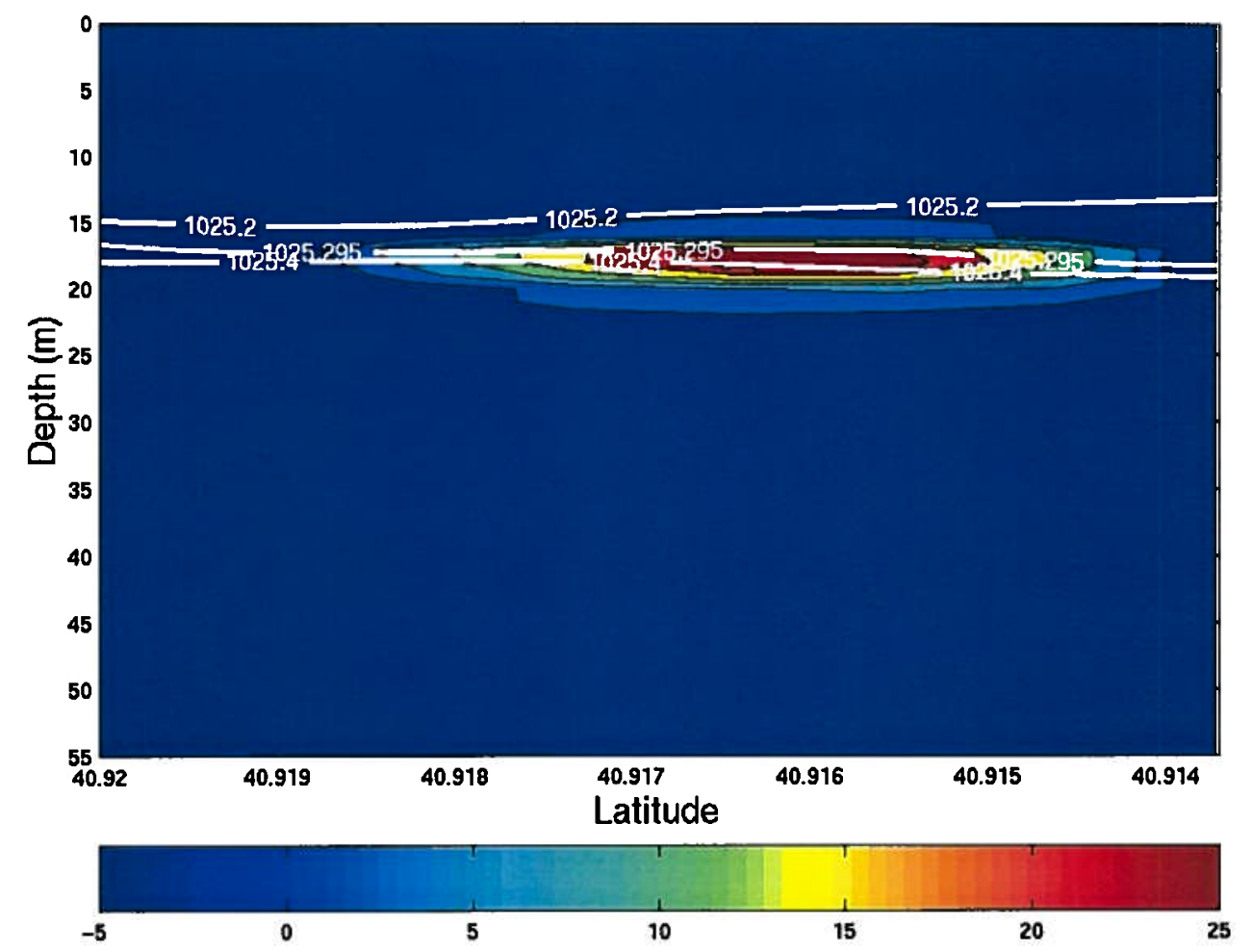

Figure C.6. Survey 1 , Contour 3 vertical section dye contour. Rhodamine dye concentrations are given in units of $\mu \mathrm{g} \mathrm{L}^{-1}$. Density contours are plotted as white lines/labels in units of $\mathrm{kg}$ $\mathrm{m}^{-3}$. 


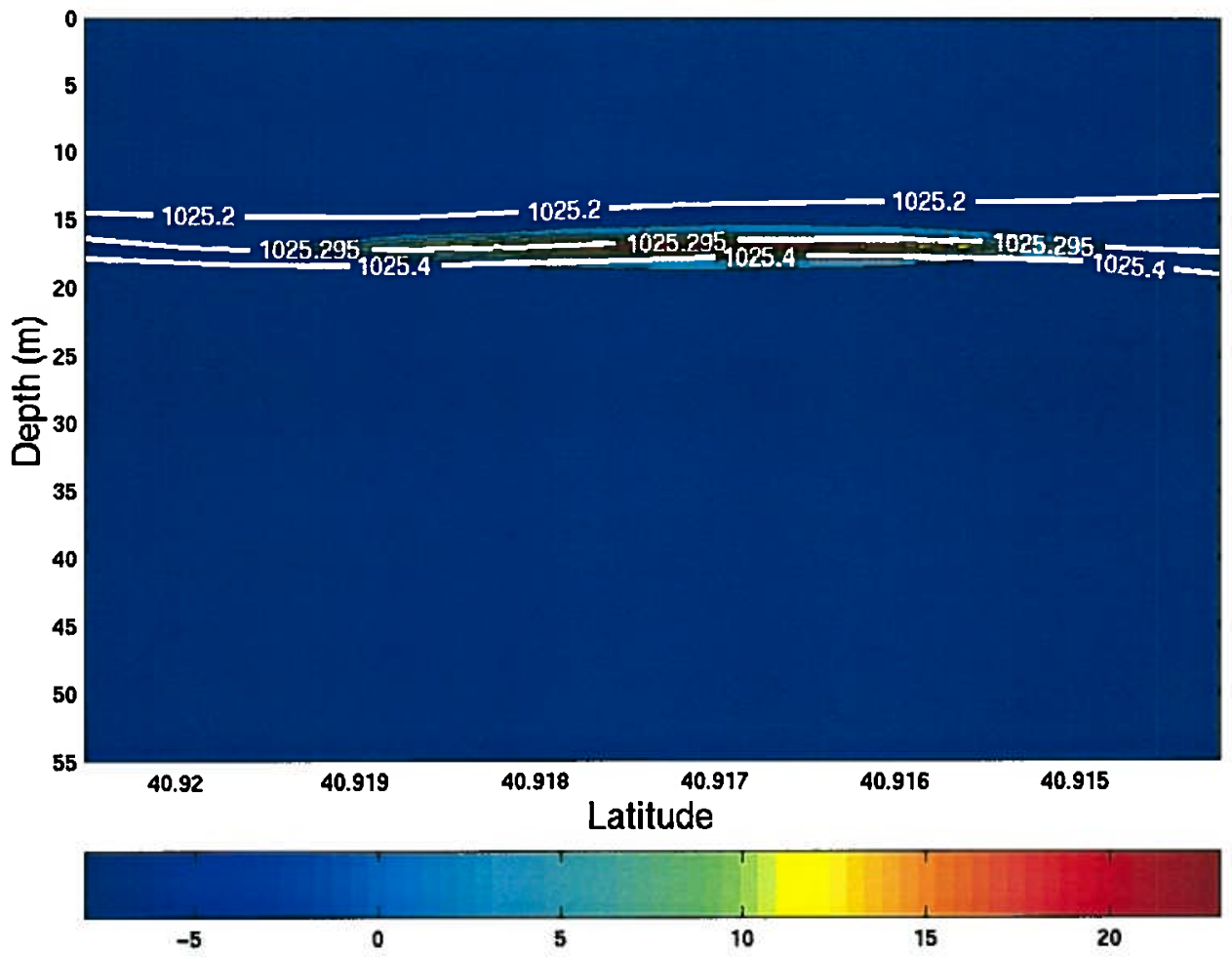

Figure C.7. Survey 1 , Contour 4 vertical section dye contour. Rhodamine dye concentrations are given in units of $\mu \mathrm{g} \mathrm{L}^{-1}$. Density contours are plotted as white lines/labels in units of kg $\mathrm{m}^{-3}$. 


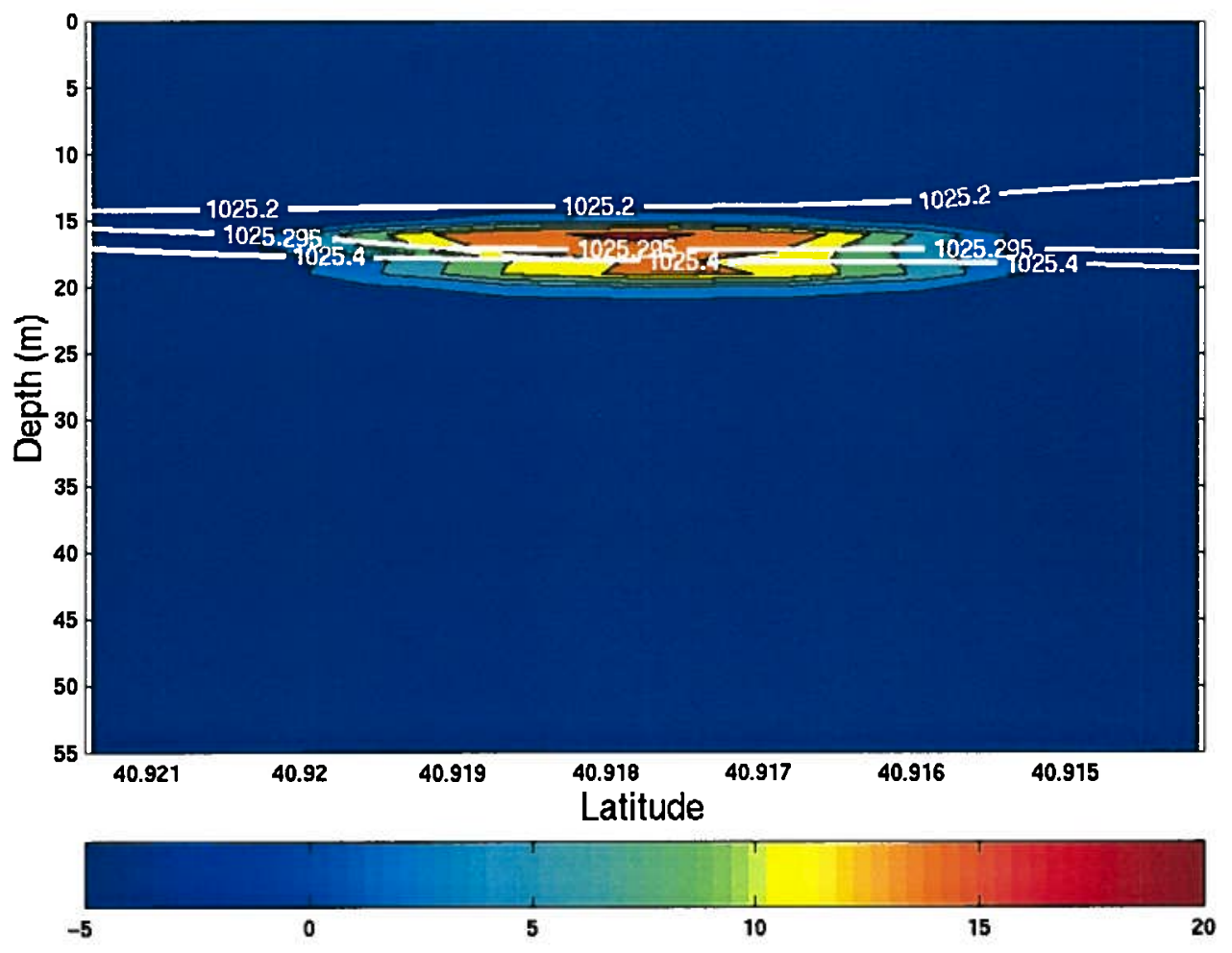

Figure C.8. Survey 1 , Contour 5 vertical section dye contour. Rhodamine dye concentrations are given in units of $\mu \mathrm{g} \mathrm{L}^{-1}$. Density contours are plotted as white lines/labels in units of $\mathrm{kg}$ $\mathrm{m}^{-3}$. 


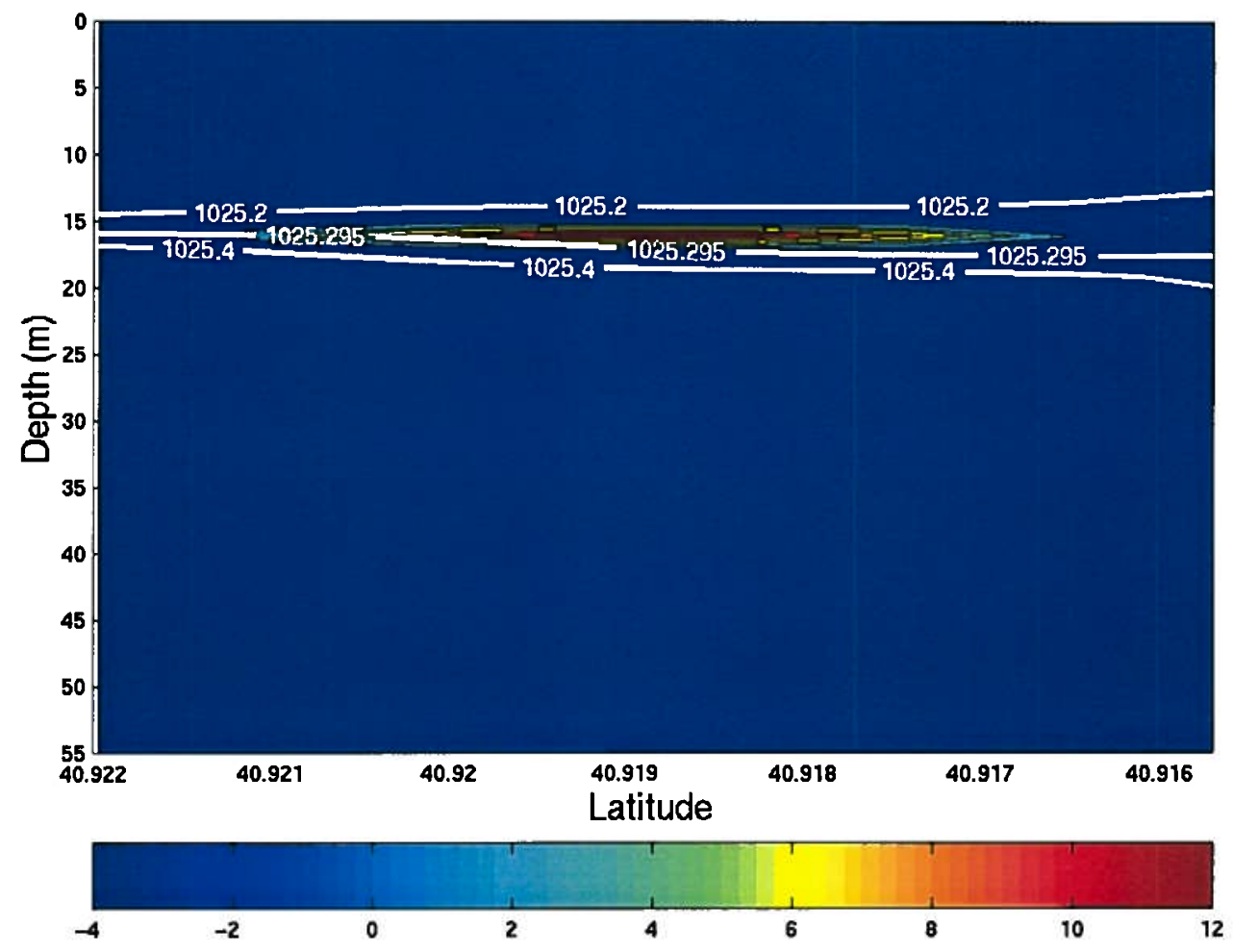

Figure C.9. Survey 1, Contour 6 vertical section dye contour. Rhodamine dye concentrations are given in units of $\mu \mathrm{g} \mathrm{L}^{-1}$. Density contours are plotted as white lines/labels in units of $\mathrm{kg}$ $\mathrm{m}^{-3}$. 


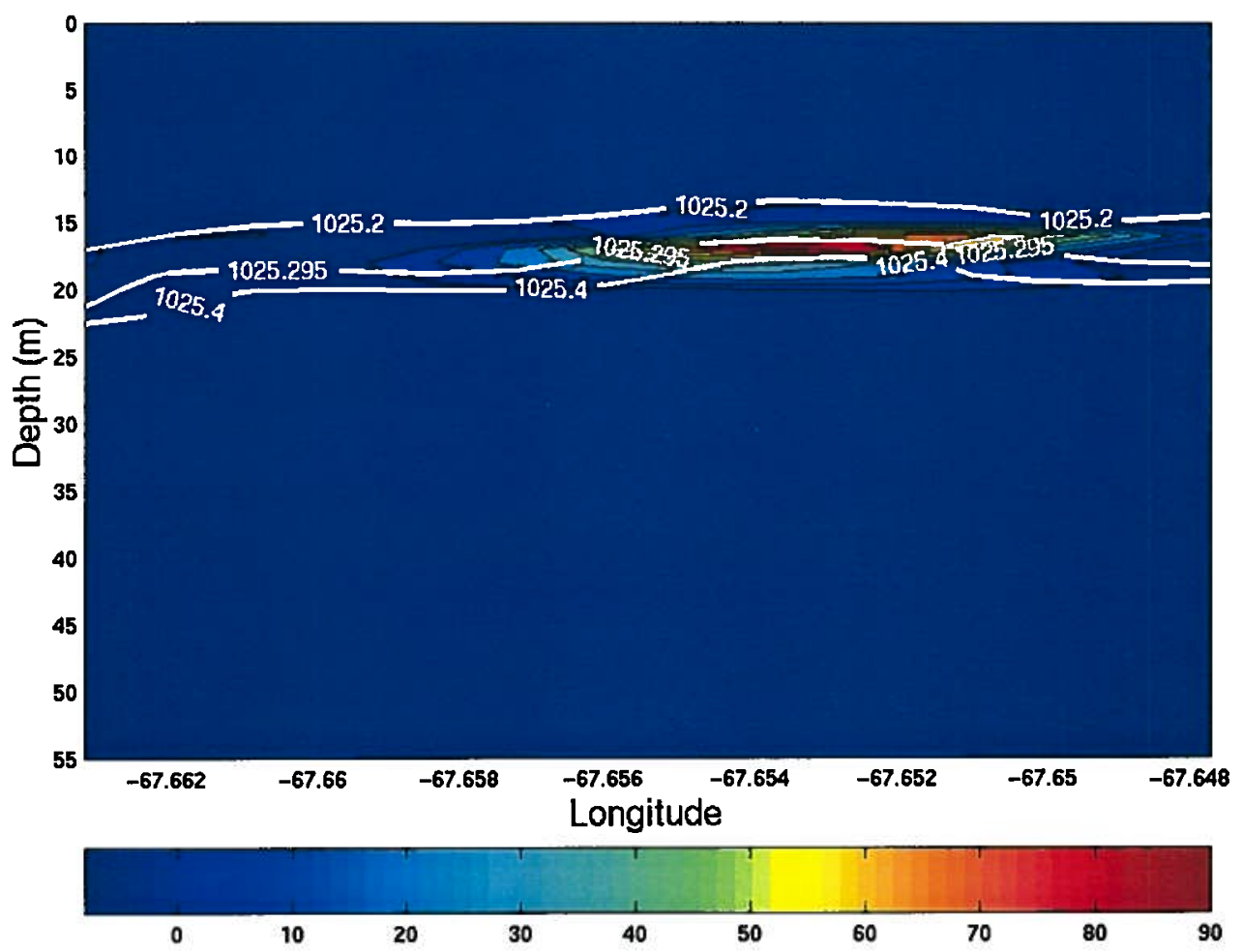

Figure C.10. Survey 1 , Contour 7 vertical section dye contour. Rhodamine dye concentrations are given in units of $\mu \mathrm{L} \mathrm{L}^{-1}$. Density contours are plotted as white lines/labels in units of $\mathrm{kg} \mathrm{m}^{-3}$. 


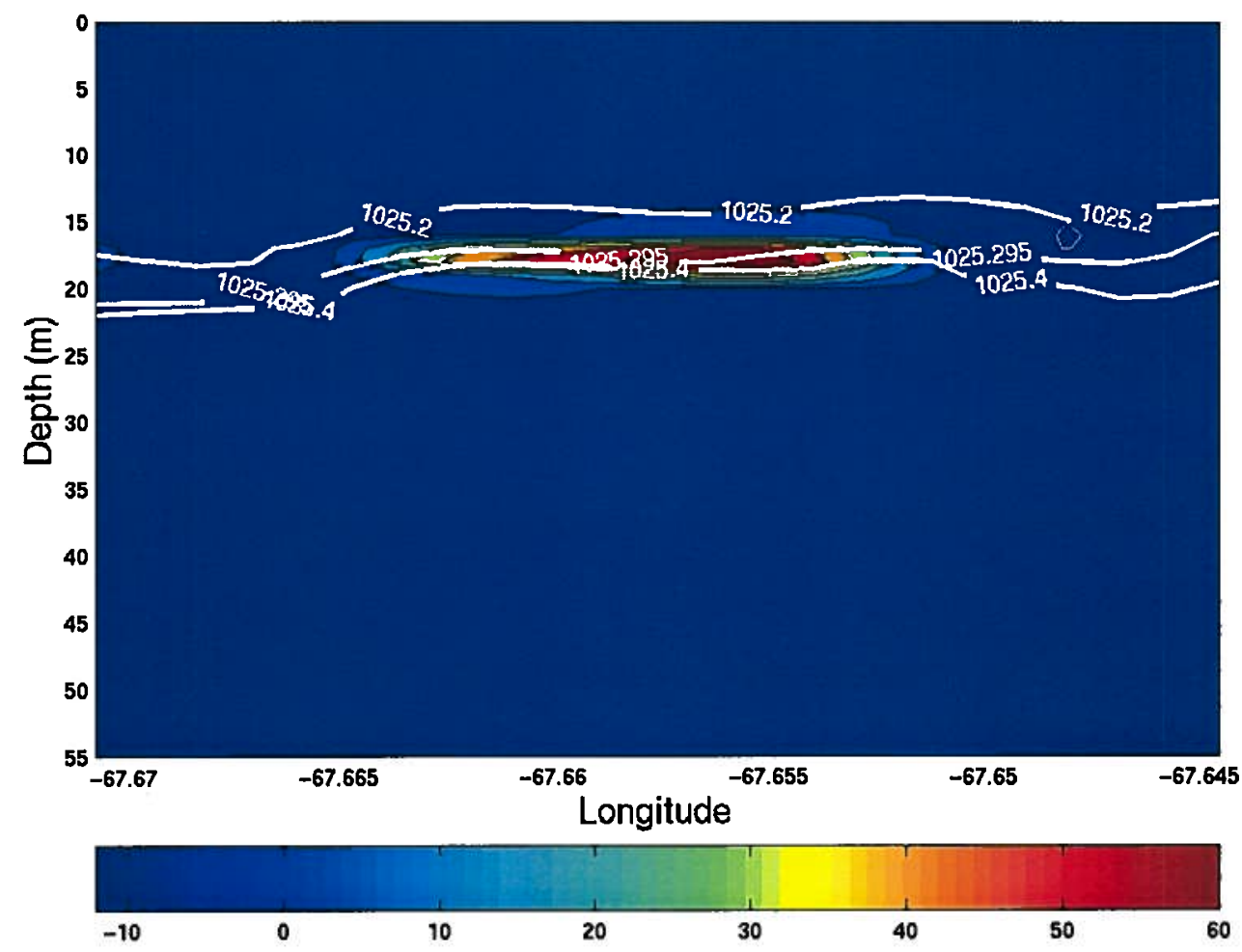

Figure C.11. Survey 1 , Contour 8 vertical section dye contour. Rhodamine dye concentrations are given in units of $\mu \mathrm{g} \mathrm{L}^{-1}$. Density contours are plotted as white lines/labels in units of $\mathrm{kg} \mathrm{m}^{-3}$. 


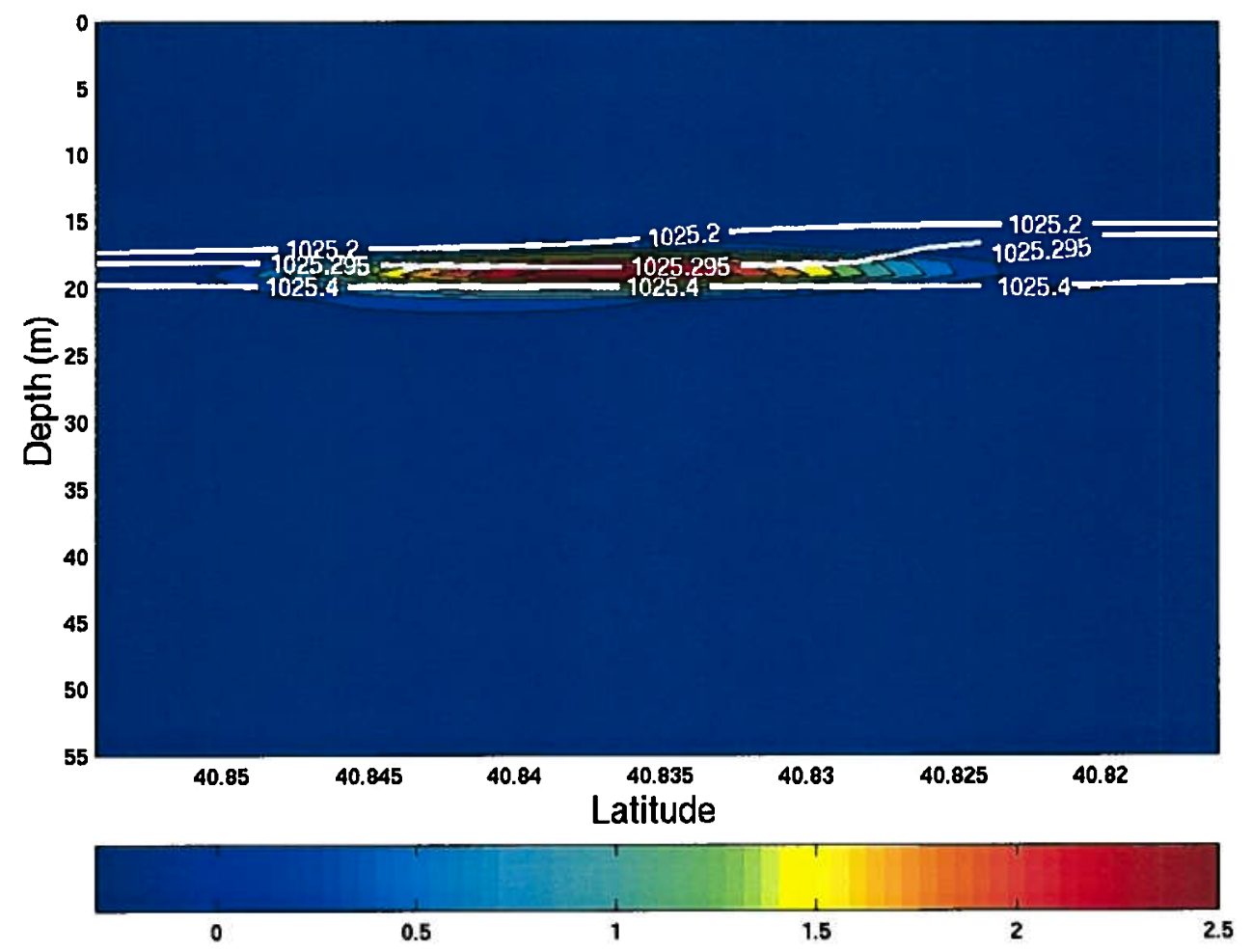

Figure C.12. Survey 2, Contour 1 vertical section dye contour. Rhodamine dye concentrations are given in units of $\mu \mathrm{g} \mathrm{L}^{-1}$. Density contours are plotted as white lines/labels in units of $\mathrm{kg} \mathrm{m}^{-3}$. 


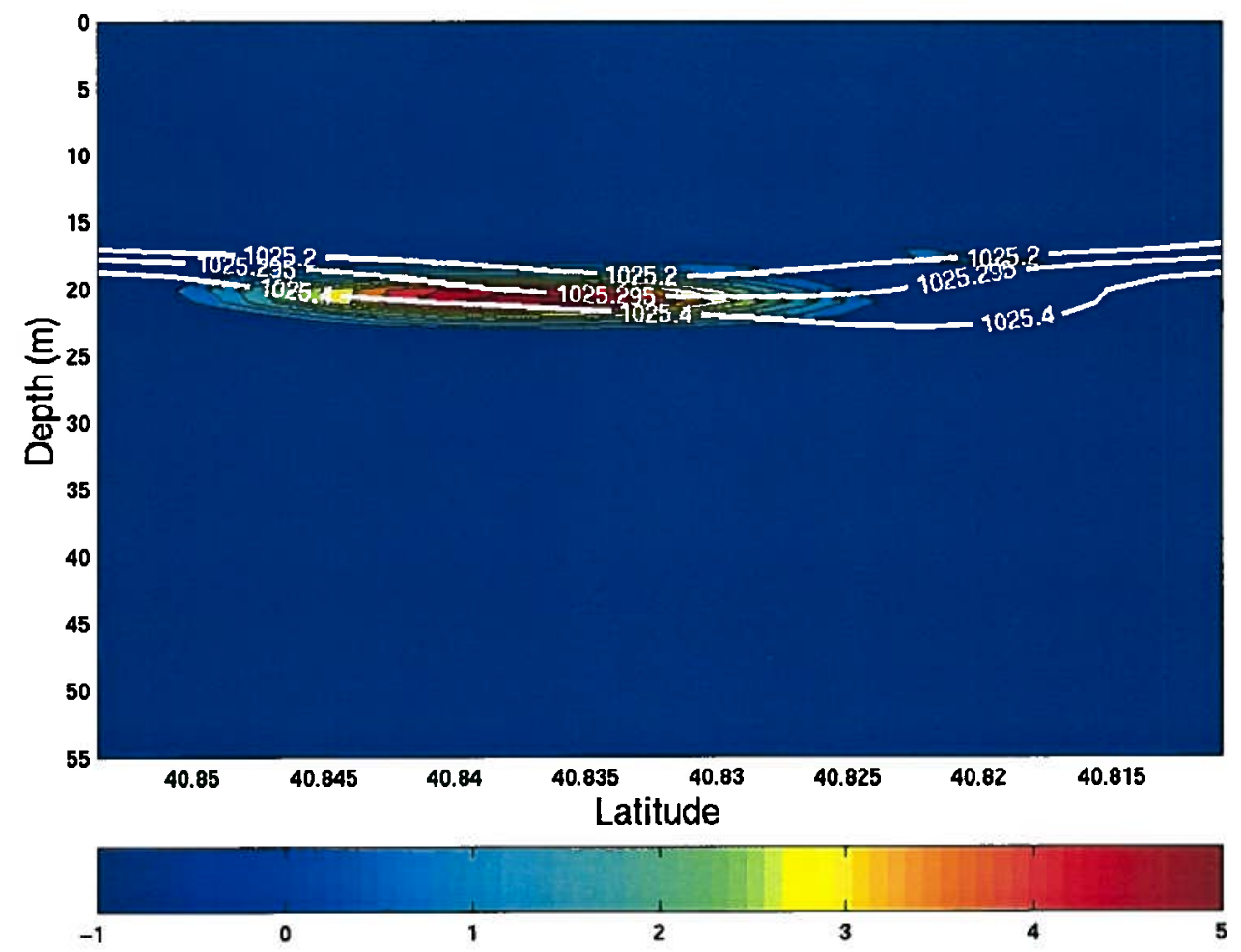

Figure C.13. Survey 2, Contour 2 vertical section dye contour. Rhodamine dye concentrations are given in units of $\mu \mathrm{g} \mathrm{L}^{-1}$. Density contours are plotted as white lines/labels in units of $\mathrm{kg} \mathrm{m}^{-3}$. 


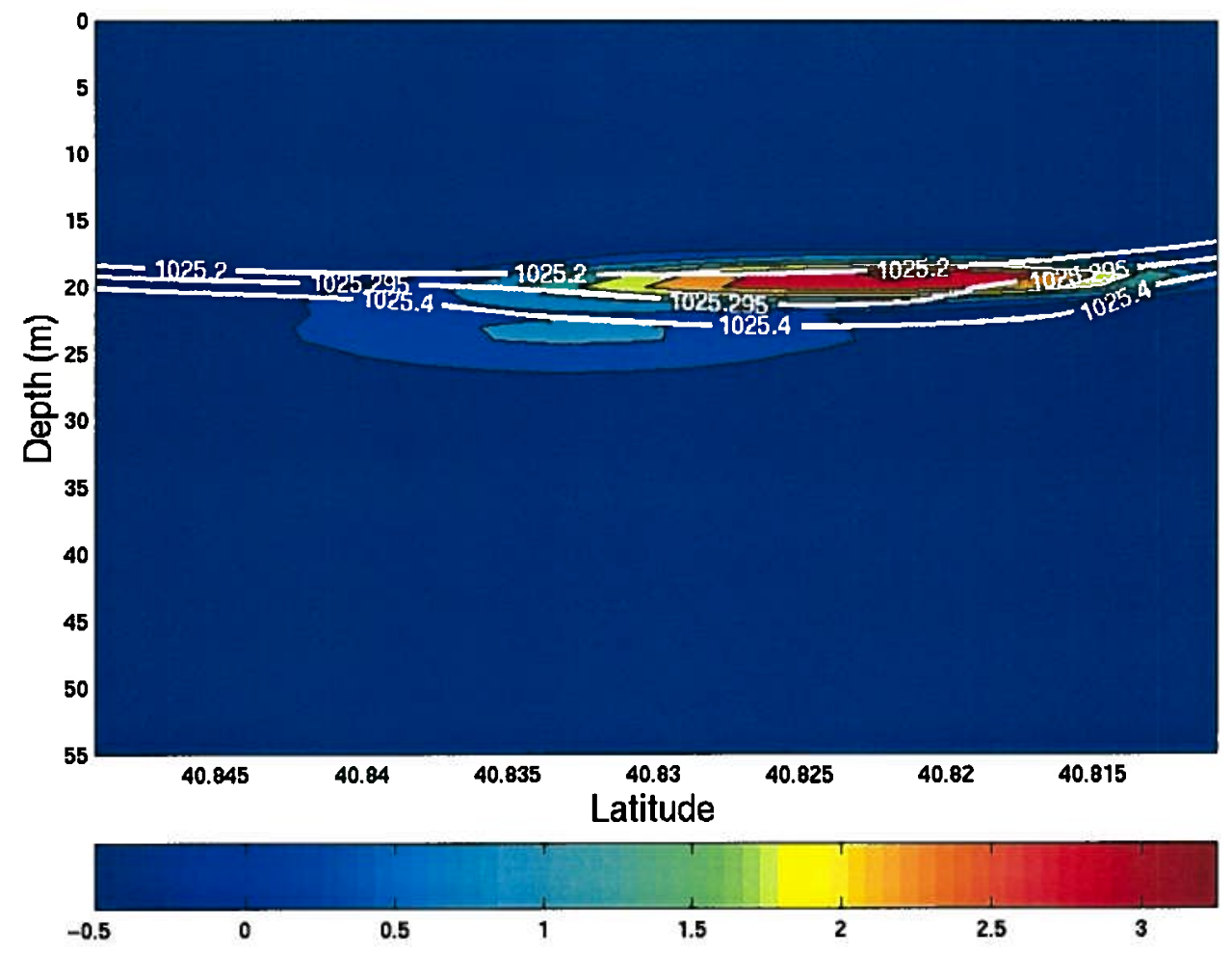

Figure C.14. Survey 2, Contour 3 vertical section dye contour. Rhodamine dye concentrations are given in units of $\mu \mathrm{g} \mathrm{L}^{-1}$. Density contours are plotted as white lines/labels in units of $\mathrm{kg} \mathrm{m}^{-3}$. 


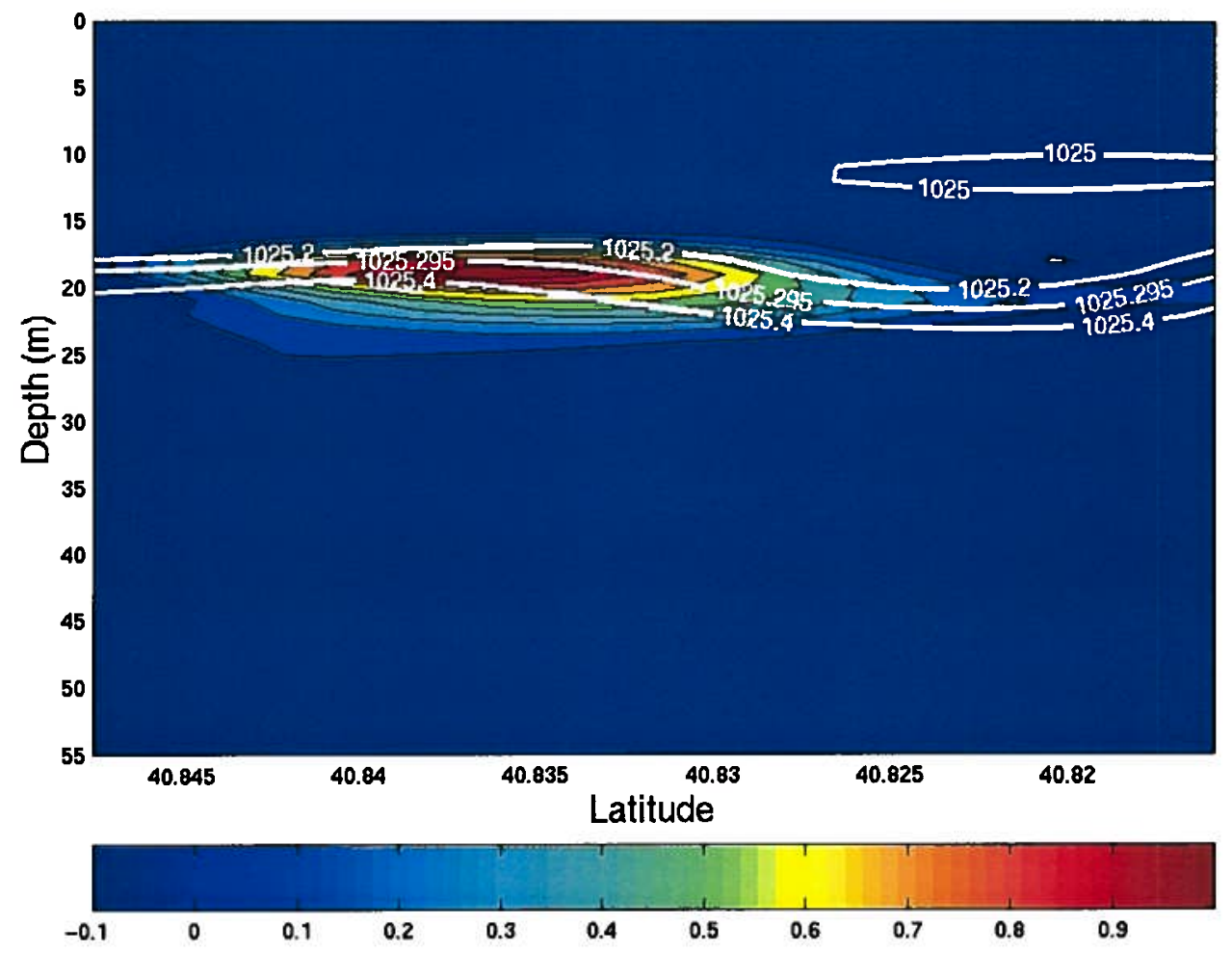

Figure C.15. Survey 2, Contour 4 vertical section dye contour. Rhodamine dye concentrations are given in units of $\mu \mathrm{g} \mathrm{L}^{-1}$. Density contours are plotted as white lines/labels in units of $\mathrm{kg} \mathrm{m}^{-3}$. 


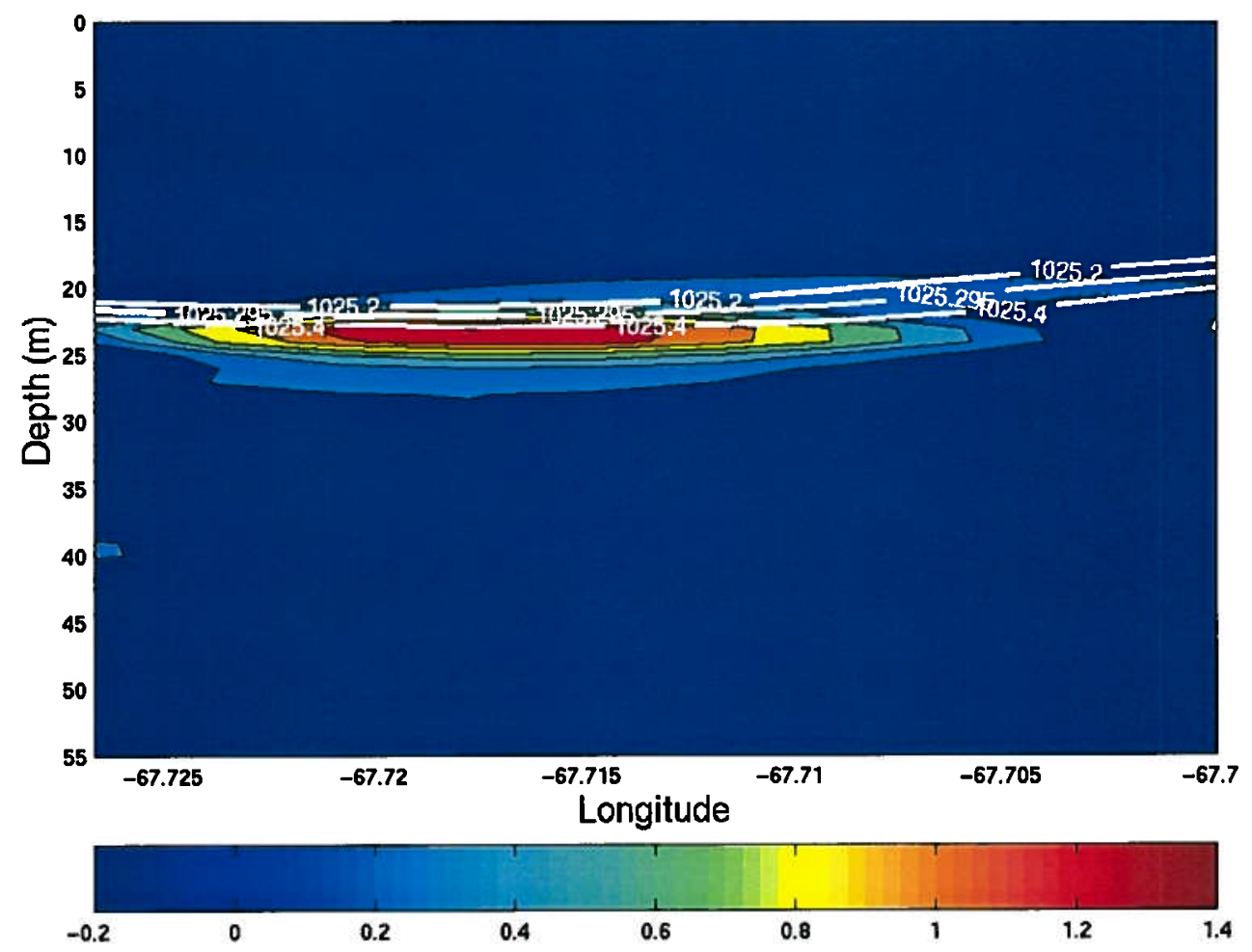

Figure C.16. Survey 2, Contour 5 vertical section dye contour. Rhodamine dye concentrations are given in units of $\mu \mathrm{g} \mathrm{L}^{-1}$. Density contours are plotted as white lines/labels in units of $\mathrm{kg} \mathrm{m}^{-3}$. 


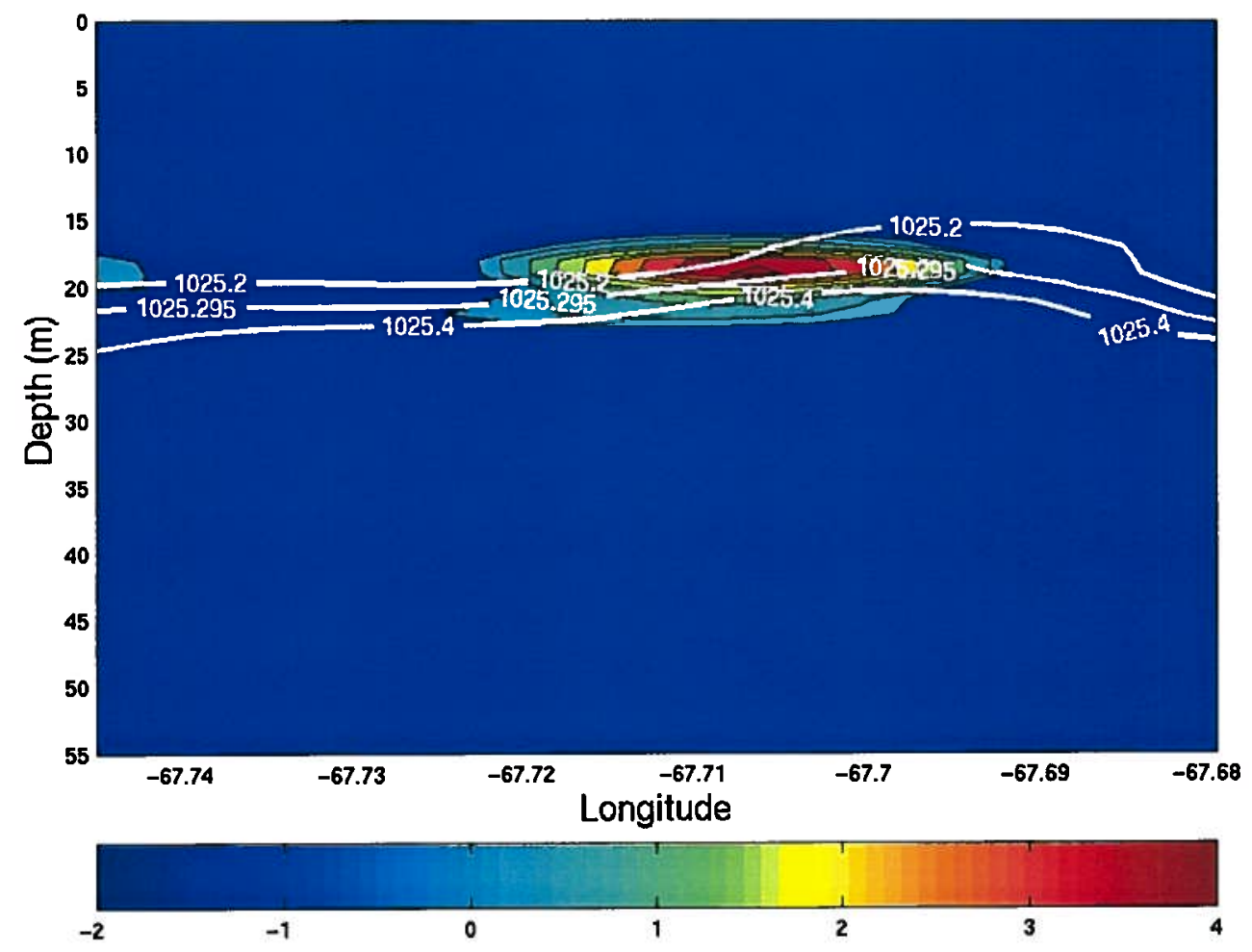

Figure C.17. Survey 2, Contour 6 vertical section dye contour. Rhodamine dye concentrations are given in units of $\mu \mathrm{g} \mathrm{L^{-1 }}$. Density contours are plotted as white lines/labels in units of $\mathrm{kg} \mathrm{m}^{-3}$. 


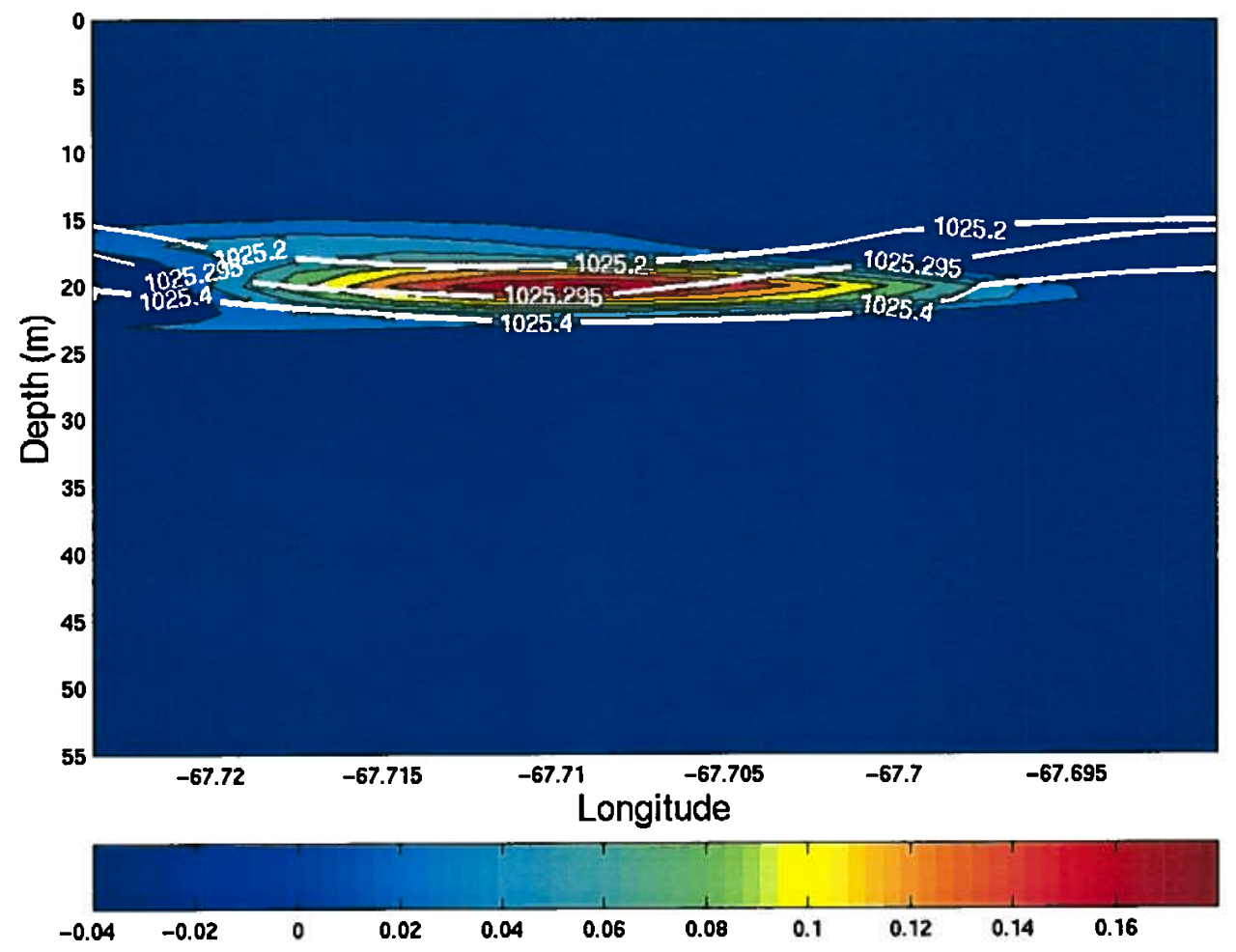

Figure C.18. Survey 2, Contour 7 vertical section dye contour. Rhodamine dye concentrations are given in units of $\mu \mathrm{g} \mathrm{L}^{-1}$. Density contours are plotted as white lines/labels in units of $\mathrm{kg} \mathrm{m}^{-3}$. 


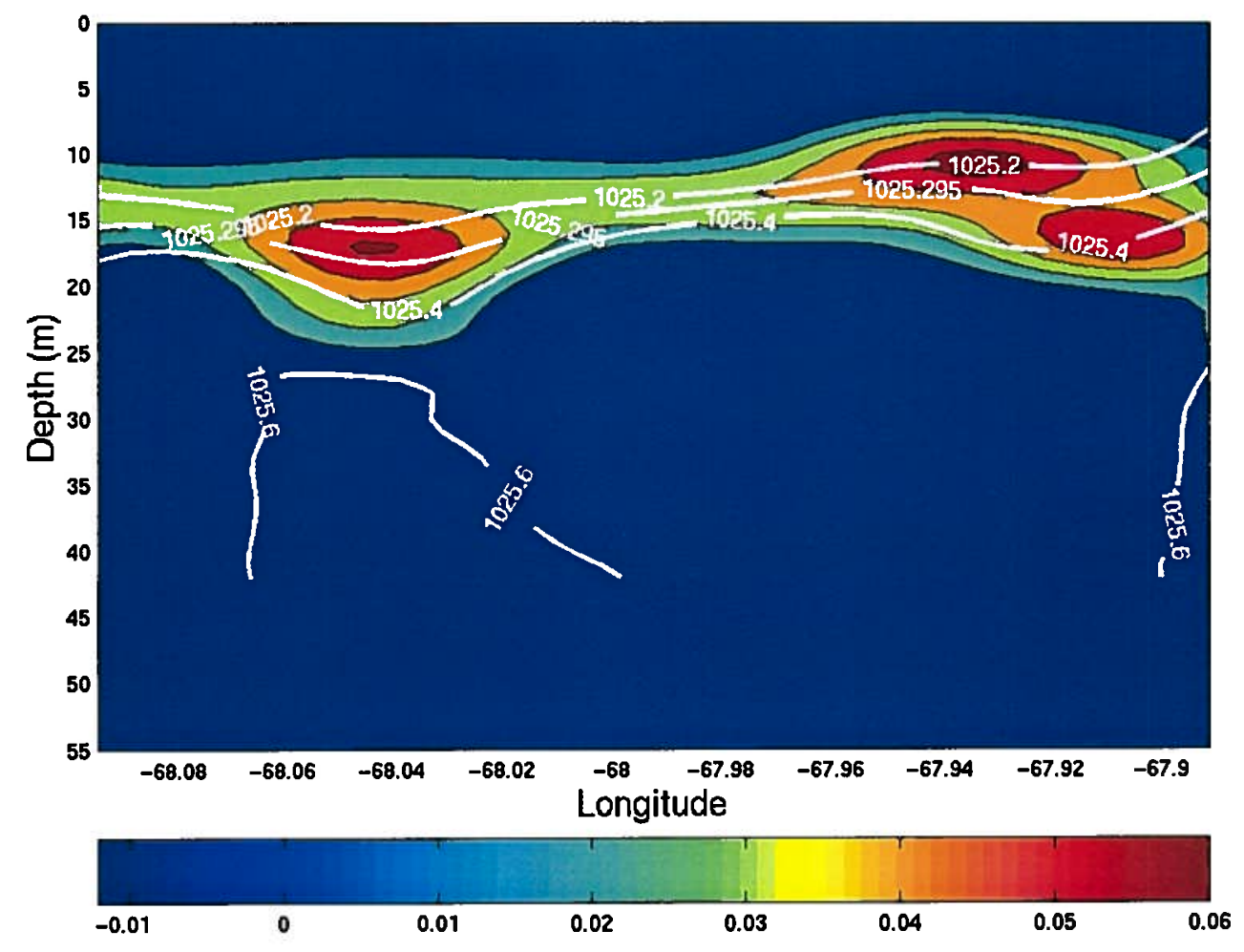

Figure C.19. Survey 3 , Contour 1 vertical section dye contour. Rhodamine dye concentrations are given in units of $\mu \mathrm{g} \mathrm{L}^{-1}$. Density contours are plotted as white lines/labels in units of $\mathrm{kg} \mathrm{m}^{-3}$. 


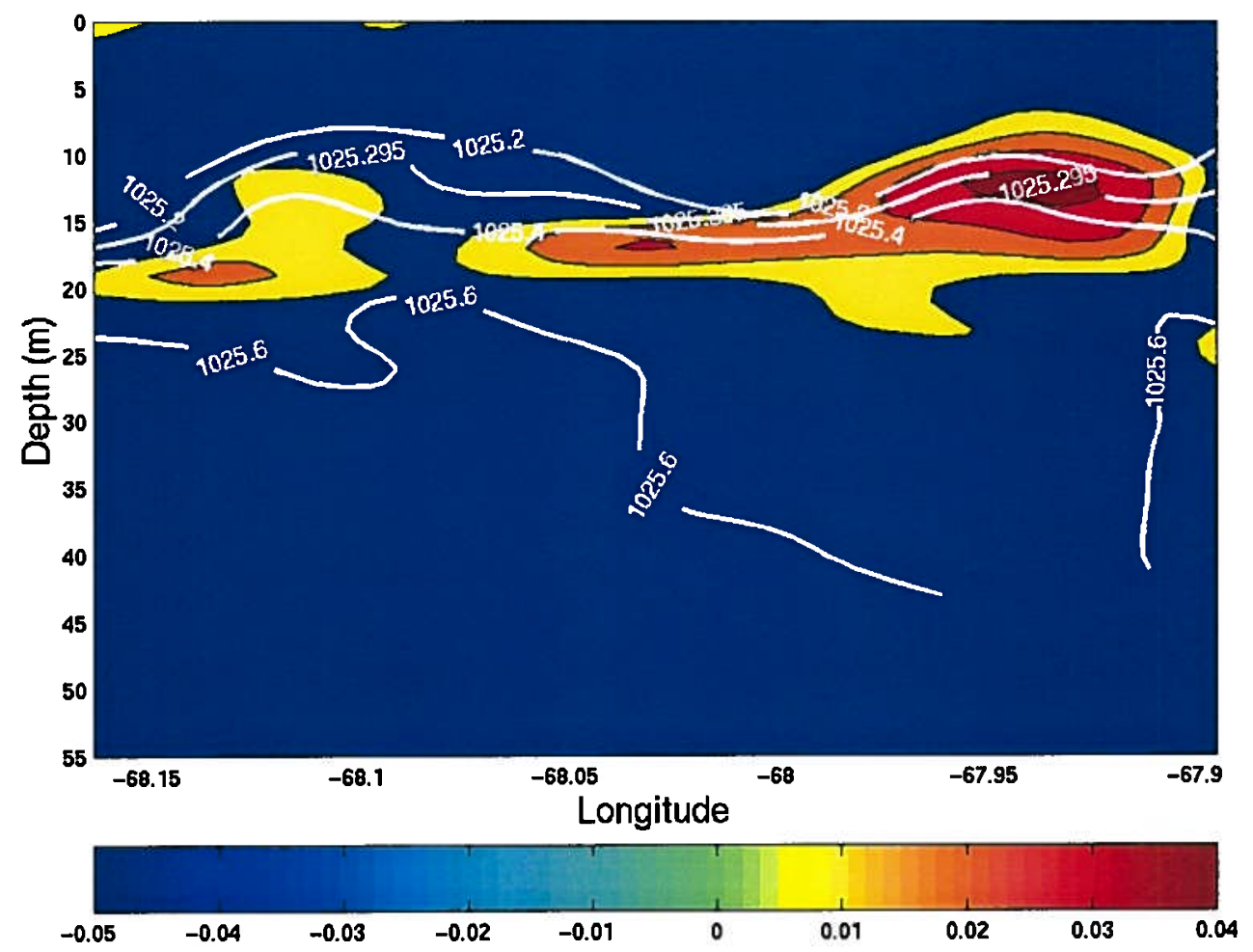

Figure C.20. Survey 3 , Contour 2 vertical section dye contour. Rhodamine dye concentrations are given in units of $\mu \mathrm{g} \mathrm{L}^{-1}$. Density contours are plotted as white lines/labels in units of $\mathrm{kg} \mathrm{m}^{-3}$. 


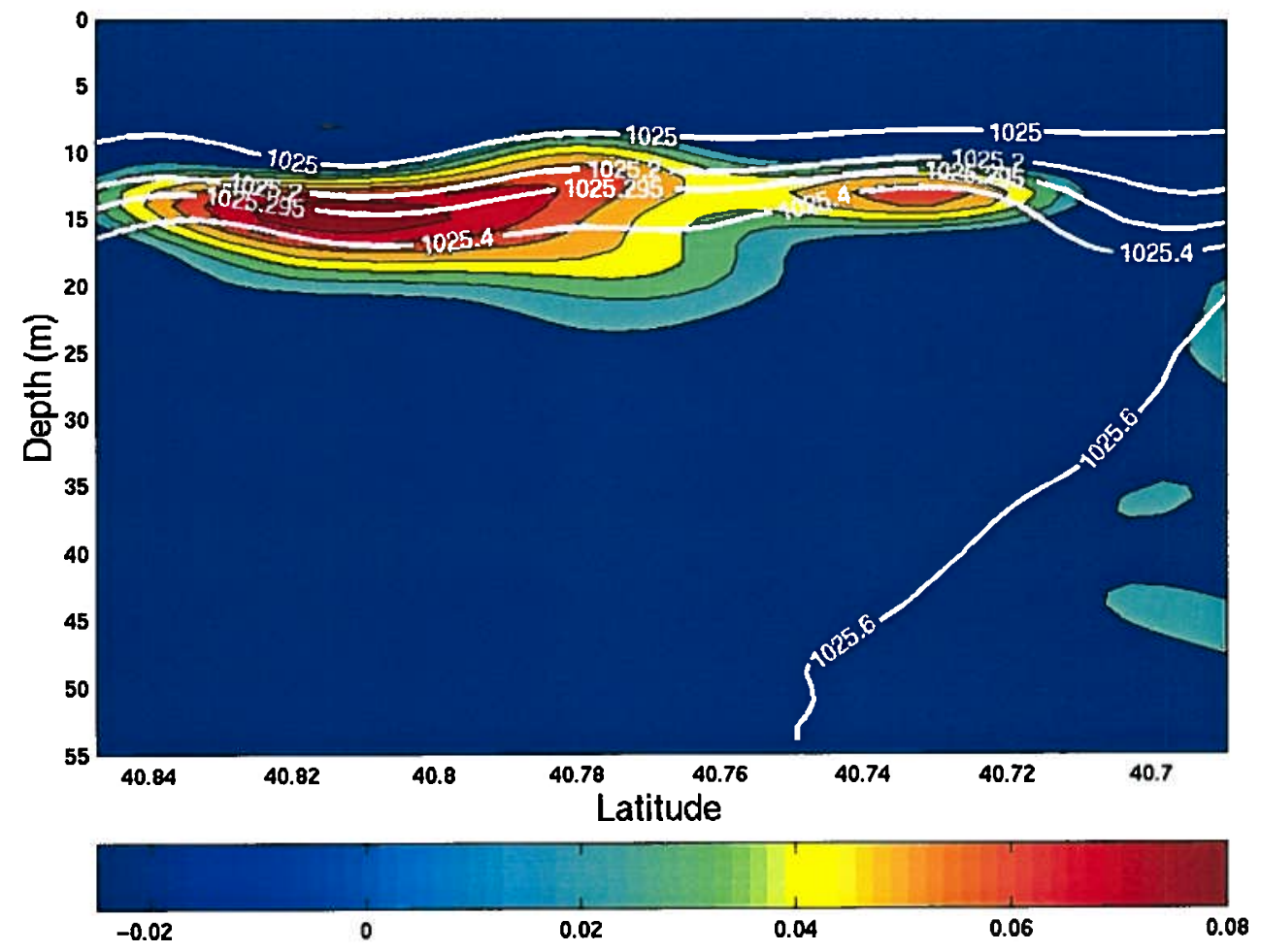

Figure C.21. Survey 3, Contour 3 vertical section dye contour. Rhodamine dye concentrations are given in units of $\mu \mathrm{g} \mathrm{L}^{-1}$. Density contours are plotted as white lines/labels in units of $\mathrm{kg} \mathrm{m}^{-3}$. 